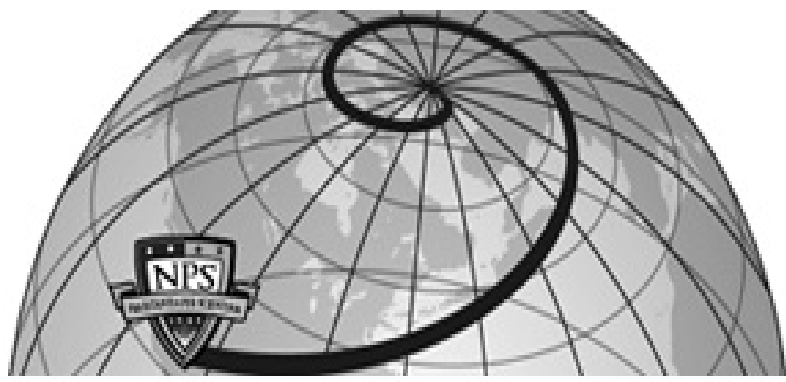

Calhoun: The NPS Institutional Archive DSpace Repository

1970-04

\title{
Climatological wave data for Colombo, Ceylon
}

\author{
Perera, Edward M. A.
}

Monterey, California. Naval Postgraduate School

http://hdl.handle.net/10945/14905

Copyright is reserved by the copyright owner

Downloaded from NPS Archive: Calhoun

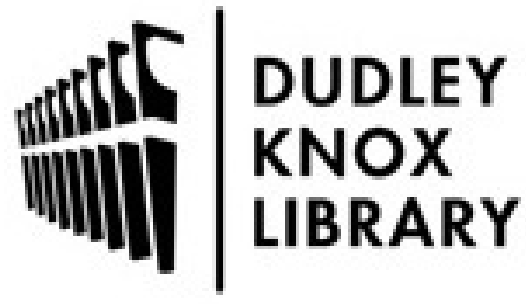

http://www.nps.edu/library
Calhoun is the Naval Postgraduate School's public access digital repository for research materials and institutional publications created by the NPS community. Calhoun is named for Professor of Mathematics Guy K. Calhoun, NPS's first appointed -- and published -- scholarly author.

Dudley Knox Library / Naval Postgraduate School 411 Dyer Road / 1 University Circle Monterey, California USA 93943 
CLIMATOLOGICAL WAVE DATA

FOR COLOMBO, CEYLON

Edward M. A. Perera 



\section{United States \\ Naval Postgraduate School

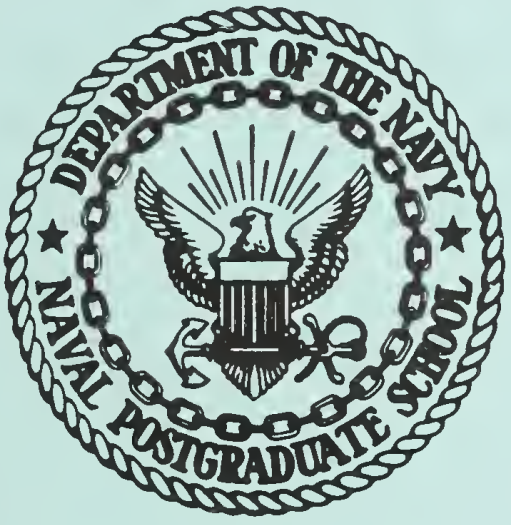

\section{THESIS}

\section{CLIMATOLOGICAL WAVE DATA}

FOR COLOMBO, CEYLON

Edward M. A. Perera

\section{Apri1 1970}

This document has been approved for public release and sale; its distribution is unlimited. 
$\rightarrow$ 
Climatological Wave Data for Colombo, Ceylon

by

Edward M. A. Perera

Lieutenant Commander, Ŕoyal Ceylon Navy

B.Sc., University of London, 1957

Submitted in partial fulfillment of the requirements for the degree of

MASTER OF SCIENCE IN OCEANOGRAPHY

from the

NAVA L POSTGRADUATE SCHOOL

April 1970 


\section{ABSTRACT}

Deep-water wave statistics for Colombo on the west coast of Ceylon have been compiled using the Sverdrup-Munk-Bretschneider wave-hindcast method applied to 12-hourly weather maps of the West Indian and South Atlantic Oceans for the one-year period from June 1968 through May 1969. Results of the wave-hindcast analysis are presented in the form of monthly and annual height-period-direction frequency distributions. The predominant waves are in the one to three foot height range, have periods centered about 13-14 seconds, and arrive from westerly to south-southwesterly directions. Wave action is most frequent in May through September and least in December.

The wind waves and local swell on the west coast of Ceylon strongly reflect the seasonal Monsoons. The principal source of distant swell for this coast is the prevailing westerly wind belt of the Southern

Hemisphere between Argentina and the longitude of Ceylon $\left(80^{\circ} \mathrm{E}\right)$. The subtropical anticyclone in the central Indian Ocean is a relatively quiet source region for swell compared to the Monsoon belt and the prevailing westerlies. 


\section{TABLE OF CONTENTS}

I. INTRODUCTION . . . . . . . . . . . . . . . . 7

II. METHOD OF OBTAINING CLIMATOLOGICAL WAVE DATA . . . . . . . 8

A. AVAILABLE METHODS . . . . . . . . . . . 8

B. CHOICE OF SMB METHOD . . . . . . . . . . . . 10

III. SELECTION OF WEATHER MAPS . . . . . . . . . . . . . 13

A. REGION COVERED . . . . . . . . . . . . . . . 13

B. PERIOD COVERED . . . . . . . . . . . . . . 16

C. SETS OF WAVE ANALYSES DERIVED . . . . . . . . . . . . . 16

IV. HINDCAST PROCEDURE . . . . . . . . . . . . . . . 18

A. HINDCAST OF DISTANT SWELL . . . . . . . . . . . . . 18

1. The Wind Field ............ . . 18

2. Fetch and Duration . . . . . . . . . . 22

3. Minimum Swell Height . . . . . . . . . . 23

4. Summary of Hindcast Procedure . . . . . . . . 24

B. HINDCAST OF LOCAL SWELL . . . . . . . . . . . . 25

C. HINDCAST OF SEA . . . . . . . . . . . . . . . 25

V. STATISTICAL WAVE DATA ................... 27

A. METHOD OF COMPILATION . . . . . . . . . . . . . 27

1. Monthly Frequency Distributions of Sea, Local Swell, and Distant Swell . . . . . . . . 27

2. Monthly Frequency Distributions of Combined Waves ............... . . 29

3. Annual Distributions ............ 31

B. WAVE STATISTICS GRAPHS . . . . . . . . . . . 32

1. General Properties . . . . . . . . . . 32 
2. Characteristics of Sea, Local Swe11, and

Distant Swe 11

3. Peak Values .............. . . . 33

VI. WAVE CLIMATOLOGY OF WESTERN CEYLON . . . . . . . . . . . 41

A. REGIONS OF WAVE GENERATION . . . . . . . . . . . 41

B. TRAdE WIND BELT ................... . . . . . 41

C. SUBTROPICAL HIGH PRESSURE BELT . . . . . . . . . . . 47

VII. UTILITY OF THE WAVE STATISTICS . . . . . . . . . . . 51

APPENDIX A - Notes on the Use of the Statistical Tables . . . . 53

APPENDIX B - Monthly Frequency Distribution of Sea, Local Swe11, Distant Swell . . . . . . . . . 55

Annual Distribution of Sea . . . . . . . . 65

$\begin{aligned} \text { APPENDIX C - Monthly and Annual Frequency Distributions } & \\ & \text { of all Waves . . . . . . . . . . . . . . } 66\end{aligned}$

APPENDIX D - Wave Hindcasting Curves . . . . . . . . . . 80

REFERENCES . . . . . . . . . . . . . . . . . . 84

INITIAL DISTRIBUTION LIST . . . . . . . . . . . . . 85

FORM DD 1473 . . . . . . . . . . . . . . . . . . 87 


\section{LIST OF ILLUSTRATIONS}

Figure

Geographical Location of Ceylon

Possible Wave Generating Areas for Colombo

Example of Rota Weather Map

Example of NWC Weather Map

Air Mass Stability and Isobar Curvature Factors

Monthly Distribution of Wave Height

Annual Distribution of Wave Period

Monthly Distribution of Wave Period

Annual Distribution of Wave Direction

Monthly Distribution of Wave Direction January and February 


\section{ACKNOWLEDGMENTS}

The author wishes to thank the Captain of the Royal Ceylon Navy and the Oceanographer of the United States Navy for providing the opportunity for him to pursue the Oceanography program at the Naval Postgraduate School in Monterey, California.

Professor Warren C. Thompson, under whose able direction this study was both planned and fulfilled, deserves special recognition. The author is greatly indebted to him for his counsel, encouragement, and patience shown. It was indeed a pleasure and a rewarding experience to work under him.

The author also wishes to thank Assistant Professor Edward B. Thornton, the Second Reader, for his helpful suggestions on the draft thesis.

The support of Captain W. S. Houston, USN, formerly Commanding Officer, Fleet Weather Central, Rota, Spain and of Lieutenant Commander J. W. King, Head of the Naval Detachment at the National Weather Records Center, Asheville, North Carolina, in providing the two sets of weather maps used is acknowledged. 


\section{INTRODUCTION}

Ceylon is an island country situated in the South Indian Ocean. Figure 1 shows its geographica 1 location. Colombo $\left(7^{\circ} \mathrm{N}, 80^{\circ} \mathrm{E}\right)$ is her capital and principal harbor. Lacking major natural resources, the island's economy is turning more and more to dependence on the sea. Plans are currently afoot for the construction of several small harbors for Ceylon's infant fishing industry which is concentrated mainly on the west coast. In the design of harbors, wave statistics are needed for determining breakwater orientations, heights, and construction materials, and for anticipating sanding problems caused by the effect of the harbor on littoral drift. It is believed that climatological wave data will also have other practical military and civil applications in Ceylon in connection with coastal patrol, shoreline erosion, beach preservation, and related coastal engineering activities.

Statistical wave data for Ceylon are not available and therefore this study was undertaken in part to compile climatological wave data for deep water off Colombo. It will be seen that the statistics presented herein are applicable to most of the west coast of Ceylon.

In carrying out this study various problems were met and some innovations were introduced in the application of the wave hindcasting technique used and in the compilation of the wave statistics. These are described in the following pages. In addition, the seasonal wave regime on the west coast of Ceylon is examined in relation to the synoptic and seasonal weather character of the West Indian and South Atlantic Oceans. 


\section{METHOD OF OBTAINING CLIMATOLOGICAL WAVE DATA}

\section{A. AVAILABLE METHODS}

Climatological wave data can be defined as a statistical compilation of the frequency of occurrence of waves of various height, period, and direction by months, seasons, or averaged over a year for a given location at sea or along a coast. The method chosen in this study for compiling wave statistics is the wave-hindcast method, in which a series of historical synoptic weather maps are analyzed for their windfield characteristics and a conventional technique is applied to forecasting the waves produced which arrive at Ceylon.

There are several wave-forecasting methods in existence and a comparative description of each has been given by Timmie [1969]. In a broad sense they can be classified into two main groups, the spectral methods and the non-spectral empirical methods.

Among the spectral approaches, the Pierson-Neumann-James [1953] or PNJ method is probably the most widely used. The PNJ method describes the sea state and the swell characteristics in the form of an energy spectrum, and enables the forecaster to obtain various height and period parameters of the waves generated. This method, or variants of it, is the one most frequently used by scientists interested in the mechanism of energy transfer and propagation as it gives more information on the energy distribution in the waves. However, it has a lesser degree of acceptance in engineering applications where the dominant wave heights and periods are mainly used. 


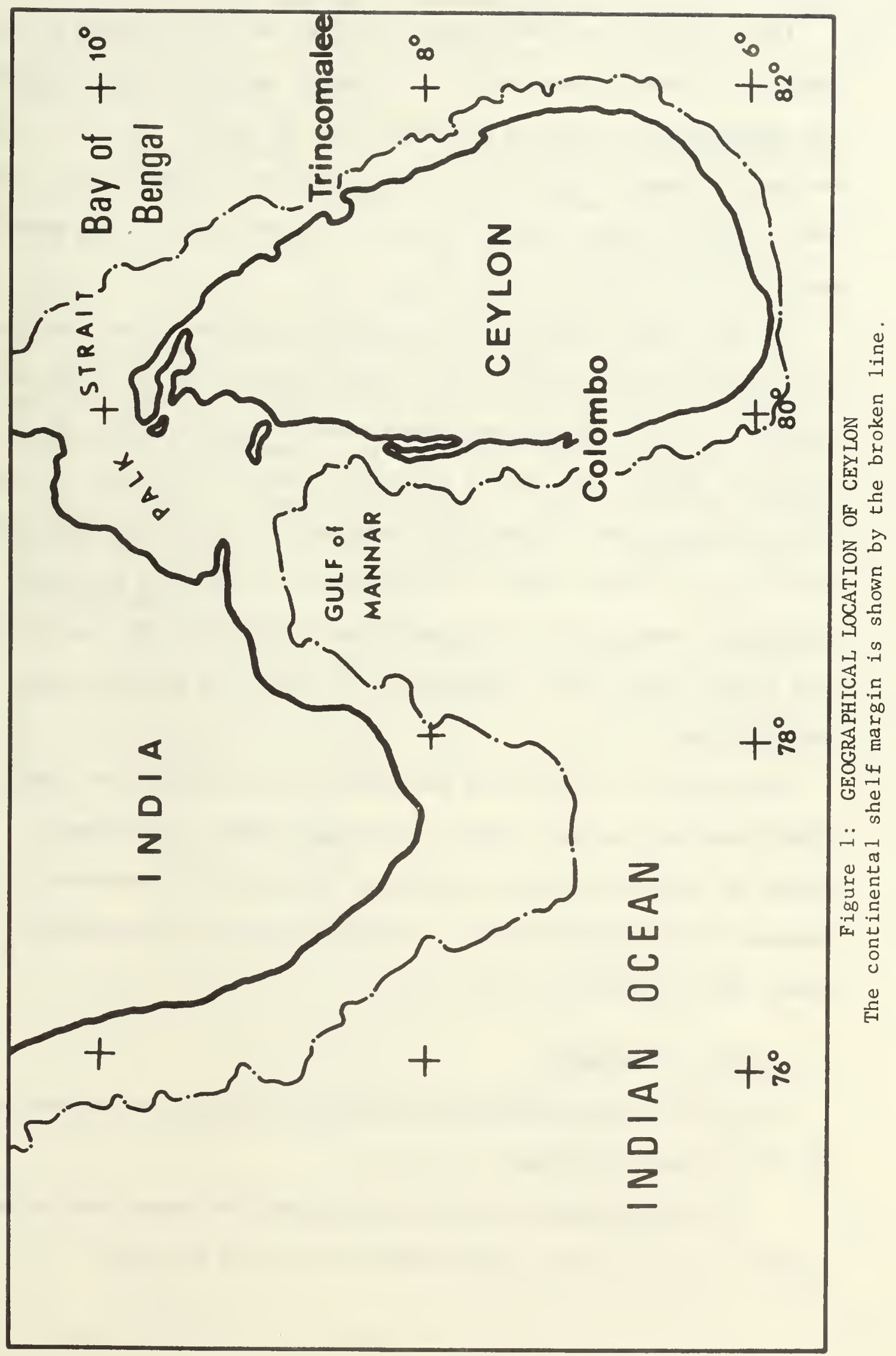


There is also the French spectro-angular densities method by Gelci, Cazale, and Vassal [1958] which is in common use by European scientists and engineers, particularly the French and the Dutch. It is not suited for manual synoptic work as it is extremely time consuming, but it has been claimed by these authors to give very good results using numerical analys is.

The most widely used of the non-spectral methods is the Bretschneider modification of the Sverdrup-Munk [1947] wave-forecasting technique and referred to as the Sverdrup-Munk-Bretschneider or SMB method [Bretschneider, 1952]. This method provides a forecast in terms of a significant wave height and a significant wave period. The significant wave height is the average height of the highest one-third of the waves. The significant wave period is the period associated with the significant wave height, and closely approximates the period of maximum energy concentration.

Evaluations of the PNJ and SMB methods have been made by Timmie [1969], Rattray and Burt [1956], and Wiege1 [1966]. According to Wiegel (p. 239), "One thing is apparent from the few comparisons of forecasts with observed waves: no major procedure is appreciably better than the others in use today."

\section{B. CHOICE OF SMB METHOD}

For this study the SMB wave-forecasting technique was adopted mainly for the following reasons:

(1) The method is simpler and quicker than other methods and appears to give forecast results that are equally as good. 
(2) The applications of this study in Ceylon will involve mostly coastal engineering problems in which data on the dominant height and period are ordinarily adequate.

(3) Even though the PNJ method provides a more complete description of the sea, its format of wave-hindcast presentation in several studies in which it has been applied (National Marine Consultants - California Coast [1960], Oregon-Washington Coast [1961]) is identical with that using the SMB method; i.e., the wave statistics are presented in the form of frequency of occurrence of various combinations of significant height, dominant period, and wave direction. A more detailed or complete presentation would be extremely cumbersome and the time required to compile and prepare the additional data would be significant.

(4) This investigator anticipates that additional wave studies will be made in Ceylon under his direction. Therefore, it was desirable to gain experience in a technique that is both easy to teach and simple to use. 


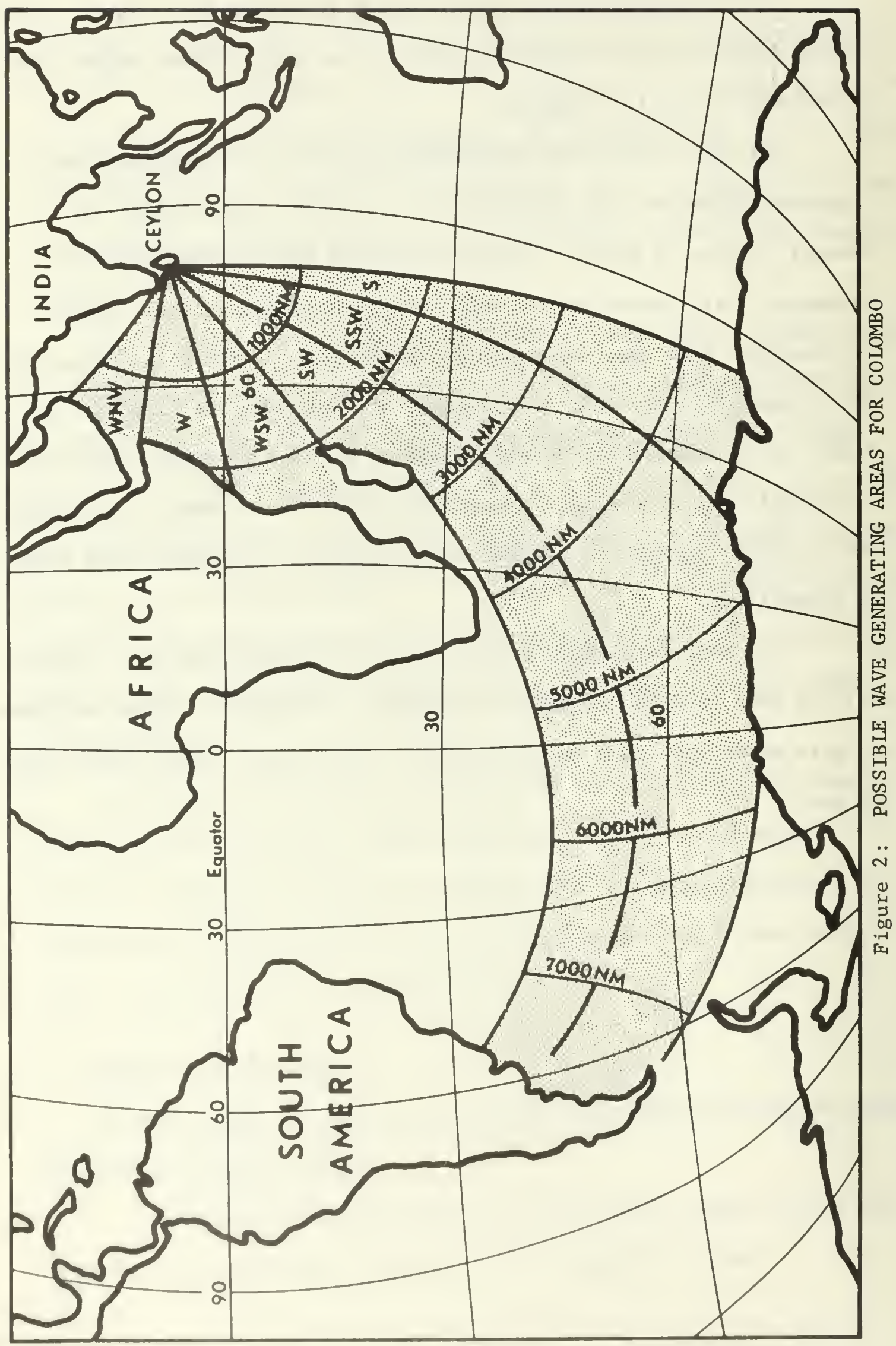




\section{SELECTION OF WEATHER MAPS}

\section{A. REGION COVERED}

Prior to the selection of the weather maps to be used in hindcasting it was necessary to determine the regions of origin of ocean waves that would arrive at Colombo. Figure 2 shows the possible wave-generating areas based upon great-circle propagation of swell. It may be noted that swe 11 can be generated as distant as the coast of Argentina, 7500 nautical miles from Ceylon, and that it may transit the entire South Atlantic Ocean. The potential wave-generating region with respect to Colombo is bounded directionally on the northwest by the Indian Peninsula, and on the south by wave refraction across the continental shelf along the west coast of Ceylon.

A study of weather-map sources indicated that to obtain complete coverage of the possible wave-generating areas affecting Colombo, two separate sets of surface weather maps were necessary. The following two sets were chosen:

1. 12-hourly weather maps (at 0000 and 1200 GiT) of the northern Indian Ocean down to $40^{\circ} \mathrm{S}$. These maps are in Mercator projection and were obtained from the Fleet Weather Central at Rota, Spain.

2. 12-hourly weather maps (at 0000 and 1200 GMT) of the two quadrants of the Southern Hemisphere from $90^{\circ} \mathrm{W}$ through $0^{\circ}$ to $90^{\circ} \mathrm{E}$. These maps are in polar stereographic projection and were obtained from the National Weather Center (NWC) in Washington, D. C. Both sets were analyzed by the originating agencies. Examples of these maps are shown in Figures 3 and 4 . 


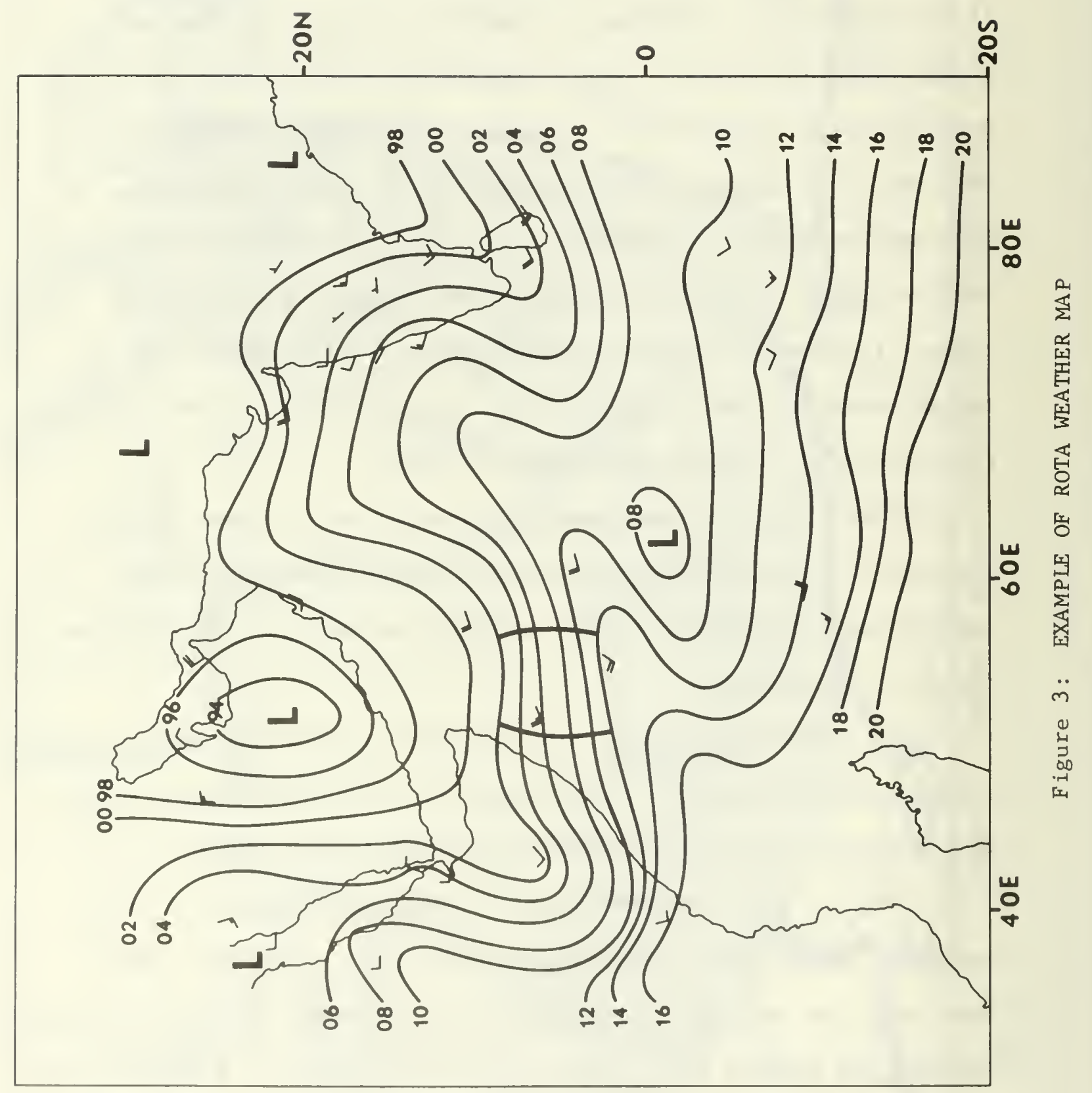




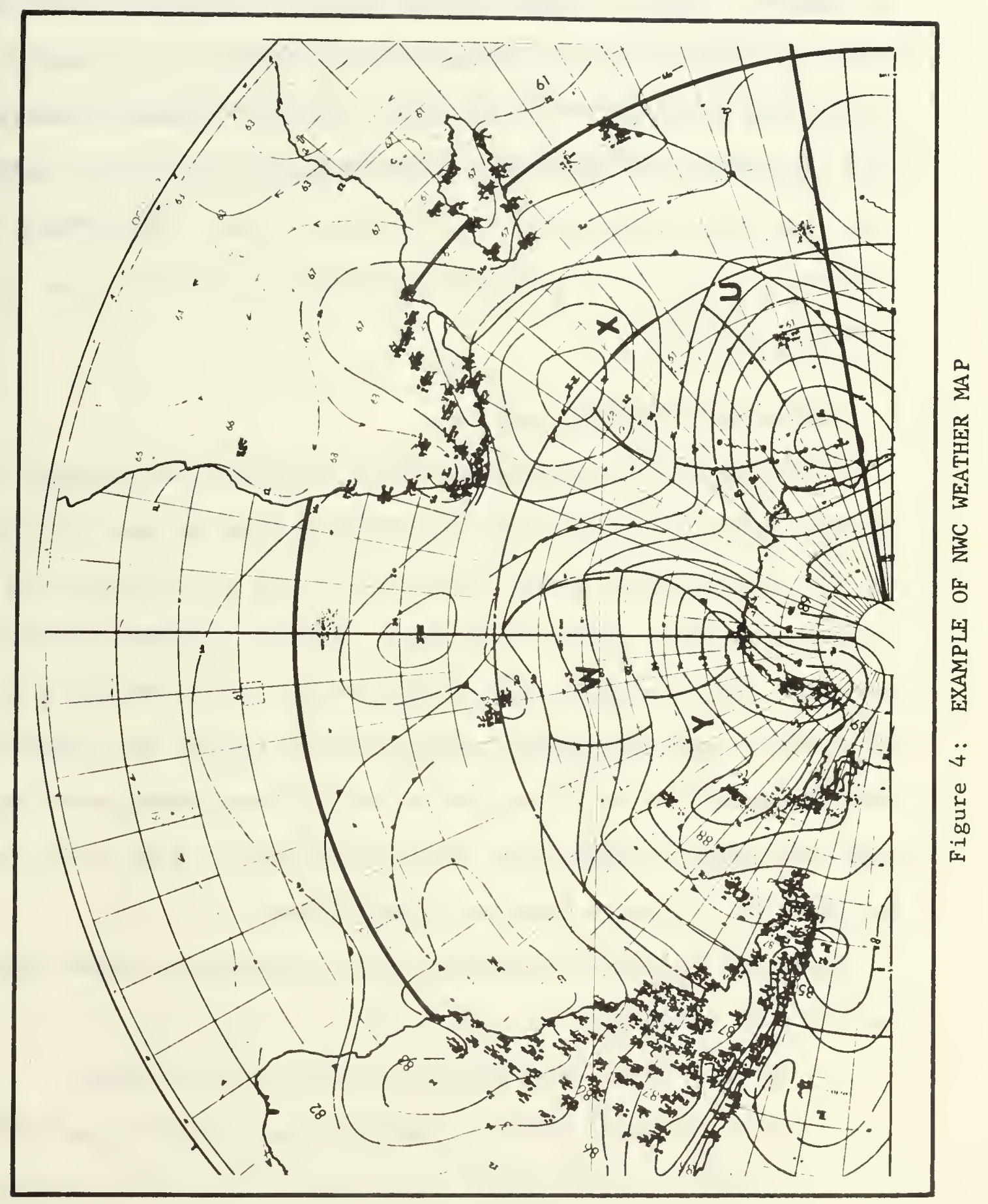




\section{B . PERIOD COVERED}

Past work on the preparation of wave statistics (National Marine Consultants, [1960 and 1961]; Roper, [1960]) indicates that a coverage of three full years or more would be desirable in order to minimize the effect of yearly variations in wave occurrence and thereby produce better wave statistics. In this study, however, because of practical time limitations and the difficulty of obtaining two sets of weather maps preferably covering the same interval of time, weather maps covering the period of one complete year from June 1968 through May 1969 were analyzed.

\section{SETS OF WAVE ANALYSES DERIVED}

It was clear at the beginning of the study that two different sets of wave information would have to be derived from the maps for Colombo-locally generated wind waves, and swe 11 arriving from distant wind areas. It was further convenient and useful to separate the swell hindcasted from both sets of weather maps at $20^{\circ} \mathrm{S}$ because of (a) basically different synoptic wave-generating conditions prevailing on the equatorial side of the subtropical high-pressure cell in the Indian Ocean compared with the higher latitudes, and (b) frequent lack of data in the lower latitudes of the Indian Ocean on the Rota maps.

Therefore the analysis was done and is presented as three separate sets of wave statistics:

(1) Wind Waves (Sea) at Colombo (from the Rota maps).

(2) Local Swe 11 from the equatorial and tropical zones $\left(25^{\circ} \mathrm{N}\right.$ to $20^{\circ} \mathrm{S}$ ) in the northern Indian Ocean (from the Rota maps). 
(3) Distant Swe11 from beyond $20^{\circ} \mathrm{S}$ in the South Indian and South Atlantic Oceans (from the NWC maps).

The statistics compiled on all three sets of waves are presented in the form of monthly and annual height-period-direction frequency distributions in the tables of Appendices B and C. All heights and periods presented in these tables are the significant height and significant period. All of the wave statistics derived apply to deep water directly off Colombo. 


\section{HINDCAST PROCEDIRE}

A. HINDCAST OF DISTANT SWEZT

\section{The Wind Fie ld}

The fundamental parameter needed for wave hindcasting is the surface wind. The NWC maps contain relatively few weather reports in the oceans and it was necessary to derive the surface wind field from the surface pressure analysis. Surface wind reports were used wherever they were available. Ship reports are also uncommon on the Rota maps, but weather reports at land stations around the northern Indian Ocean are comparatively numerous.

In delineating wind areas in the Southern Hemisphere from the sea-level pressure field, it was assumed that the surface wind blows $10^{\circ}$ to $15^{\circ}$ to the right of the isobar direction. A wind direction was considered to be capable of producing swell if the wind had a bearing of $30^{\circ}$ or less from the great-circle route to Colombo in the case of straight and parallel isobars, and $45^{\circ}$ or less in the case of curved isobars.

To facilitate the acceptance or rejection of a possible wind area (the fetch), a transparent overlay, similar to Figure 2, was prepared for use with the weather maps under analysis. The overlay contained great circles drawn from Colombo defining the direction sectors south $\left(180^{\circ}-191-1 / 4^{\circ}\right)$, south-southwest $\left(191-1 / 4^{\circ}-213-3 / 4^{\circ}\right)$, and southwest $\left(213-3 / 4^{\circ}-236-1 / 4^{\circ}\right)$. Superimposed on the great-circle curves was a family of orthogonal lines of distance from Colombo spaced at a 200 nautical-mile interval. The overlay was used to determine the 
direction of the surface wind with respect to the great-circle route to Colombo, the direction sector from which the waves from the wind area would arrive at Colombo, and also to measure the fetch and the decay distance. It may be noted in Figure 2 that Distant Swe 11 arrives at Colombo only in the narrow direction range of south to southwest.

The geostrophic wind speed was estimated from the isobar spacing using a conventional geostrophic wind scale. The surface wind speed was then computed using the relationship: $V_{\mathrm{S}}=\mathrm{V}_{\mathrm{g}} \times \mathrm{S} \times \mathrm{C}$ where $V_{S}=$ Surface wind speed in knots

$$
\begin{aligned}
& \mathrm{V}_{\mathrm{g}}=\text { Geostrophic wind speed in knots } \\
& \mathrm{S}=\text { Air-mass stability factor } \\
& \mathrm{C}=\text { Isobar-curvature factor. }
\end{aligned}
$$

The quantity $S$ was evaluated in the following manner by interpolation of the set of stability factors presented by Sverdrup and Munk [195I], which is reproduced below:

$\begin{array}{clc}\mathrm{T}_{\mathrm{W}}-\mathrm{T}_{\mathrm{a}}\left({ }^{\circ} \mathrm{F}\right) & \text { Stability } & \underline{\mathrm{S}} \\ <-7 & \text { Stable } & 0.55 \\ -7 \text { to } 0 & \text { Indifferent } & 0.60 \\ 1 \text { to } 4 & \text { Indifferent } & 0.65 \\ 5 \text { to } 10 & \text { Unstable } & 0.70 \\ 11 \text { to } 15 & \text { Unstable } & 0.75 \\ >15 & \text { Unstable } & 0.85 \\ \text { where } \mathrm{T}_{\mathrm{W}}=\text { Water temperature } & \\ \mathrm{T}_{\mathrm{a}}=\text { Air temperature. } & \end{array}$

Because of the sparsity of wind observations in the Southern Ocean, observations of the air and sea temperature were seldom available for use in obtaining the stability factor. The factor was estimated, 
however, by making the following assumptions. It was reasoned that, if the air trajectory prior to entering the fetch lay along a latitude line or approximately so (i.e., the winds were westerly), the air-sea temperature difference would be negligible and the air mass would be of indifferent or neutral stability $(S=0.65)$; similarly, if the wind trajectory before entering the fetch was directly from the south, so that the air-mass moved over relatively warmer water as it flowed into lower, warmer latitudes, the air-mass would be highly unstable $(S=0.80)$. A trajectory directly from the southwest was assumed to produce a condition of intermediate stability $(S=0.75)$. A trajectory directly from the northwest, in which warm air would be expected to pass over cooler water, was considered to produce a stable air mass $(S=0.60)$. In synoptic situations in which the air flow prior to entering the fetch curved cyclonically or anticyclonically, the air-mass stability was estimated in the same manrer. The stability factors associated with wind trajectories in the Southern Ocean that can produce swell which would arrive in Ceylon are shown diagramatically in Figure 5. Figure 5 also shows the isobar-curvature factor $C$ for the different wind trajectories. The values have been taken from the set of curvature factors presented by Sverdrup and Munk [1951], which is reproduced below:

$\begin{array}{llcc}\begin{array}{l}\text { Air-mass } \\ \text { Stability }\end{array} & \begin{array}{l}\text { Cyclonic } \\ \text { Stable }\end{array} & \begin{array}{l}\text { Moderate } \\ \text { or Straight }\end{array} & \text { Great } \\ \text { Indifferent } & 0.95 & 1.00 & 1.05 \\ \text { Unstable } & 0.95 & 1.00 & 1.10 \\ & & 1.00 & 1.15\end{array}$

The isobar curvature, defined by Bretschneider [1952], was estimated visually in practice. 


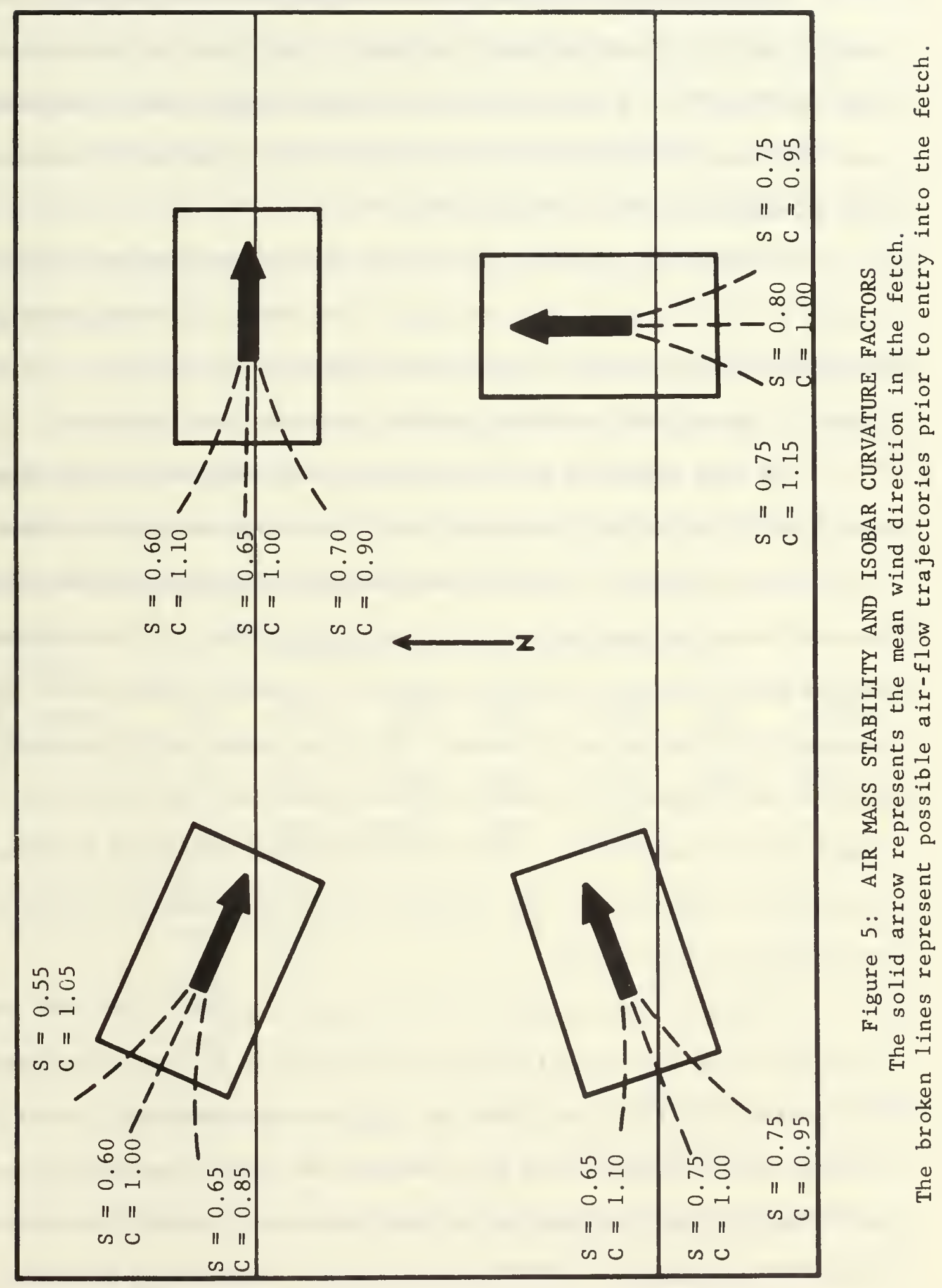




\section{Fetch and Duration}

On each weather map the pertinent fetches were delineated and measured using the overlay described above. As there could be more than one fetch on a given map, the individual fetches were labelled and each fetch was followed on the subsequent weather maps until its ultimate disappearance due to dying winds.

A fetch was treated as stationary if the fetch front did not move by more than $3^{\circ}$ latitude from one map to the next. In these cases the wind waves at the forward edge of the fetch were hindcasted in the usual manner by taking both the fetch and the duration into account.

In some cases the fetch advanced toward Ceylon with the westerly wind flow of the higher latitudes, and if the rate of advance of the fetch front exceeded $3^{\circ}$ latitude between 12 -hourly maps, the fetch was assumed to be a moving fetch. A $3^{\circ}$ latitude advance of the fetch front between maps represents a mean velocity of 15 knots, which is the group velocity of 10-second period waves. In these cases, only the wind duration was assumed to control the wave dimensions, and the fetch length had no significance. This procedure greatly reduced the time to make the hindcasts and was considered to be reasonably accurate for the purpose of this study.

Initially, each new wind field generating wave trains was considered to have been in existence six hours prior to its first appearance on a weather map (i.e., the wind at the first map time had already been blowing for six hours). The wind duration as of the time of the next and subsequent weather maps was derived using the equivalent-duration method of Bretschneider [1952] applied to the intervening 12-hour interval between maps. 
3. Minimum Swe 11 Height

With practical applications in mind, it was decided that waves arriving at Colombo having a height less than one foot would be of minor importance. Accordingly, wind waves in any fetch found to have a height of one foot or less were discarded immediately. It was realized, in the case of Distant Swell, that it was possible for waves which were greater than one foot in the fetch to be lower than one foot upon arrival at Colombo.

In order to recognize and discard these cases and thereby save the time of going through the swell-hindcast procedure, the following table was constructed which gives the decay distance for various combinations of wave height in the fetch, $\mathrm{H}_{\mathrm{F}}$, and minimum fetch, $F_{\text {min }}$, that will yield a swe 11 height at Colombo of one foot:

Height in Fetch

\begin{tabular}{crrrrrrr}
$\mathrm{H}_{\mathrm{F}}$ (feet) & $\underline{50}$ & $\underline{100}$ & $\underline{200}$ & $\underline{300}$ & $\underline{400}$ & $\underline{600}$ & $\underline{800}$ \\
\hline 5 & 525 & 850 & 1600 & 2000 & 2200 & 3200 & 4000 \\
10 & 1800 & 3000 & 5000 & 6000 & 7000 & & \\
15 & 3100 & 5000 & & & & \\
20 & 4500 & 8000 & & & & \\
25 & 6000 & & & & & \\
30 & 8000 & & & & &
\end{tabular}

The minimum fetch, $F_{\text {min }}$, as used in the SMB method, is defined as the smaller of the two fetches, namely, the actual fetch and the fetch equivalent to the wind duration (the fetch that would permit a wind with a particular speed to put into the sea the same energy and 
hence generate same size waves as would be generated by the same wind speed blowing for the given duration).

An example of the use of the table is as follows. If $\mathrm{H}_{F}$ is 10 feet and $F_{\text {min }}$ equals $100 \mathrm{MM}$, then the swell height will, be reduced to one foot after travelling over a decay distance of $3000 \mathrm{NM}$. A1I decay distances greater than 3000 NM would produce waves that are less than one foot high at Colombo. Therefore, only if the decay distance is equal to or less than 3000 MM would these waves be considered for swe 11 computation.

\section{Summary of Hindcast Procedure}

The steps used in performing a wave hindcast are shown sequentially in the following table. The table is essentially a reproduction of the wave-hindcasting data sheet prepared for this study.

\section{Step}

Wave train

Date-time

Isobar spacing

Mean latitude

Geostrophic. wind, $V_{g}$

Stability correction, $\mathrm{S}$

Curvature correction, C

Surface wind, $V_{S}$

Fetch, F

Wind duration

Wave direction at Colombo

Height in fetch, $\mathrm{H}_{\mathrm{F}}$

Period in fetch, $\mathrm{T}_{\mathrm{F}}^{\mathrm{F}}$

Decay distance, D

Minimum fetch, $F_{\text {min }}$

$\mathrm{T}_{\mathrm{D}}^{\mathrm{D}} / \mathrm{T}_{\mathrm{F}}^{\mathrm{F}}$

Height at end of decay, $H_{\text {D }}$

Period at end of decay, $\mathrm{T}_{\mathrm{D}}^{\mathrm{D}}$

Trave 1 time, $\Delta t$

Expected time of arrival
Obtained from

Weather map

Weather map

Weather map

Weather map

Geostrophic wind scale

Eigure 5 \& weather map

Figure 5 \& weather map

$V_{\mathrm{S}}=V_{\mathrm{g}} \times \mathrm{S} \times \mathrm{C}$

Over lay on weather map

Weather map

Overlay on weather map

Plate D-1

Plate D-I

Overlay on weather map

Plate D-1

Plate D-2

Plate D-2

Plice D-3

Weather map time $+\Delta t$

\section{Purpose}

\section{Identify fetch}

Calculate geo. wind

Calculate geo. wind

Calculate surface wind

Calculate surface wind

Calculate surface wind

Determine, $\mathrm{H}_{\mathrm{F}}, \mathrm{T}_{\mathrm{F}}$

Determine $\mathrm{H}_{\mathrm{F}}, \mathrm{T}_{\mathrm{F}}^{\mathrm{F}}$

Determine $\mathrm{H}_{\mathrm{F}}$, $\mathrm{T}_{\mathrm{F}}^{\mathrm{F}}$

Final resule

Determine $H_{H}$

Determine $T^{D}$

Calculate $H_{D}^{D}, T_{D} \& \Delta t$

Determine $\mathrm{H}_{\mathrm{D}}^{\mathrm{D}} / \mathrm{H}_{\mathrm{F}}, \mathrm{T}_{\mathrm{D}} / \mathrm{T}_{\mathrm{F}}$

Calculate $\mathrm{H}_{\mathrm{D}}^{\mathrm{D}}$

Calculate $T^{D}$

Fina 1 resule

Fina 1 result

Estimate arrival time 


\section{B. HINDCAST OF LOCAL SWELL}

The tropical and equatorial zones of the western Indian Ocean shown on the Rota weather maps were analyzed for Local Swell. The potential swell-generating region is bounded by the south and west-northwest directions (Figures 1 and 2). Due to the sheltering effect of the Indian Subcontinent, no swell of any significance arrives at Colombo from directions to the north of west-northwest. For the purpose of facilitating the analysis, an overlay similar to that described earlier was prepared for the Rota weather maps showing direction sectors and lines of equal distance (every 150 NM) from Colombo.

In low latitudes the calculation of the geostrophic wind velocity from the isobaric spacing is unreliable. Hence, the surface wind was obtained only from reported winds, and, in some cases when wind observations were lacking, by objectively comparing the isobaric spacing with adjacent maps in which the pressure field could be related to reported winds. Except for the manner of obtaining the wind speed, the analysis was the same as that described for Distant Swell.

\section{HINDCAST OF SEA}

As in the case of Local Swe 11, only observed surface winds were used in hindcasting wind waves at Colombo. The wind speed on most weather maps was fairly low, averaging about 10 knots, and usually gave rise to the condition of the fully arisen sea. When the seas were not fully arisen, which was sometimes the case with strong winds, the wind duration ordinarily controlled the wave dimensions.

The deep-water location for which the wave hindcasts were prepared lies off the continental shelf some 15 NM seaward of Colombo; however, 
the wind-wave hindcasts effectively apply over the shelf as well and do not have to be decayed to a selected coastal site. Of course, both wind waves and swe 11 must be modified for the effects of shoaling and refraction in order to obtain their characteristics at Colombo or at any other selected site in shallow water. 


\section{STATISTICAL WAVE DATA}

\section{A. METHOD OF COMPILATION}

\section{Monthly Frequency Distributions of Sea, Local Swel1, and Distant Swe 11}

Separate sets of wave data were compiled for Sea, Local Swe11, and Distant Swe11. This was considered necessary and convenient, as discussed earlier, due to the necessity of using two sets of weather maps and to the relative lack of data on the Rota maps, particularly with regard to hindcasting Local Swell. The statistics were compiled so as to show the frequency of occurrence of waves by significant height, significant period, and direction ( $\mathrm{H}, \mathrm{T}$, and $\psi$ ). Tables B-1 to B-12 in Appendix B present these statistics as monthly distributions, and Table B-13 shows, in a similar format, the annual distribution of waves due to Sea alone.

For the most accurate computation of wave statistics, the time distributions of $\mathrm{H}$ and $\mathrm{T}$ for each wave train arriving at Colombo should be plotted, and notations made of the direction of arrival. From such graphs, the duration of occurrence of waves within different increments of $\mathrm{H}, \mathrm{T}$, and $\psi$ could be measured. This exceedingly time-consuming process was circumvented by the procedures described in the following paragraphs.

A given fetch, for as long as it existed, yielded one hindcasted set of waves ( $H, T$, and $\psi$ ) arriving at Colombo for each 12 hourly weather map. Thus, for the life of the fetch, two sets of wave data per day were produced. In preparing the table of sea (wind wave) statistics, each set of waves hindcasted was considered to have a 
duration of 12 hours. Accordingly, for a 31-day (744-hour) month with complete weather coverage, one wave set would have a frequency of occurrence of $\frac{12}{744} \times 100=1.5 \%$ of the month. In the case of months with some missing weather data, the percentage was arrived at by a slight modification. For example, the Sea statistics for September (Table B-9) were based on 4412 -hourly weather maps, whereas there are actually 60 12-hourly intervals in the month. This means that in September, 16 weather maps had no data. In computing the frequencies of occurrence, it was assumed that the percentage frequencies for the entire month are the same as those for the 44-interval month. Therefore each windwave set would have a frequency of occurrence of $\frac{12}{12 \times 44} \times 100=2.3 \%$ of the month. The table in Appendix A shows the number of 12-hourly weather maps containing wind data on which the compilation of the wave statistics for Sea, Local Swell, and Distant Swell was based..

In the case of swe11, particularly the Distant Swell, the two sets of waves generated each day (one per weather map) arrived at Colombo some days later with arrival times that were sometimes chronologically reversed from their order of generation, were occasionally nearly simultaneous, or followed one another by several days. Each swell set was tabulated by its date of arrival at Colombo. The number of swell sets arriving on any given day varied from none to 7 , and this number equated to 24 hours was considered to determine the duration of each set on that day.

It was assumed that when there were two or more arrivals of wave sets of one foot or greater on a given day (from one or more wind areas) there would not be a "calm" period on that day; if there was only one occurrence of waves of ono foot or greater, then there would also be 
one occurrence of waves under one foot during that day, or one "calm" interval of 12-hours duration; finally, if there were no occurrences of waves of one foot or more, then that entire day was considered "calm". By "calm" is meant the occurrence of waves under one foot in height .

The method used to calculate the swell frequency for a given month is best illustrated by an example. In February (see Table B-2) Distant Swell was based on 52 12-hourly weather maps, of which 10 intervals were found to be "calm". During the remaining 42 intervals there were 59 swell trains from various fetches of height one foot or greater. Knowing that the 59 swe 11 sets occurred in 42 12-hour intervals, the effective duration of each swe 11 set was $\frac{42 \times 12}{59}=8.54$ hours, and the frequency of occurrence in percentage of the month was $\frac{8.54 \times 100}{52 \times 12}=1.4 \%$. In February there was one Distant Swell set that arrived at Colombo with the combination $\mathrm{H}=5-6$ feet, $\mathrm{T}=17-18$ seconds, and $\psi=S S W$; hence, the frequency of occurrence of these waves is $1.4 \%$ of the month, as shown in Table B-2 for this combination. The frequency figure of $1.4 \%$ means that during February (56 12-hourly intervals), waves having these specifications can be expected to occur $1.4 \%$ of the time, or nearly 9.4 hours $(1.4 \%$ of $56 \times 12)$.

\section{Monthly Frequency Distributions of Combined Waves}

The Sea, Local Swe11, and Distant Swell sets for each month (Tables B-1 to B-12) have been combined in Tables C-1 to C-12 to give the probable monthly occurrence for all waves in deep water off Colombo. As each of the three sets did not contain an equal number of days of data (see Appendix A), it was necessary to standardize the three wave sets before combining them. Thus, in cases where the wave information was 
based on a fewer number of days than are contained in a month, the frequency of occurrence of all available data within that particular wave set were proportionately increased by a factor equal to the ratio of the number of 12-hourly intervals in the month to the number of 12 hourly intervals of observed data. This procedure implies that the wave statistics obtained from a partial month of weather maps are representative of the entire month.

The method used to combine the tables can again be illustrated by an example. The derivation of Table $\mathrm{C}-2$ from the three wave-data sets in Table B.-2 will be reviewed for the combination $\mathrm{H}=5-6$ feet, $\mathrm{T}=17-18$ seconds, and $\psi=\mathrm{SSW}$. When all of the wave data were compiled chronologically through the month according to their arrival time at Colombo by the method described in the previous section, the number of intervals of "calm" (i.e., waves under one foot) was again found to be 10 (this was a coincidence because in most months the combined wave arrivals reduced the number of "calm" intervals). Thus the number of 12 -hourly intervals of waves in February is 46 (i.e., 56-10).

Pertinent hindcast information for the three wave categories is as follows :

Sea: 29 12-hourly weather maps contained data which yielded 3 wave sets.

Loca 1 Swe 11: 22 12-hourly weather maps contained data which yielded 13 wave sets.

Distant Swell: 52 12-hourly weather maps contained data which yielded 59 wave sets.

The standardizing factors required to equate the number of wave sets to a month of complete weather data (56 12 -hourly intervals) are $\frac{56}{29}=1.93$, $\frac{56}{22}=2.55, \frac{56}{52}=1.08$, respectively. Accordingly, the number of wave sets 
that would be expected if there were no missing weather data are $3 \times 1.93=5.79$ Sea sets, $13 \times 2.55=33.15$ Loca 1 Swell sets, and $59 \times 1.08=63.72$ Distant Swel1 sets, giving a tota 1 of 102.66 wave sets in February. Therefore, each of the 102.66 wave sets had a duration of $\frac{46 \times 12}{102.66}=5.38$ hours, or occurred with a frequency of $\frac{5.38 \times 100}{56 \times 12}=0.80 \%$ of the month. The frequencies of occurrence of each wave set was obtained using the standardizing factors as follows:

Sea : $1.93 \times 0.8 \%=1.5 \%$ of the month,

Local Swe 11: $2.55 \times 0.8 \%=2.0 \%$ of the month,

Distant Swe 11: $1.08 \times 0.8 \%=0.9 \%$ of the month.

The entry in Table B-2 for the combination $\mathrm{H}=5-6$ feet, $\mathrm{T}=17-18$ seconds, and $\psi=S S W$ is $2.9 \%$, which was obtained by combining the single Local Swe 11 occurrence of this combination (frequency $=2.0 \%$ ) with the only Distant Swell occurrence of this same combination in February (frequency $=0.9 \%$ ). The frequency value of $2.9 \%$, of course, means that during February waves with the given specifications can be expected to occur $2.9 \%$ of the time during the month, or for a cumulative period of nearly 19.5 hours.

\section{Annua 1 Distributions}

Table B-13 shows the frequency of occurrence of Sea compiled for the entire year. Each value in the table was derived by summing the frequencies of occurrence shown in a given $\mathrm{H}-\mathrm{T}-\psi$ combination for al1 12 months of Sea and dividing by 12 . In a similar manner, the monthly frequency distributions of the combined waves (Tables C-1 to $\mathrm{C}-12$ ) have been averaged to produce Table $\mathrm{C}-13$, which presents the probable frequency distribution of all waves that can be expected to occur in a given year. 


\section{WAVE STATISTICS GRAPHS}

\section{General Properties}

From the statistical wave tables in the Appendices, summary graphs of the monthly and annual frequency distributions of height, period, and direction have been plotted (Figures 6-11). Figure 6 presents a histogram of the annual distribution of wave heights. The most frequently occurring waves at Colombo are in the 1-2 foot height range. This pattern is prevalent most of the year. In July, August, and November, however, the most frequently occurring waves are in the 2-3 foot height range (Figure 7) and are due to local seas at Colombo. Figure 6 also shows a cumulative frequency distribution, from which may be read directly the percentage of the year when waves greater than a specified height will be exceeded. As an example, it may be seen that waves in excess of 3 feet occurred $20 \%$ of the time. The monthly wave-height distribution graphs in Figure 7 indicate that the highest incidence of the most frequently occurring waves (1-2 foot height range) is in May and June, and that the least wave action at Colombo is experienced in December. The largest waves hindcasted were in the 13-14 foot range, and occurred in Apri1, May, and July.

Figure 8 presents the annual distribution of wave periods. The histogram may be seen to approximate a normal frequency distribution and to be peaked in the 13-14 second period band, represented by swe 11 waves. The 4-5 second peak at the short period end of the distribution is due to wind waves at Colombo. This unequal bimodal distribution of periods may also be seen in some of the monthly histograms of Figure 9. It may also be noted in Figure 9 that short-period wind waves are negligible in December. The longest periods hindcasted were in the 23-24 second range and occurred in July. 
Figure 10 shows the direction of wave arrival at Colombo to be largely limited to the south-southwest and southwest. The westerly direction is due mainly to wind waves at Colombo. The monthly graphs (Figure 11) show that waves from the west occur most frequently from May through September. The figure also shows wind waves, dominantly from the west, are negligible in December.

\section{Characteristics of Sea, Local Swe11, and Distant Swel1}

Examination of Tables B-1 to B-12 shows that Sea at Colombo is characterized by 2-3 foot high waves with periods of 4-5 seconds arriving mostly from the west. Seas are most frequent during the months of May through September.

Local Swe 11 arrives at Colombo mainly as $1-2$ foot waves from the southwest to west-northwest with periods ranging from 8-14 seconds. It occurs most frequently during the months of May through August.

Distant Swell is restricted to the three directions south, south-southwest, and southwest. The waves are very often in the 1-2 foot range. The periods range from 9-24 seconds, but a high percentage of the energy is contained in the 14-16 second period band. The occurrence of Distant Swell generally increases from December to May and decreases thereafter.

\section{Peak Values}

The highest wave set hindcasted for the year occurred in a May sea generated by a westerly wind with a speed of 25 knots. The significant height and period in deep water off Colombo were 13.8 feet and 10.0 seconds, respectively. The wave height also exceeded 13 feet in April and July. 


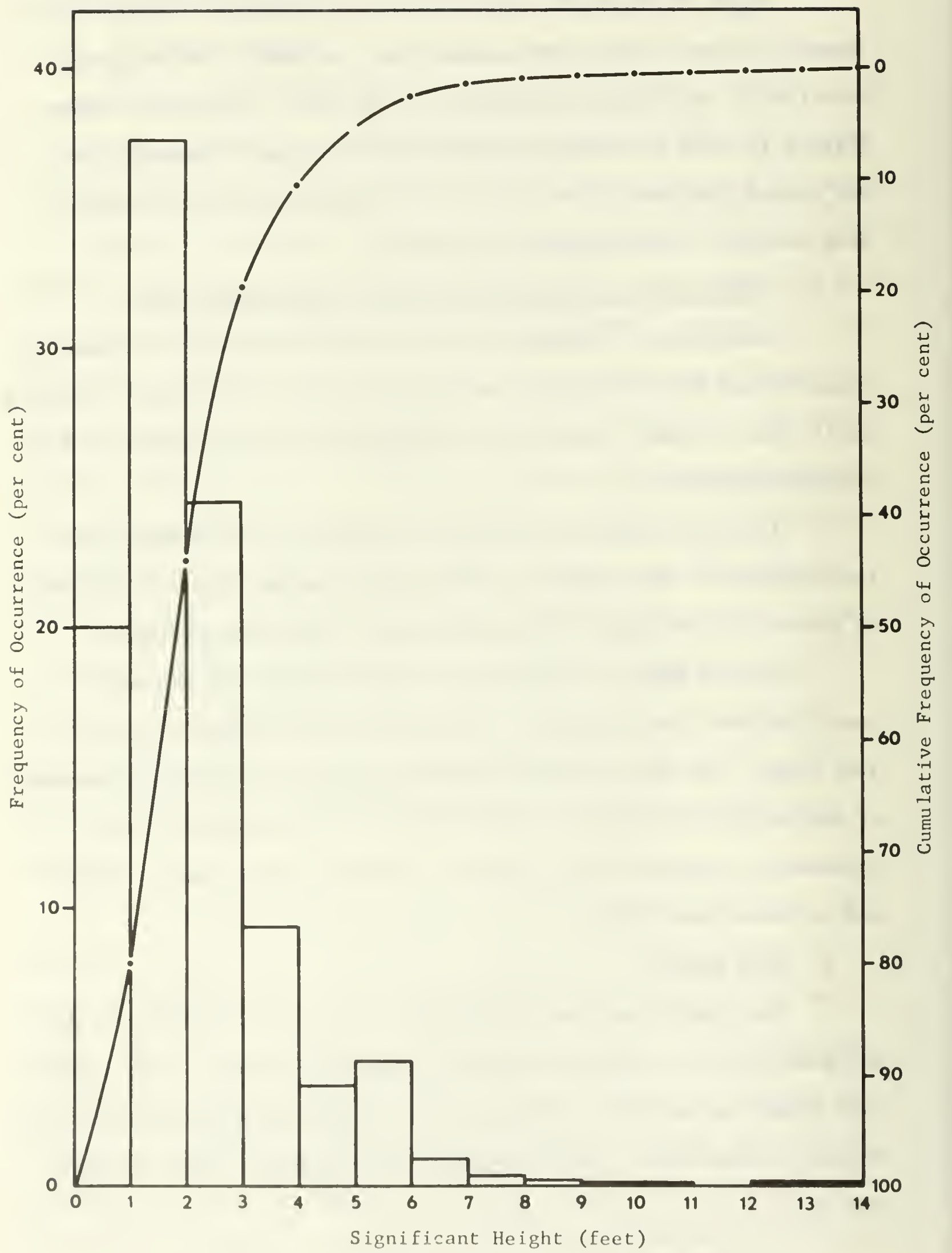

Figure 6: ANNUAL DISTRIBUTION OF WAVE HEIGHT 


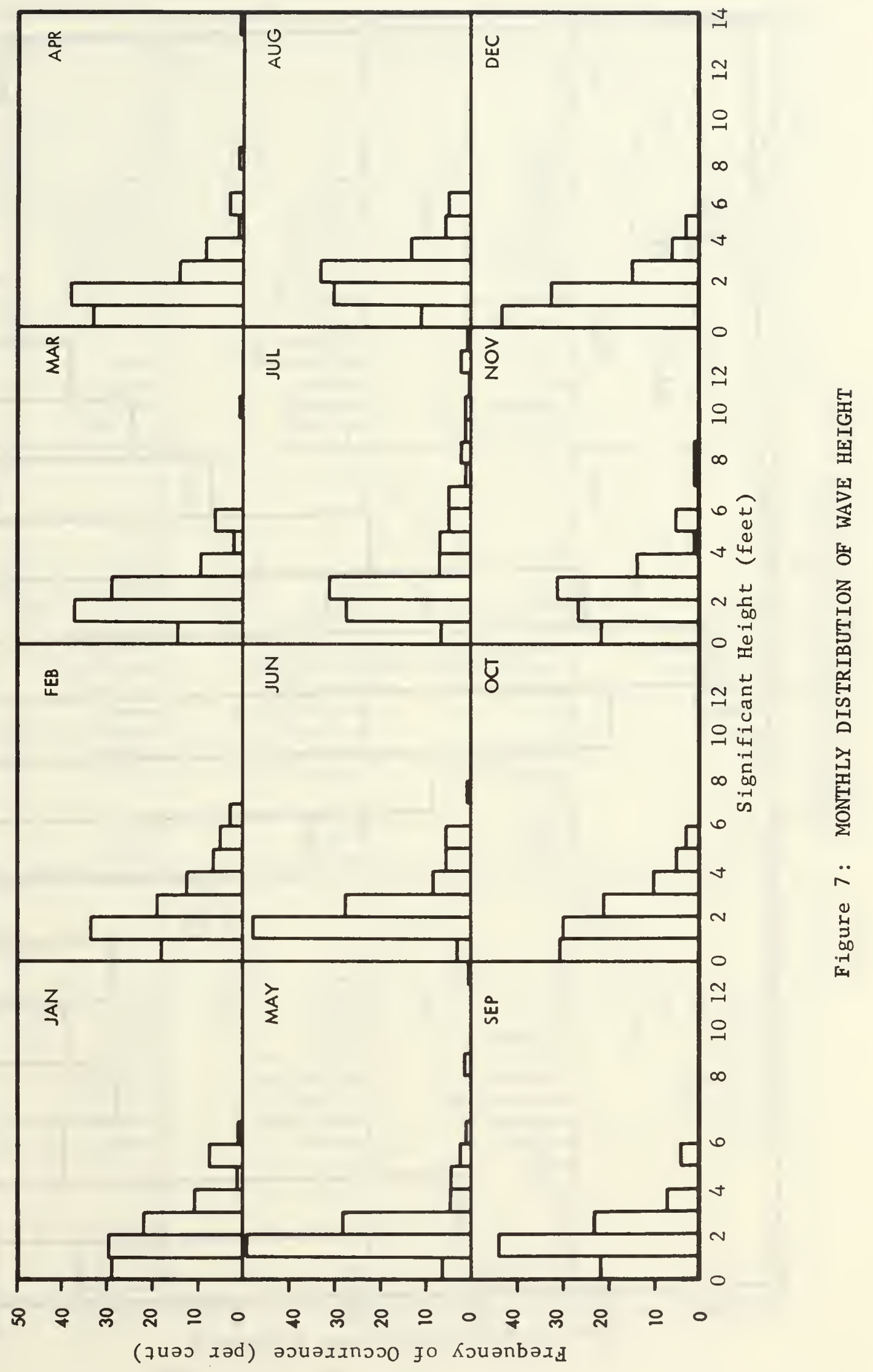




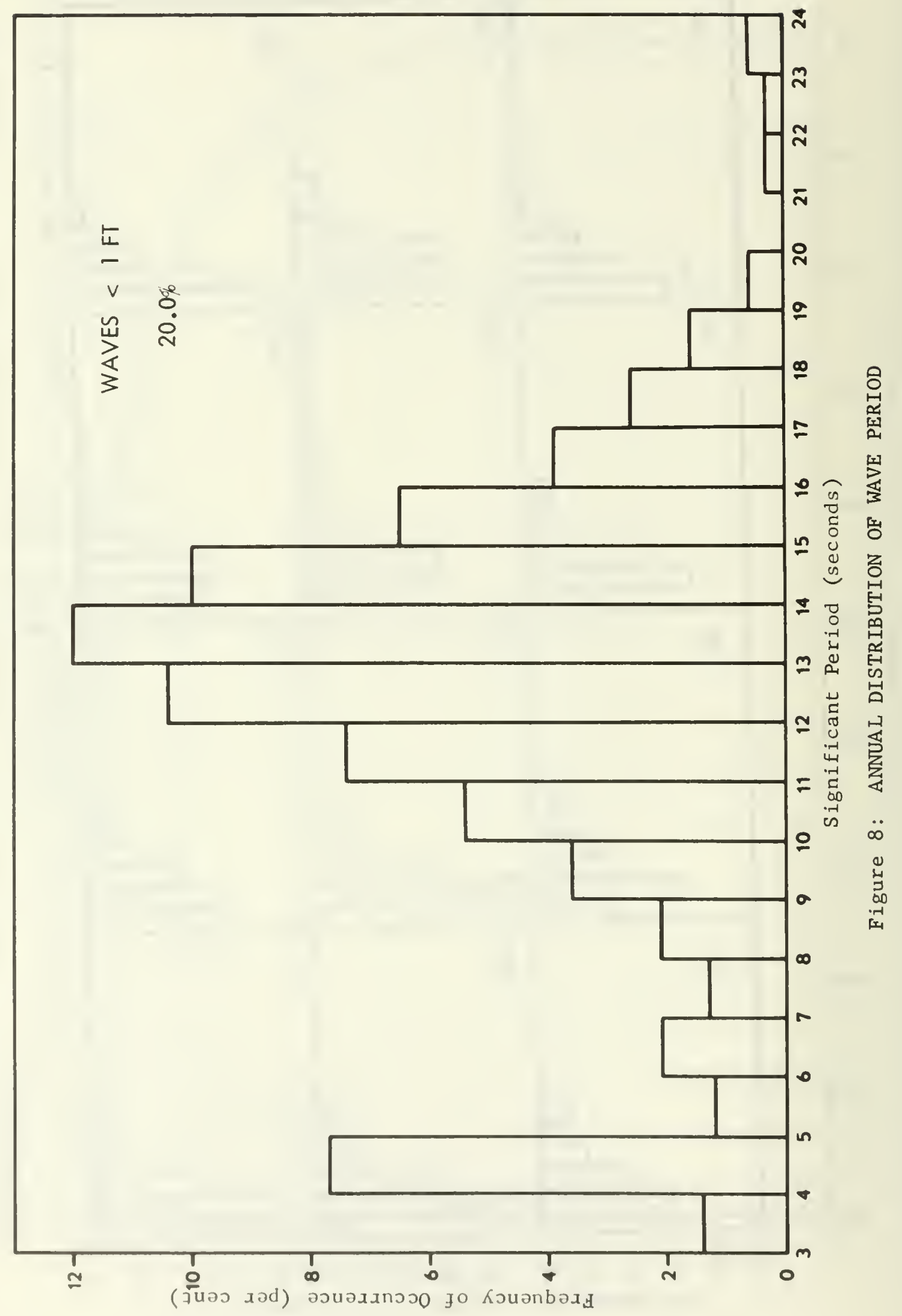




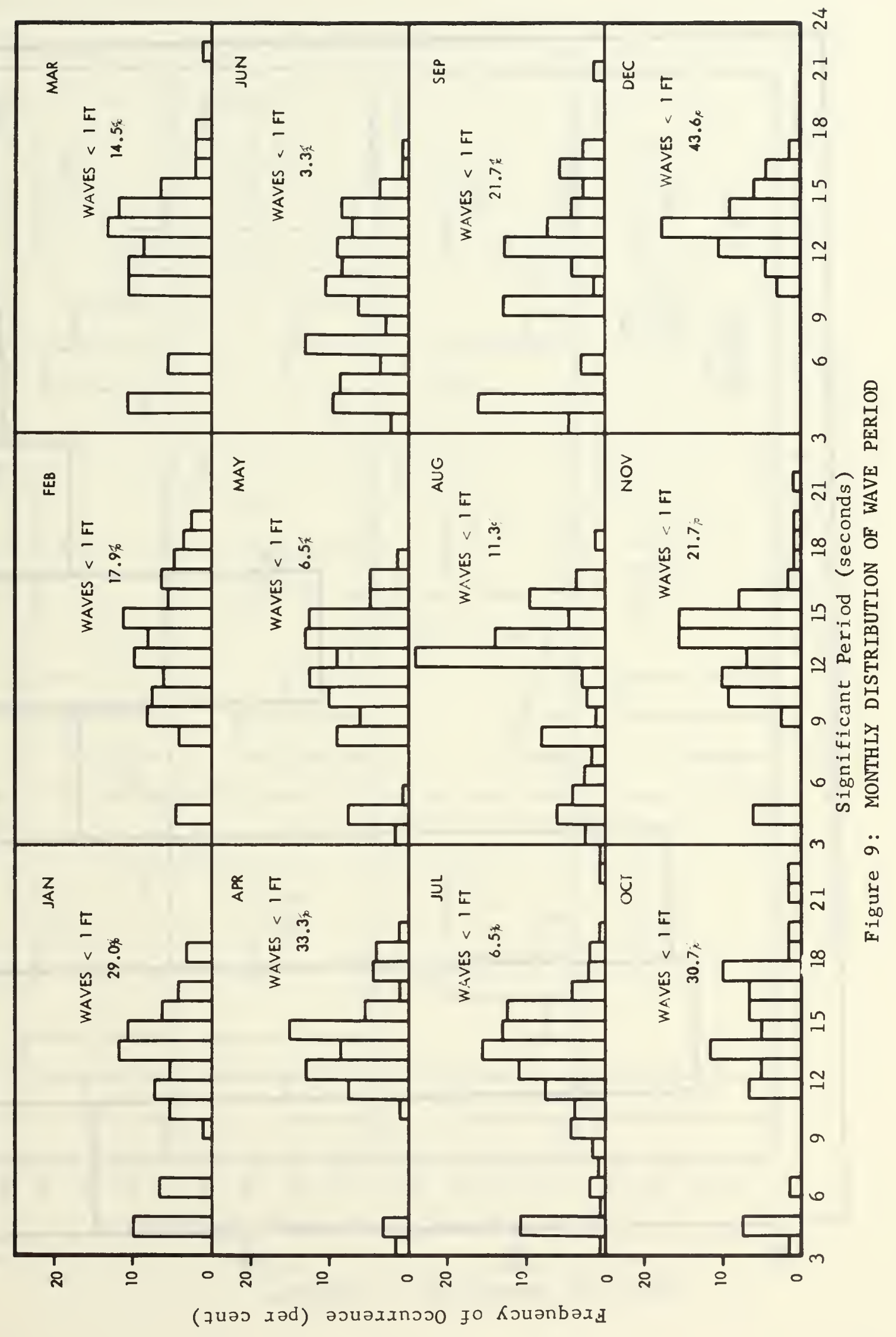




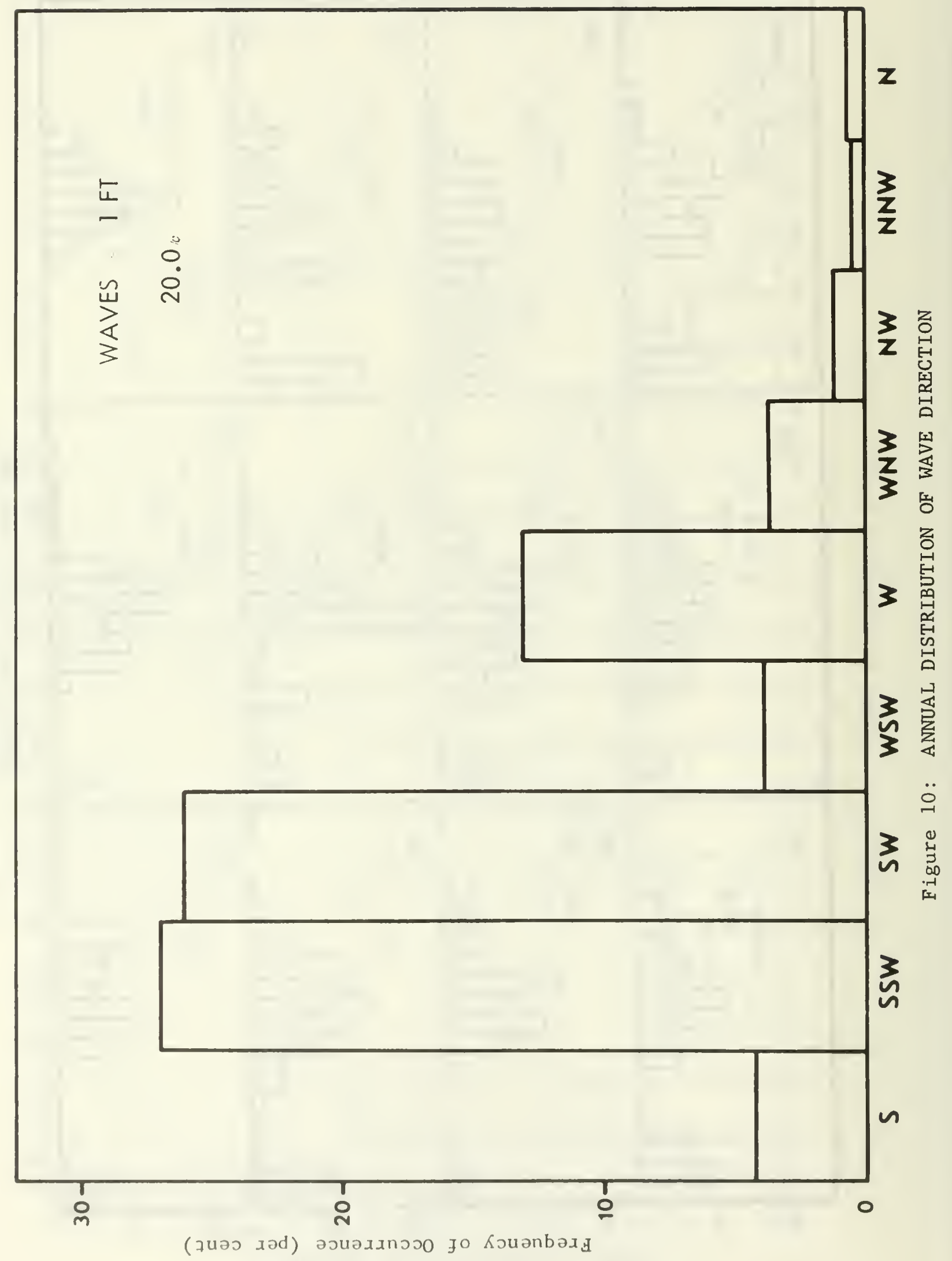




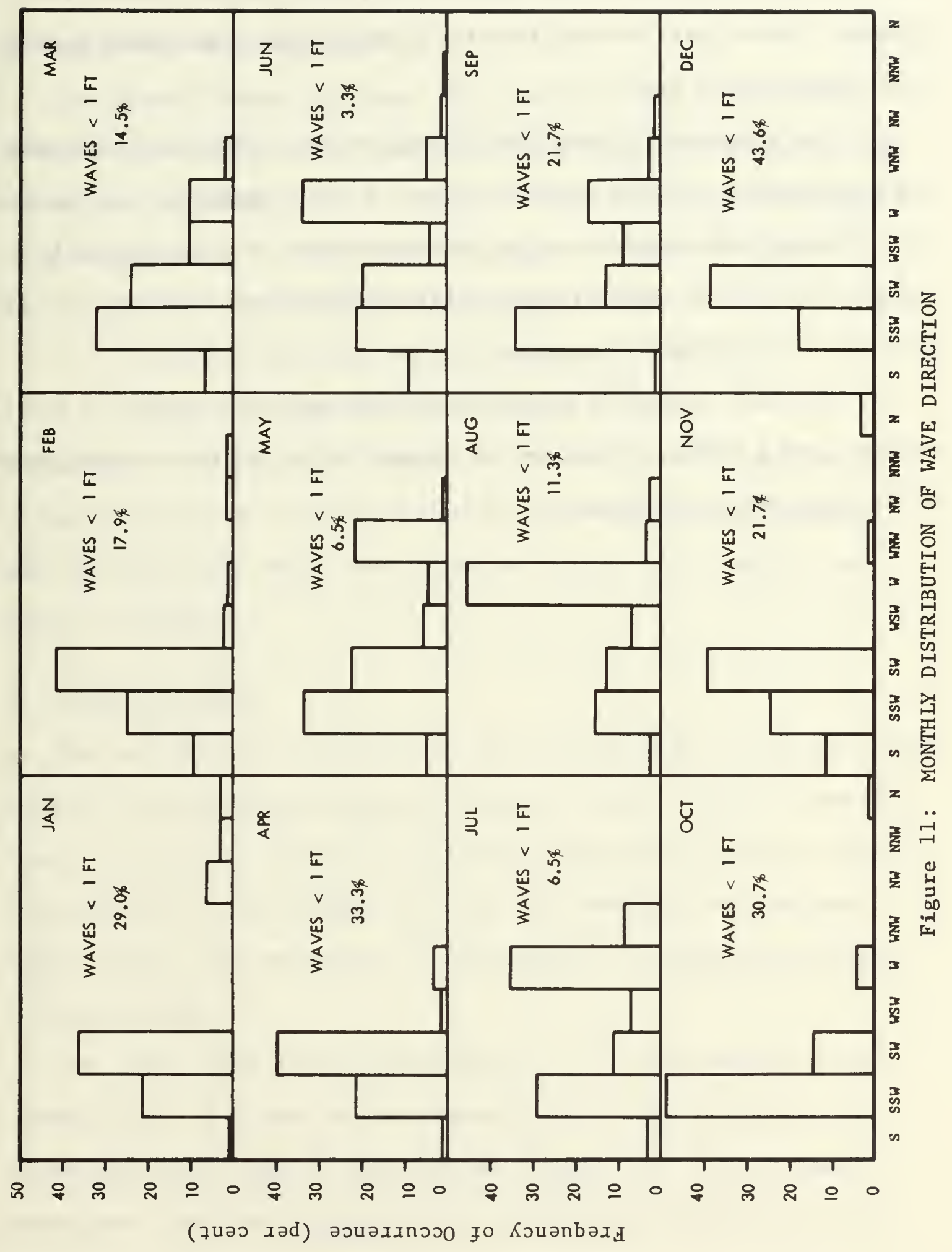


The longest period was one of 23.7 seconds in July which originated in a 56-knot wind field off the Weddell Sea, 6500 nautical miles from Colombo. Those swell arrived from the south-southwest and had a significant height of 5.4 feet.

The furthest distance from Colombo at which any significant wave train originated was 7500 nautical miles. A train generated in this area by a 25-knot wind arrived from the south-southwest in deep water off Colombo 15-1/2 days later with a significant height of a little over one foot and a period of 13.4 seconds.

The most frequently occurring wave set was $\mathrm{H}=1-2$ feet, $\mathrm{T}=12-13$ seconds, and $\psi=\mathrm{SSW}$. It arrived at Colombo for a cumulative duration of $3.3 \%$ of the year, or 12 days. 


\section{WAVE CLIMATOLOGY OF WESTERN CEYLON}

\section{A. REGIONS OF WAVE GENERATION}

The spatial window for waves arriving at Colombo includes the western Indian Ocean and extends completely across the South Atlantic in the zone of westerly winds (Figure 2). Wave generation throughout this window occurs in three main atmospheric circulation belts:

(1) Trade Wind (Monsoon) Belt $\left(20^{\circ} \mathrm{N}-20^{\circ} \mathrm{S}\right)$,

(2) Subtropical High Pressure Belt $\left(20^{\circ} \mathrm{S}-40^{\circ} \mathrm{S}\right)$,

(3) Westerly Wind Belt $\left(40^{\circ} \mathrm{S}-65^{\circ} \mathrm{S}\right)$.

These wind belts are shown diagramatically in Figure 12, and their seasonal variations are illustrated in Figures 13 and 14 . Together they determine the annual wave regime at Colombo and along the west coast of Ceylon.

\section{B. TRADE WIND BELT}

The most distinctive feature of the Trade Wind Belt over the Indian Ocean is its pronounced Monsoon circulation system, which is characterized by a seasonal reversal in the prevailing wind directions caused by differential heating between the Asian land mass and the northern Indian Ocean. The phenomenon of the Monsoon is brought about in the following manner.

The trade winds of both hemispheres meet in the equatorial lowpressure belt at a zone of convergence known as the Intertropical Convergence Zone (ICZ) or the Doldrums (Figure 12). In the Indian Ocean area this zone migrates over a wide range of latitudes in the year, as may be seen in Figure 15. It reaches its most southerly 
position (near the Equator at the longitude of Ceylon) in February and its most northerly position $\left(\sim 30^{\circ} \mathrm{N}\right)$ over the Himalayas in August. During the months of December through March the ICZ lies to the south of Ceylon, and the Northeast Trade Winds, referred to as the Northeast Monsoon, blows over Ceylon from the Bay of Bengal. At this season of the year the winds blow dominantly offshore along the west coast of Ceylon, and away from Ceylon over the northwestern Indian Ocean. During the months of June through September the ICZ Iies to the north of Ceylon. The Southeast Trades at this time of the year cross the Equator and move well into southern Asia, and in doing so are deflected by the coriolis effect so as to become a southwesterly wind, the Southwest Monsoon, over the north Indian Ocean, Ceylon, India, and Southeast Asia. The ICZ passes over Ceylon on its northward migration in May and southward again in OctoberNovember. These months will be referred to here as the transition months. As may be expected, the wave statistics for Sea and Local Swell at Ceylon, both of which originate in the equatorial and tropical Indian Ocean, reflect the seasonal change in wind direction associated with the Monsoons. In Figures 16 and 17 are shown the frequency of occurrence of waves of one foot or greater due to Sea and Local Swe11, respectively. The figures clearly reveal the influence of the onshore winds of the Southwest Monsoon during June through September, and the dominantly offshore winds of the Northwest Monsoon, as well as the irregular wind directions of the transition months, during the remainder of the year. The isolated peaks in the Local Swell in February and November may be attributed to the fact that the wave statistics compiled are based on insufficient data for these months (see Appendix A). The dominant wave direction of Sea during the Southwest Monsoon is from the west, as may be seen in Figure 11. 


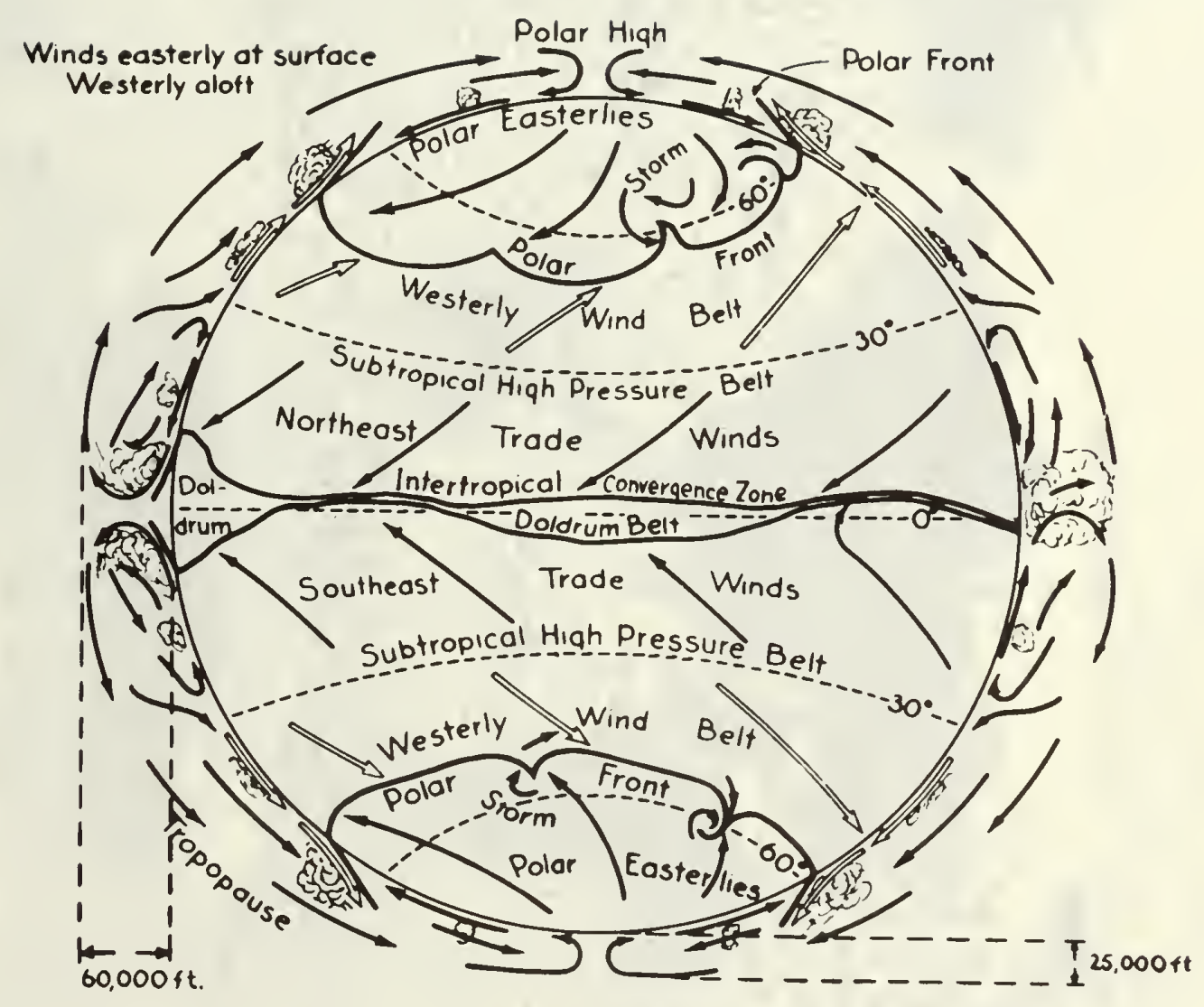

Figure 12: GENERAL PATTERN OF ATMOSPHERIC CIRCULATION

(From NAVAER 00-80U-24, 1952) 


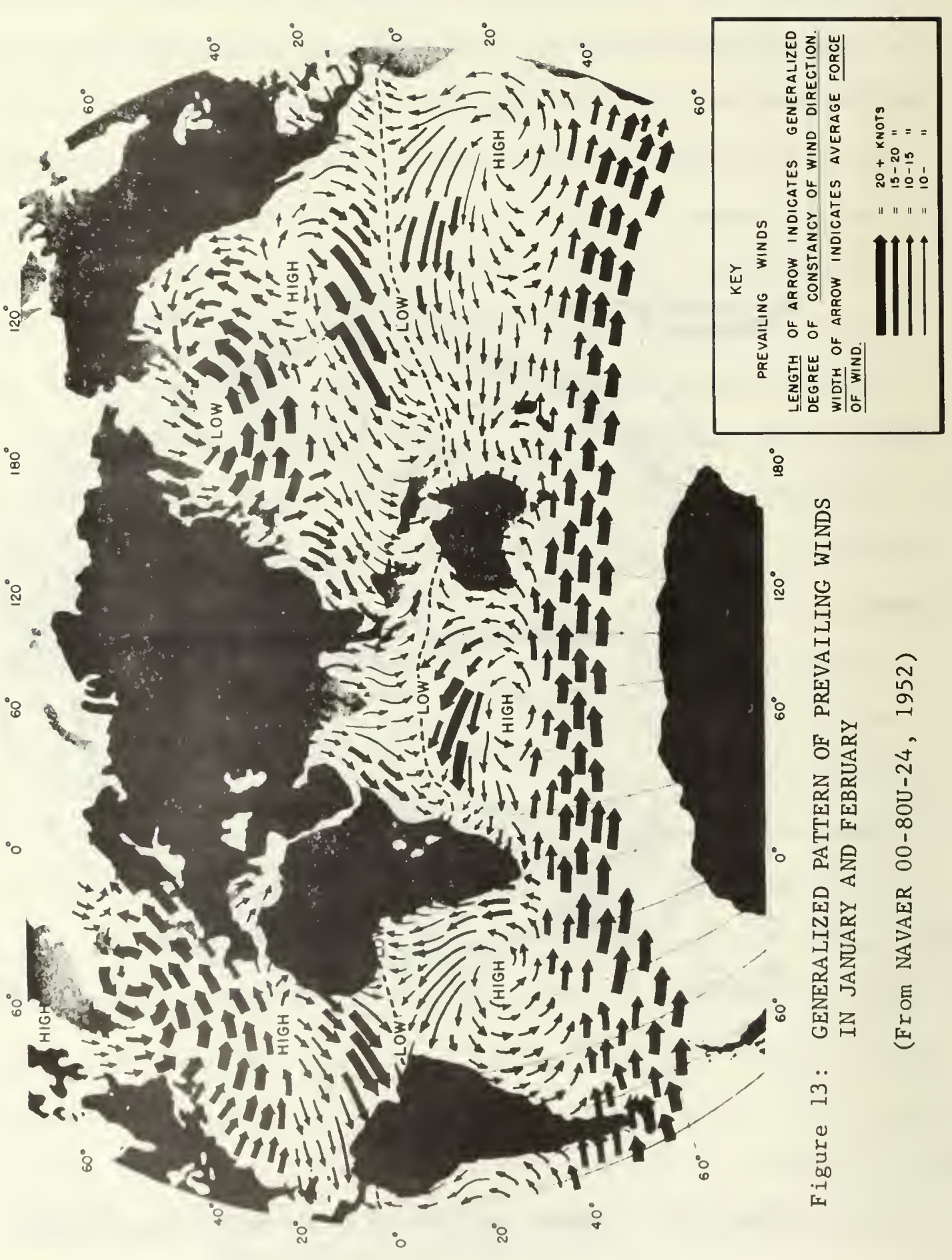




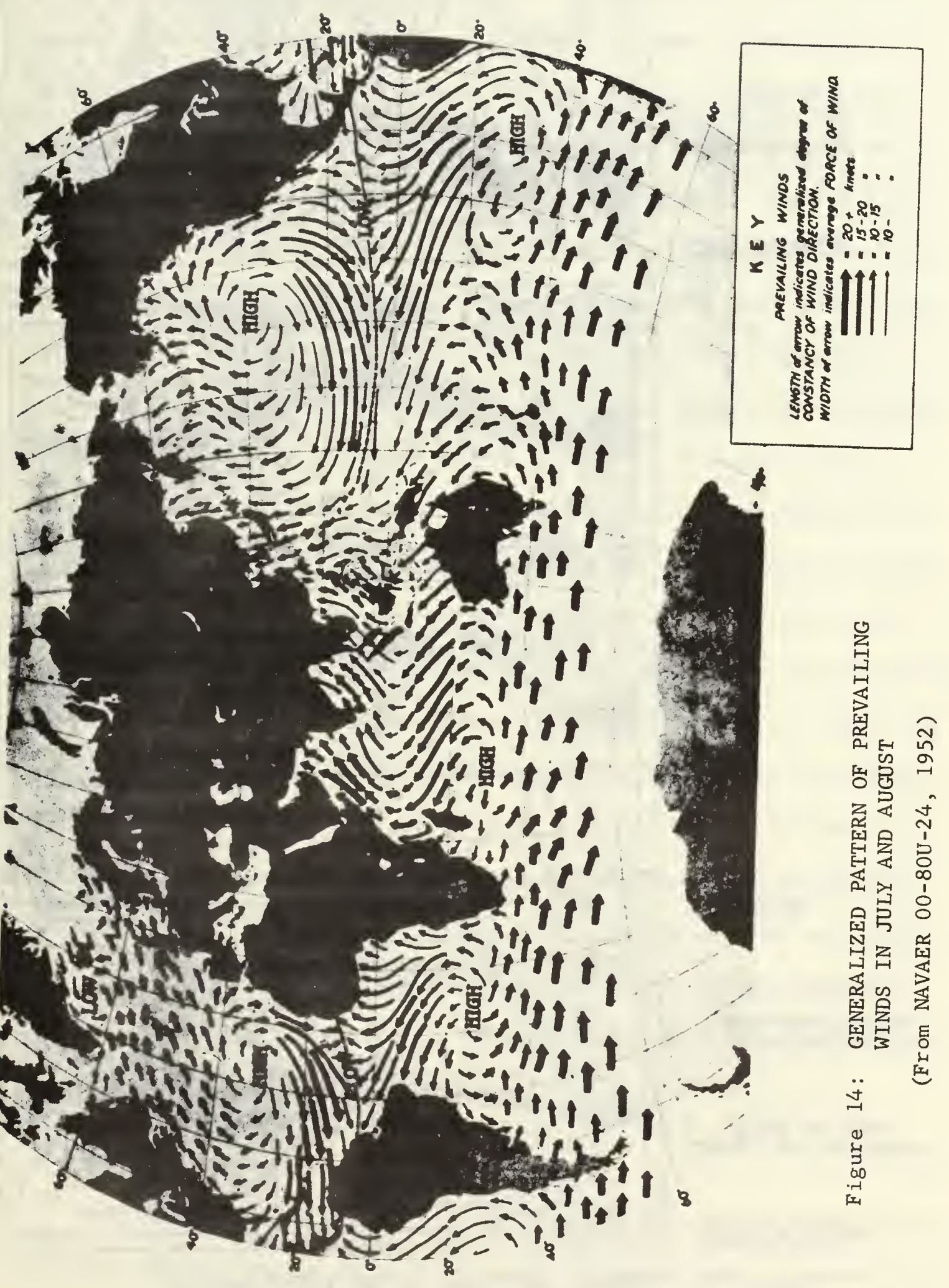




\section{FEBRUARY}

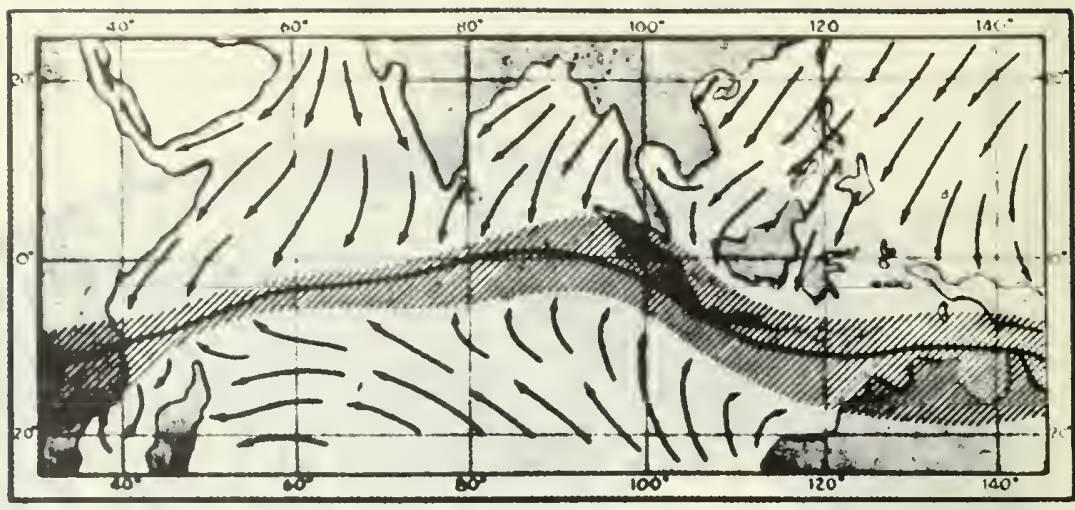

\section{AUGUST}

MEAN POSITION OF FRONT

DAY BY DAY MOVEMENT OF FRONT

\section{NOVEMBER}
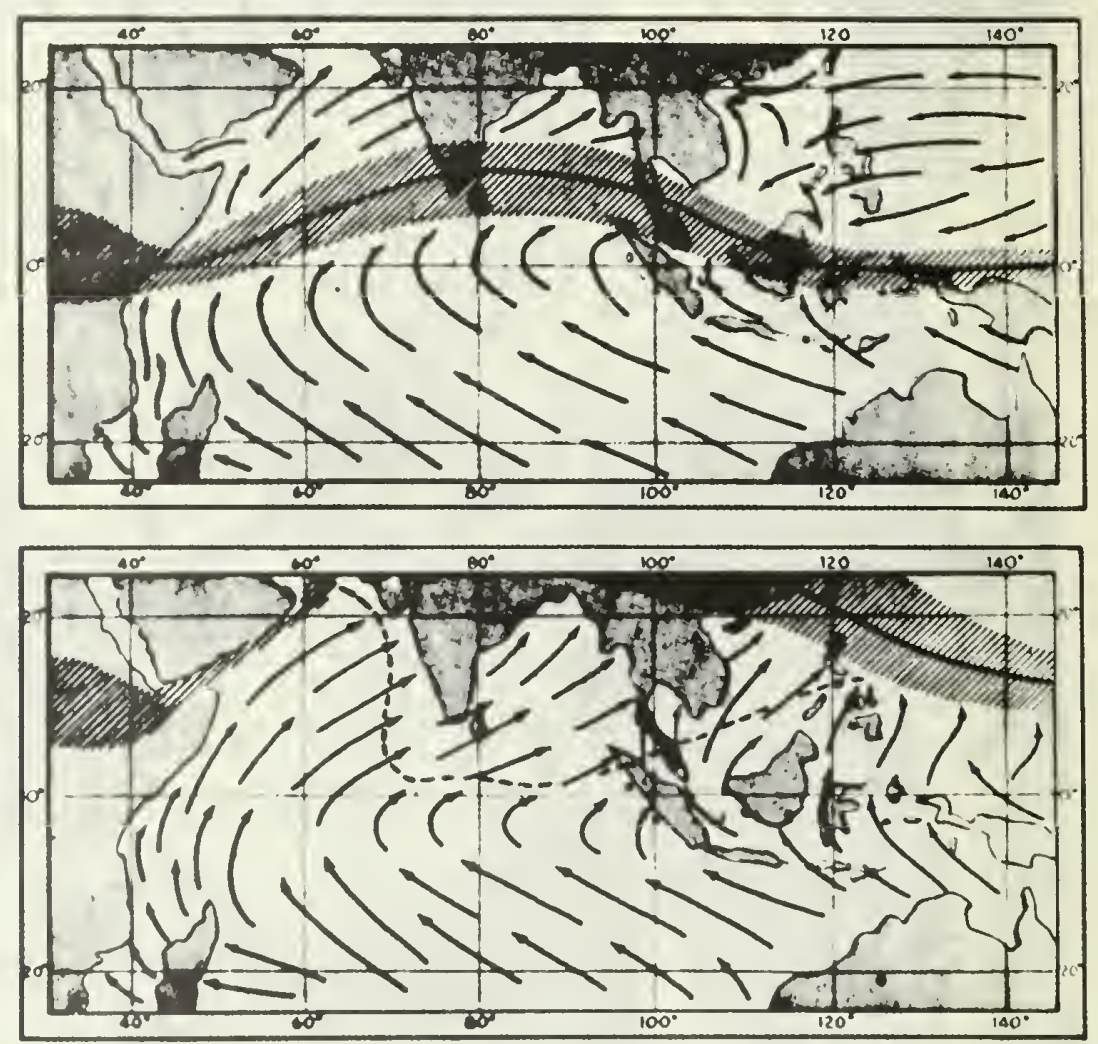

Figure 15: AVERAGE POSITIONS OF THE INTERTROPICAL CONVERGENCE ZONE IN THE INDIAN OCEAN AREA

(From NAVAER 00-80U-24, 1952) 


\section{SUETROPICAL HIGH PRESSURE BELT}

The Subtropical High Pressure Belt $\left(20^{\circ} \mathrm{S}\right.$ to $\left.40^{\circ} \mathrm{S}\right)$ is the nearest source region for Distant Swell arriving at Colombo. This belt is represented in the central Indian Ocean by a quasi-permanent highpressure cell centered at a mean latitude of $30^{\circ} \mathrm{S}$ around which the wind circulation is anticyclonic (counter-clockwise). The air flow around the north side of the anticyclone is the Southeast Trade Wind, and on the south side becomes a part of the Westerly Wind Belt. The exposure of the west coast of Ceylon to the wind direction in this circulation is such that waves are not generated on its north or west sides. In addition, the winds in the central part of the high cell are normally weak and variable, so that this region is likewise not a source region for any significant amount of swell arriving at Colombo.

The general lack of suitable swell-generating conditions in this weather belt in contrast to the Westerly Wind Belt of the more southerly latitudes, is reflected in the Distant Swell statistics for these two regions. Figure 18 shows the percentage of Distant Swell arriving at Colombo that originated in the latitude belts of $20^{\circ} \mathrm{S}-40^{\circ} \mathrm{S}$ and $40^{\circ} \mathrm{S}-65^{\circ} \mathrm{S}$. As may be seen, on ly about $7 \%$ of the swe 11 originated within the Subtropical High Pressure Belt. It may thus be seen that, with regard to waves arriving on the west coast of Ceylon, the Subtropical High Pressure Belt is a comparatively quiet zone lying between two zones of significant wave noise.

\section{WESTERLY WIND BELT}

The Westerly Wind $\operatorname{Belt}\left(40^{\circ}-65^{\circ} \mathrm{S}\right)$ is the major source region for Distant Swell arriving on the west coast of Ceylon, and is essentially 


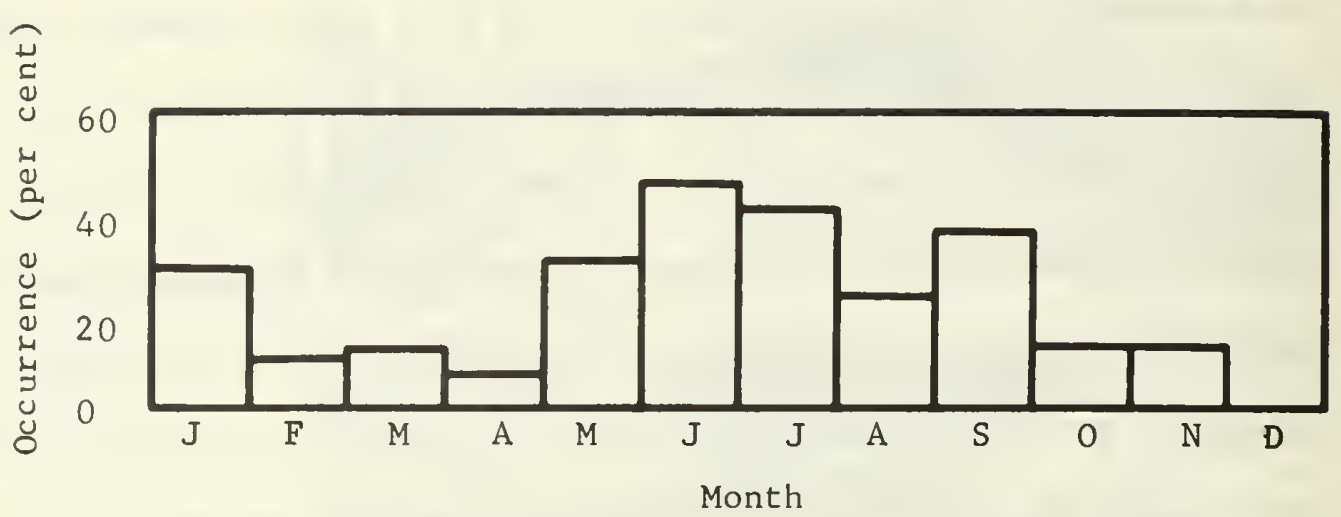

Figure 16: MONTHLY OCCURRENCE OF SEA

Waves of one foot height or greater.

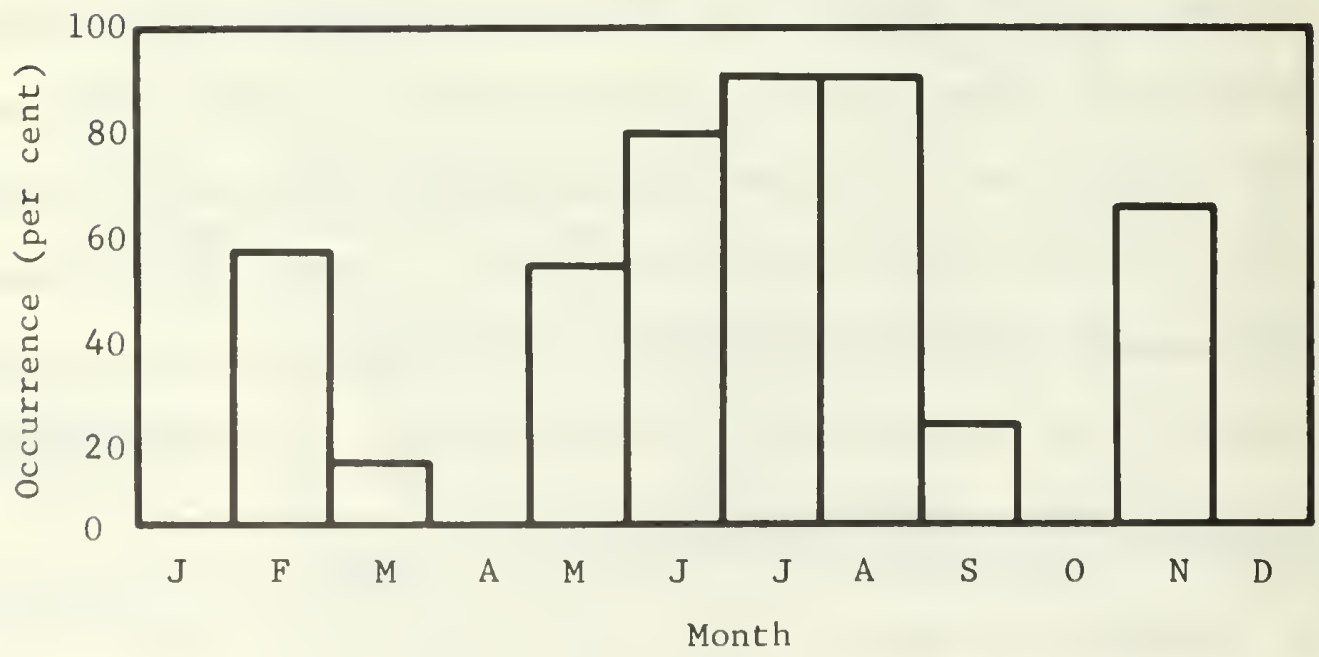

Figure 17: MONTHLY OCCURRENCE OF LOCAL SWELL Waves of one foot height or greater. 


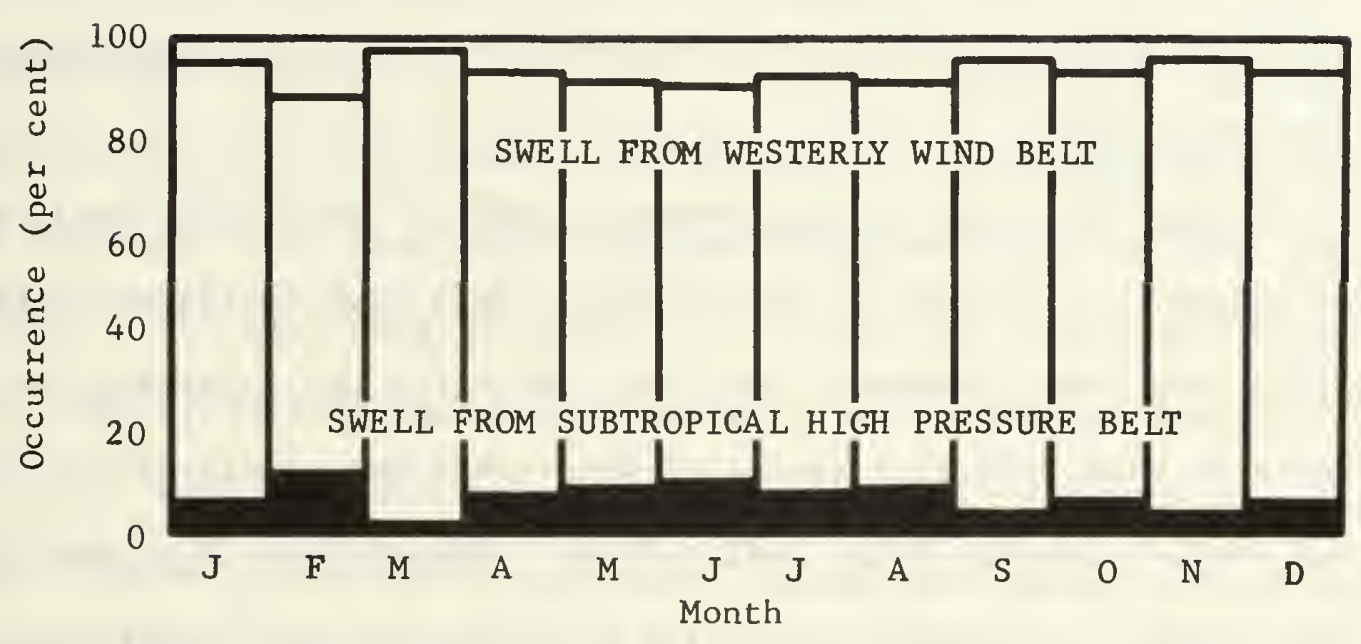

Figure 18: PERCENTAGE COMPOSITION OF DISTANT SWELL Waves of one foot height or greater.

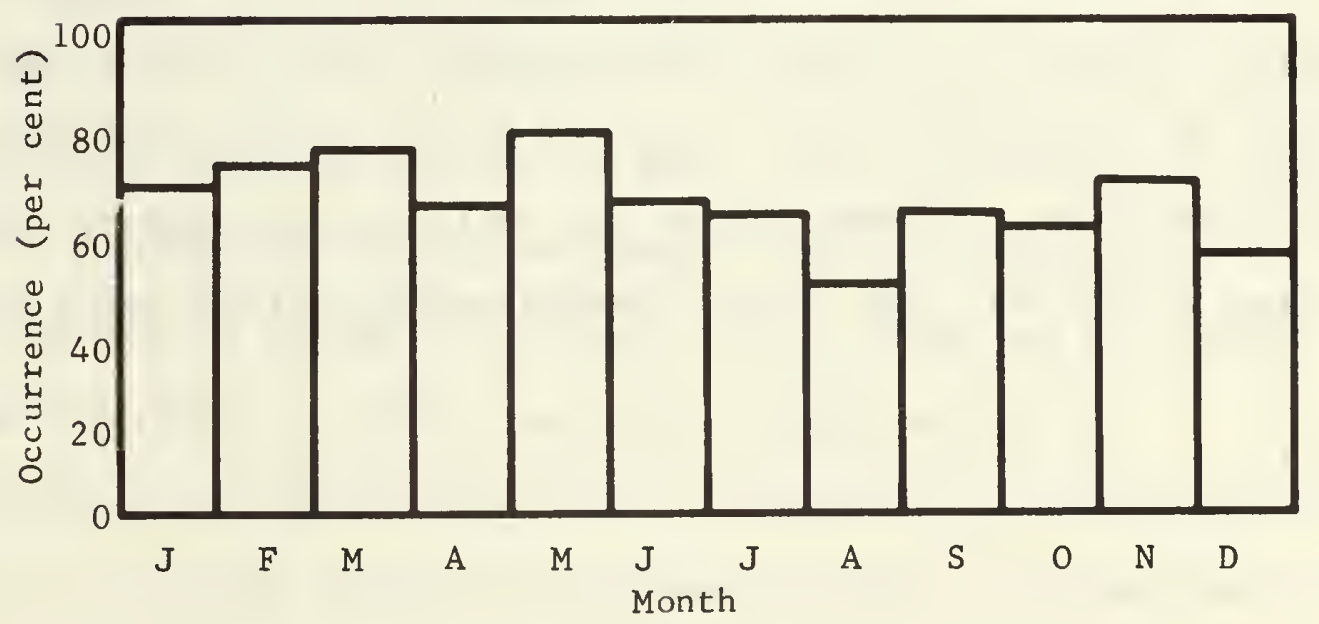

Figure 19: MONTHLY OCCURRENCE OF DISTANT SWELL ARRIVING FROM THE WESTERLY WIND BELT Waves of one foot height or greater. 
an unbroken belt extending some $8500 \mathrm{NM}$ from Argentina $\left(60^{\circ} \mathrm{W}\right)$ to the longitude of Ceylon $\left(80^{\circ} \mathrm{E}\right)$. It is a region of intense cyclonic storm systems which are advected eastward with the mean air flow across the Southern Ocean, and which are the principal source of swell emanating from this region.

Figure 18 shows that approximately 93\% of the Distant Swel1 arriving at Colombo is produced in this region. This high incidence of Distant Swell from these southerly latitudes indicates the importance of the Westerly Wind Belt as a source of waves arriving on all of the northern and eastern coasts of the Indian Ocean. From Figure 19 it may be seen that there is a seasonal variation at Colombo of the occurrence of swe 11 greater than one foot propagated from the Westerly Wind Belt, which reaches a maxima during December to May.

The hindcast results revealed that a predominance of the Distant Swell originated in the eastern South Atlantic to the south and west of Africa. Possible reasons for this are that this region has shorter decay distances to Colombo than the western South Atlantic, and also that the Indian Ocean to the south of Ceylon produces less swell in the direction of Colombo because the swell are generated by south winds on the west side of the eastward-moving cyclonic storm systems. 


\section{UTILITY OF THE WAVE STATISTICS}

This study is the only detailed climatological wave investigation on Ceylon that is known to the author. Although prepared for Colombo, the wave statistics presented in the appendices may be applied to deepwater locations with reasonable judgement along most of the west coast of Ceylon. The wave data for directions of arrival from south through west can be applied without modification to any deep-water location along the coast. Wave statistics for directions from west to north are affected by the shelter of the Indian Peninsula. Along the coastal area to the north of Colombo, the frequency of occurrence of waves from the westnorthwest must be reduced, whereas along the coast to the south of Colombo these frequencies should be increased. There will also be additional wave energy arriving from the northwest at stations along the southern half of the coast that does not reach Colombo, and which is not contained in the statistical tables.

In order to apply these statistics to a shallow-water site, shoaling and refraction modifications must be made. These procedures are given in "Shore Protection, Planning and Design" [Technical Report No. 4, U. S. Army Coastal Engineering Research Center, 1966] and in other standard references on shallow-water wave transformation.

In applying the wave statistics to coastal sites in the vicinity of Colombo, or elsewhere along the west coast of Ceylon, the user should be aware of the following limitations related to their preparation:

1. Adequate weather data for use in hindcasting the Local Swe11, in particular, were lacking in most months, except during the period May 
through August (see Appendix A). In September through January and in April the wave statistics are based on less than six days of available weather data per month.

2. Simultaneously arriving wave trains were not combined using energy addition to provide a resultant wave of higher significant height. However, in the case of small waves, as is the usual situation off Colombo, this would not appear to constitute a source of appreciable error.

3. The representativeness of the particular 12-month period selected for the study is not known. One or more additional years of wave data would be desirable to give more reliable long-term wave statistics. 


\section{APPENDIX A}

\section{NOTES ON THE USE OF THE STATISTICAL TABLES}

\section{Frequency Values}

The values entered in the statistical wave tables indicate the percentage of the month (or year in the case of an annual table) that the particular wave combination is likely to occur. For example, the frequency figure of 1.4 for the wave set $\mathrm{H}=1-2$ feet, $\mathrm{T}=9-10$ seconds, and $\psi=$ SSW listed under Distant Swe 11 for January (Table B-1, Appendix B) means that these particular waves can be expected to occur $1.4 \%$ of the time in January, or nearly 10.4 hours ( $1.4 \%$ of $24 \times 31$ ).

\section{Wave Height and Period}

The height and period ranges listed in the table are abbreviated to conserve space, and actually extend from the lower class mark of a height or period interval up to but not including the upper class mark. Thus, a wave height range of $9-10$ feet means $9.0-9.9$ feet. All heights are significant heights and all periods are significant periods .

\section{Data Coverage}

Although 365 days of weather maps were available, weather data were missing on some maps; accordingly, the wave statistics were determined only from the maps with data available. In preparing the statistical tables, it was assumed that the frequencies of occurrence of waves of each $\mathrm{H}-\mathrm{T}-\psi$ combination that were hindcasted for a partial month are representative of the full month, so that the percentage 
frequencies of occurrence are identical. The number of 12-hourly weather maps each month from which the wave hindcasts were made are listed in the following table.

\section{Ful1 Month}

January

62

February

March

April

May

June

July

August

September

October

November

December
56

62

60

62

60

62

62

60

62

60

62
Sea

18

29

37

40

54

57

59

62

44

56

30

22

\section{Loca 1 Swe 11 Distant Swe 11}

5

57

22

52

23

59

10

58

33

61

29

60

43

50

31

45

5

45

50

55

56 


\section{APPENDIX B -}

MONTHLY FREQUENCY DISTRIBUTION OF SEA, LOCAL SWELL, DISTANT SWELL ANNUAL DISTRIBUTION OF SEA 
ป્ర

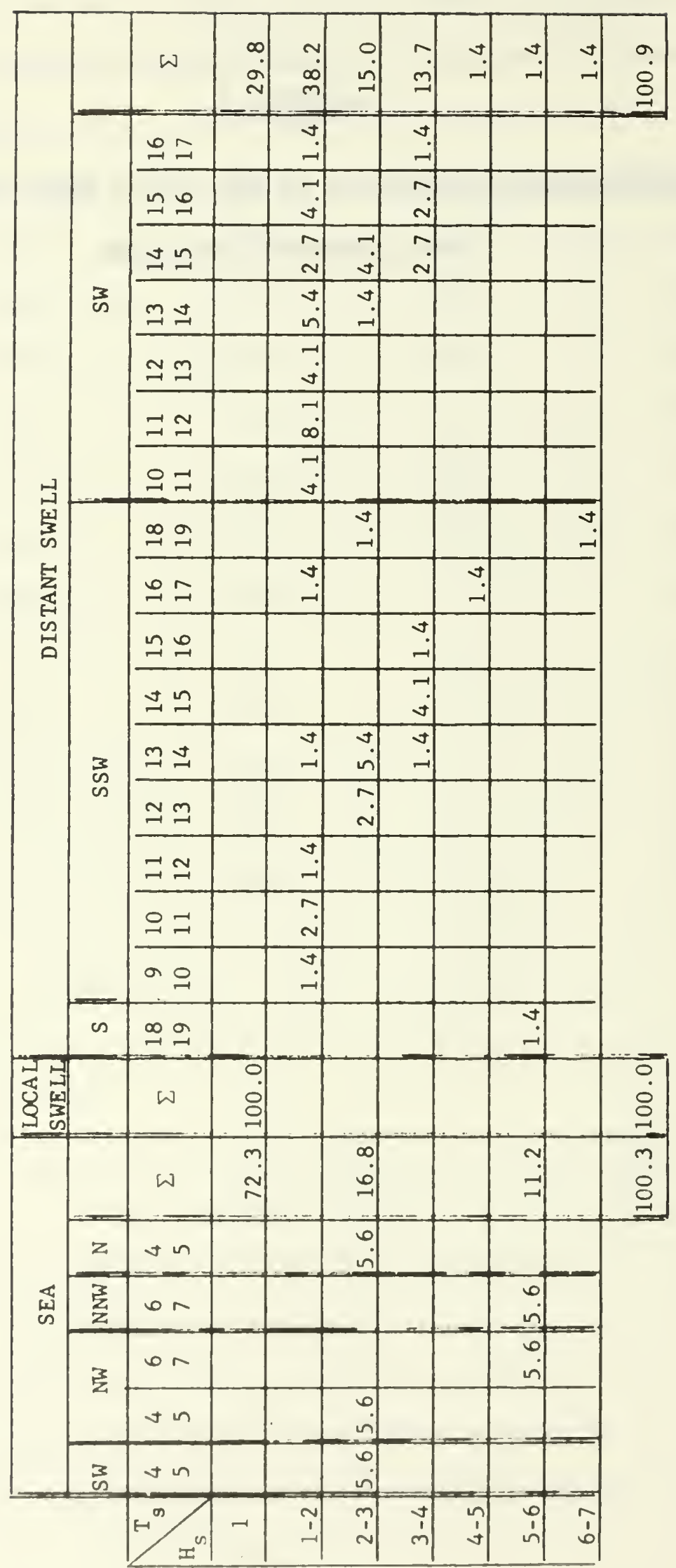



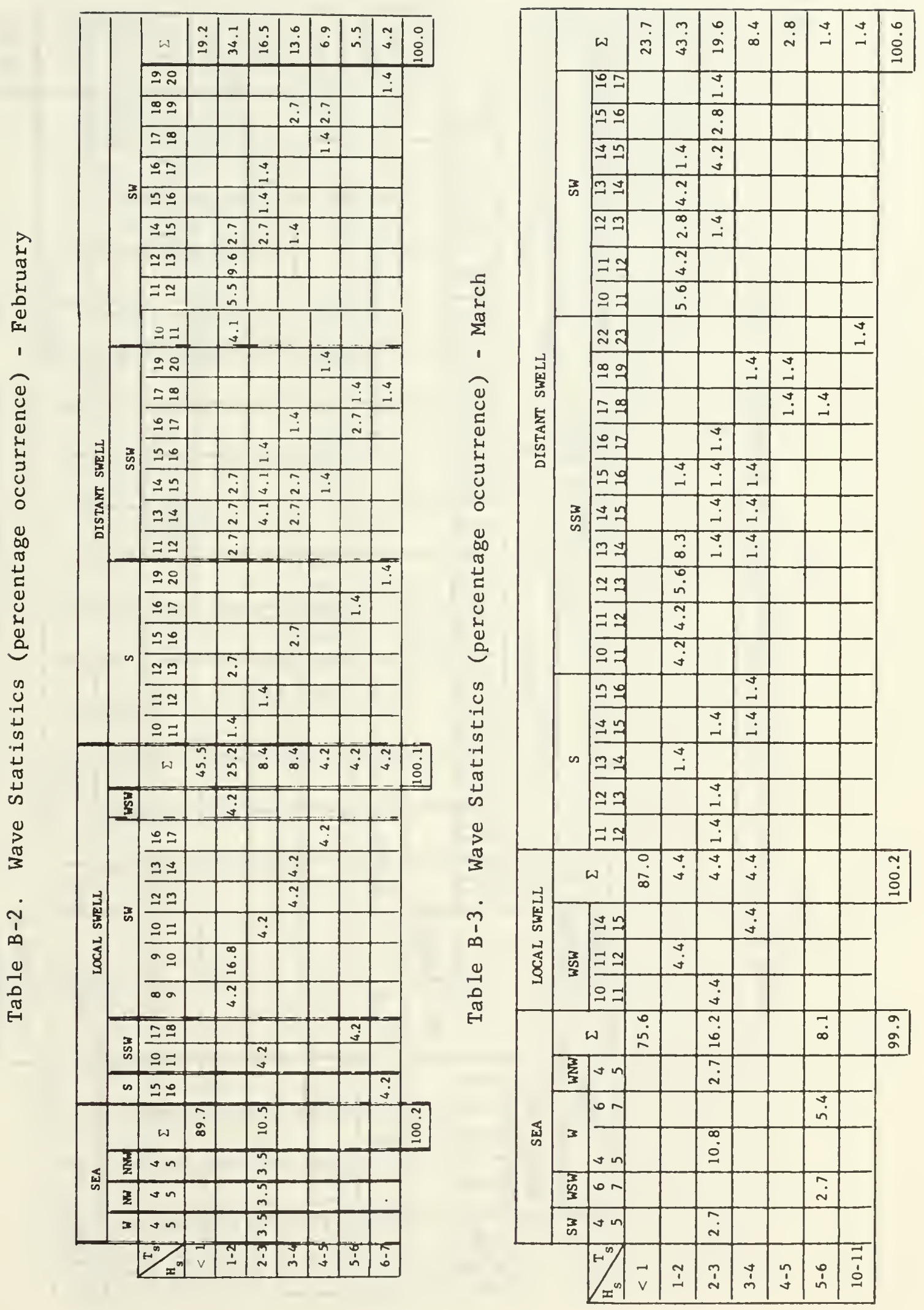


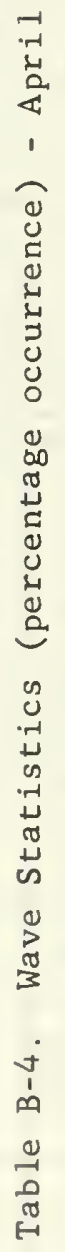

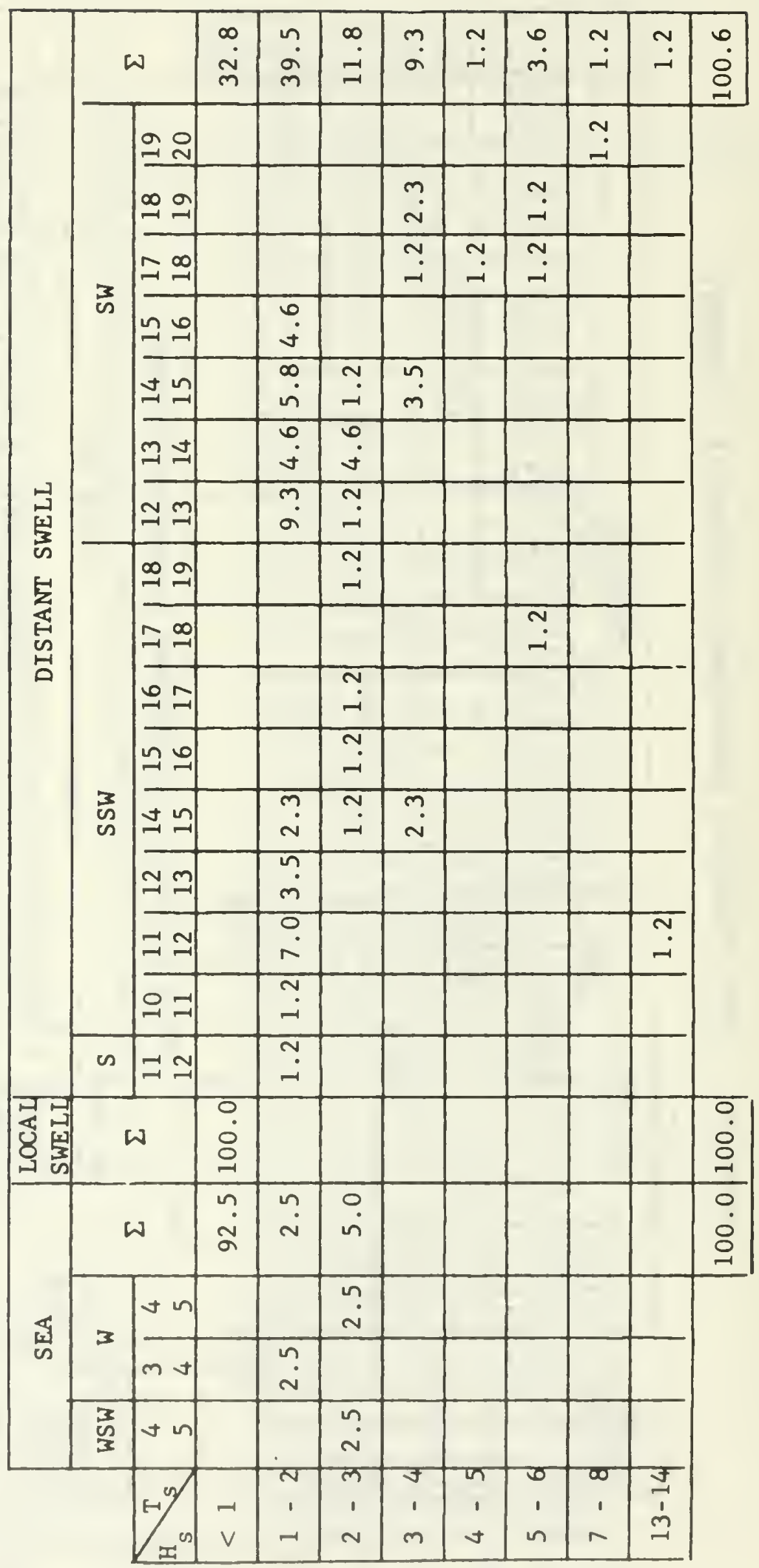



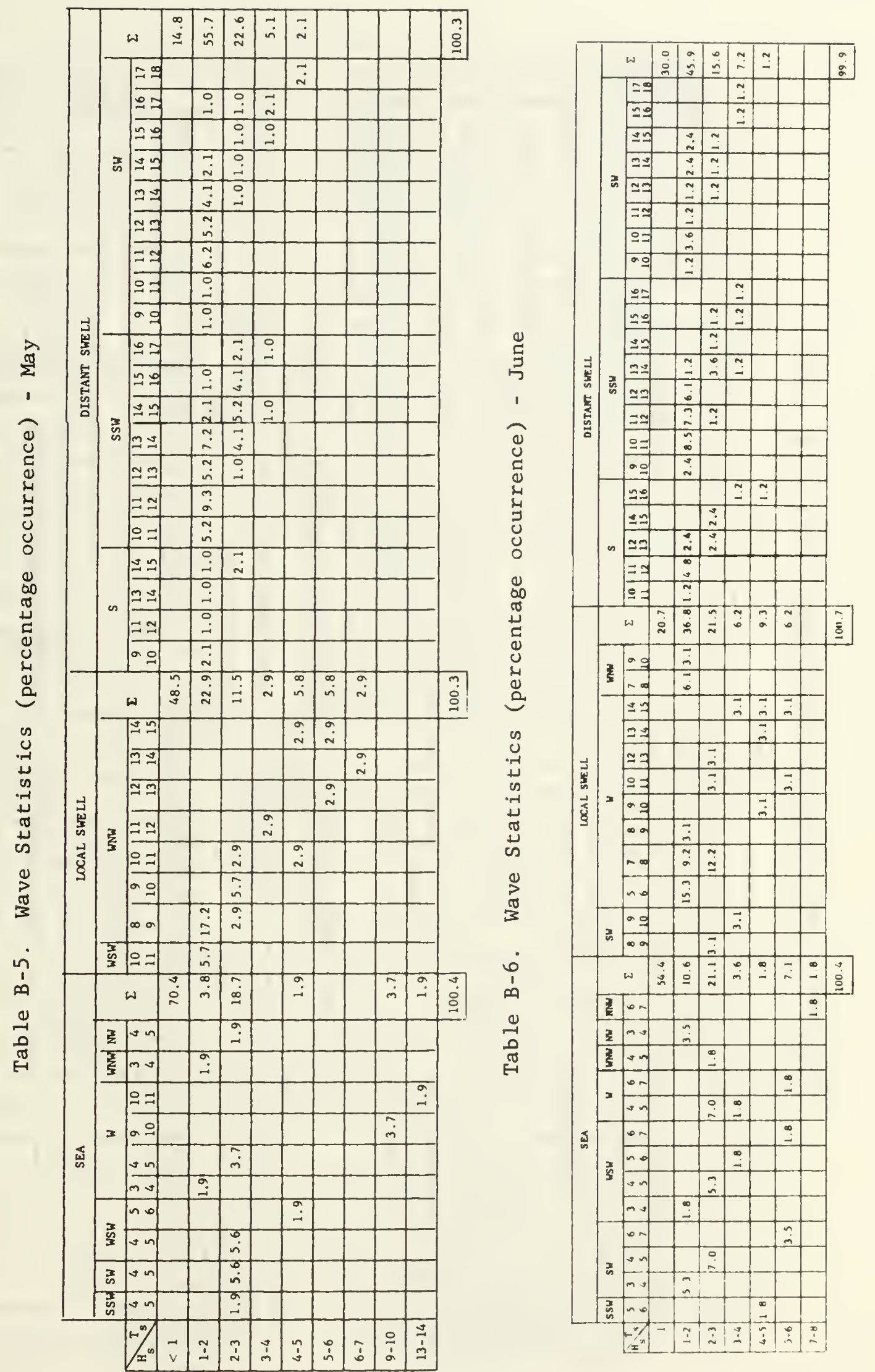

导
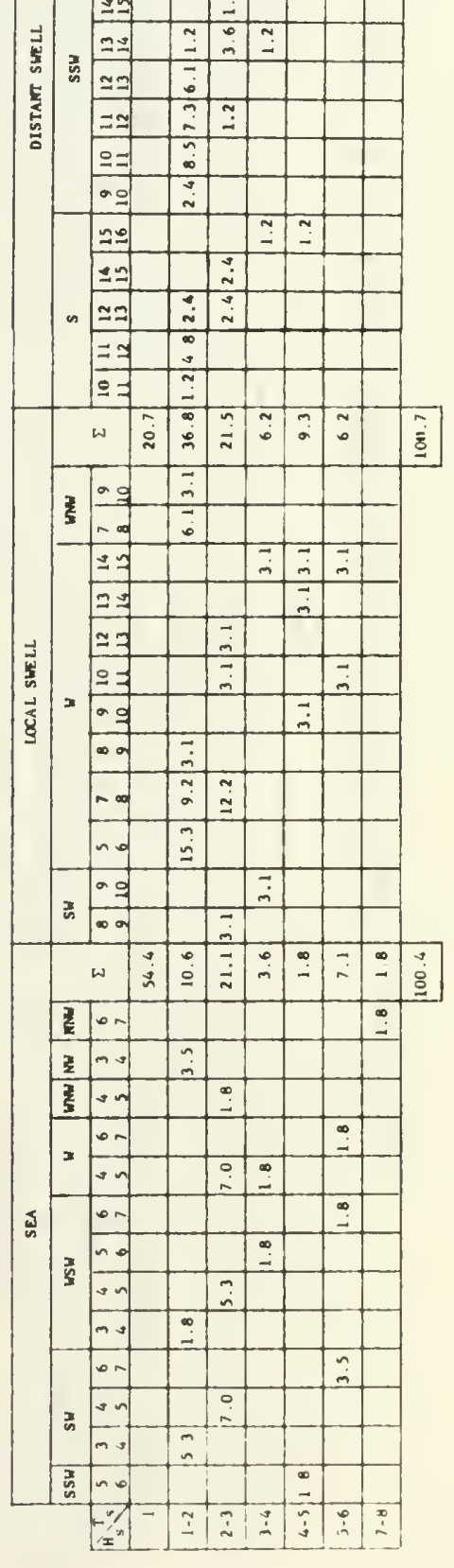

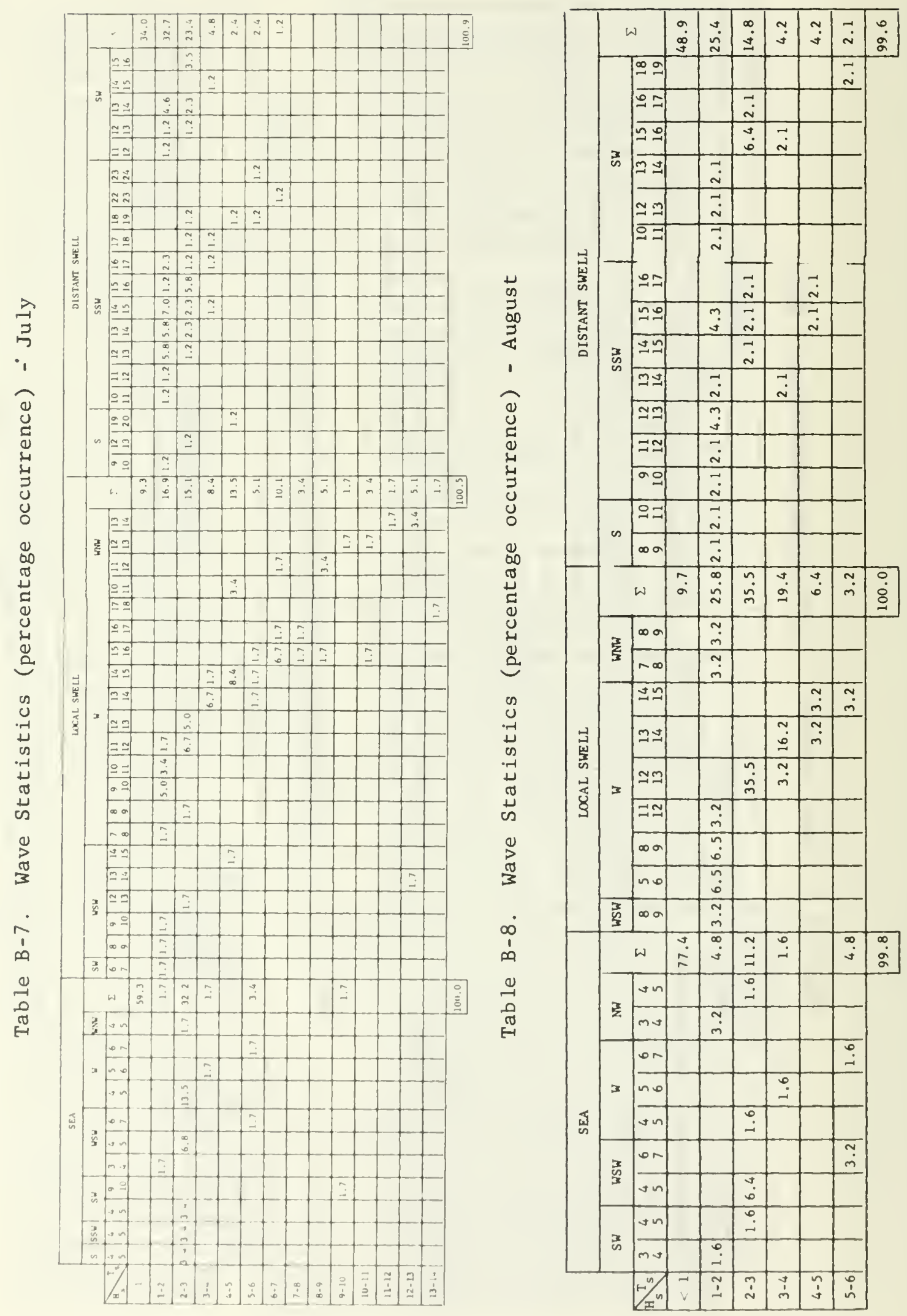
ป

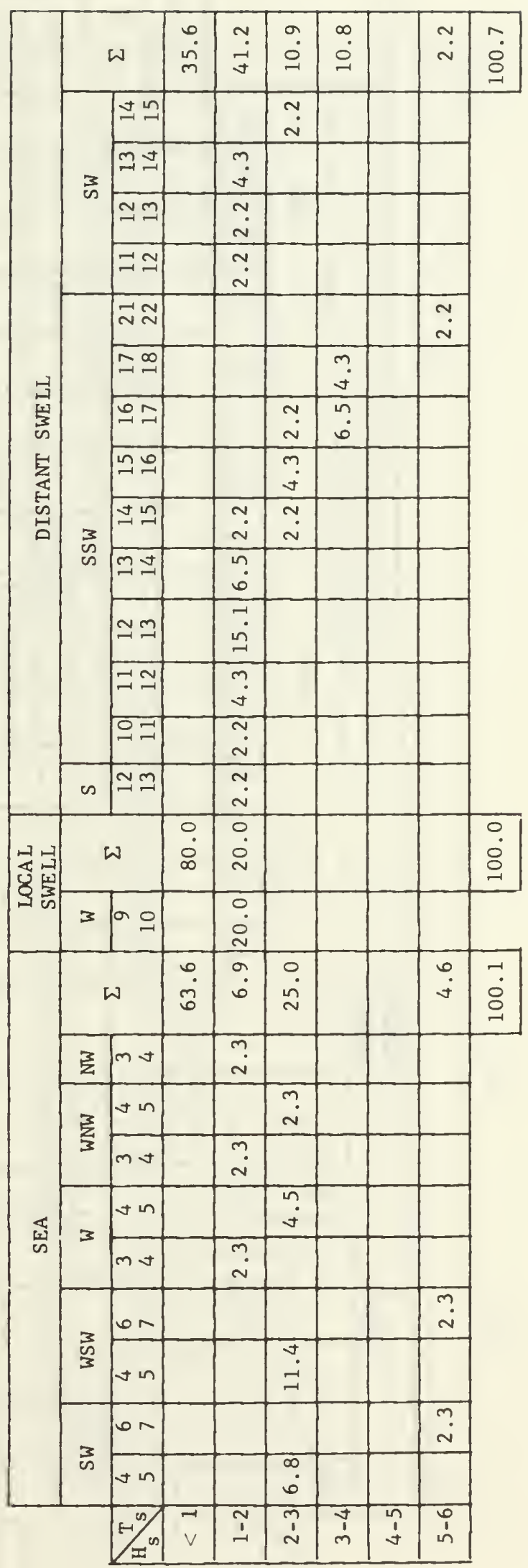




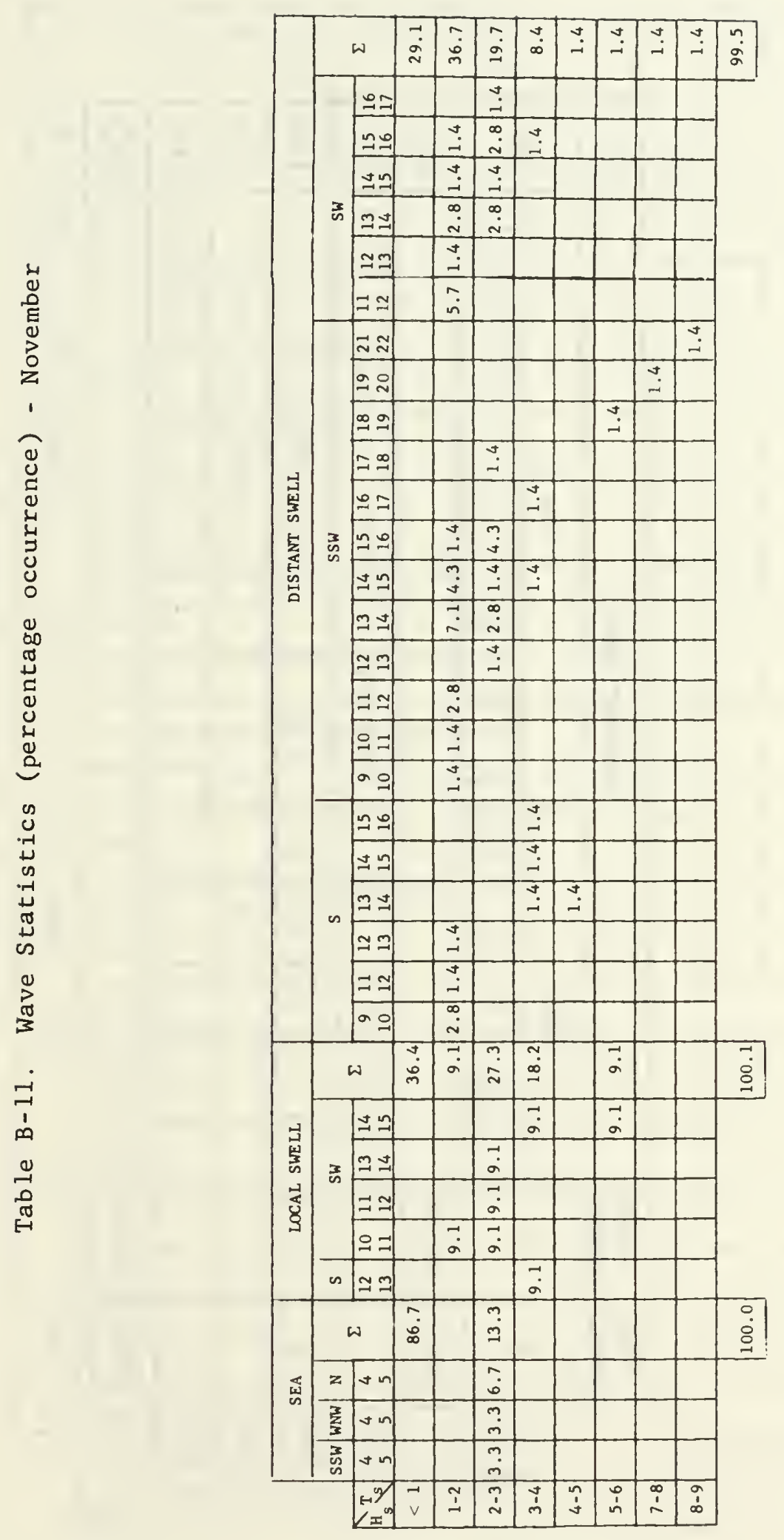


ปี

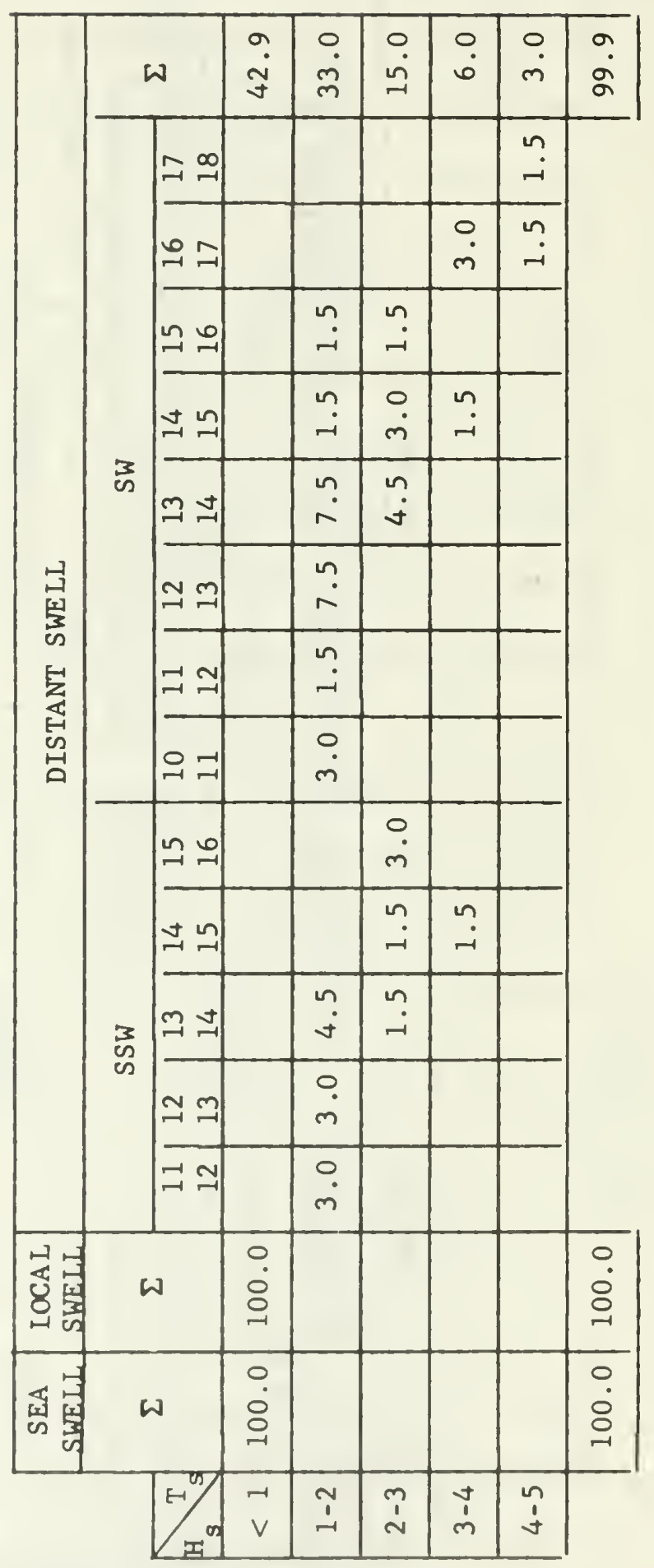




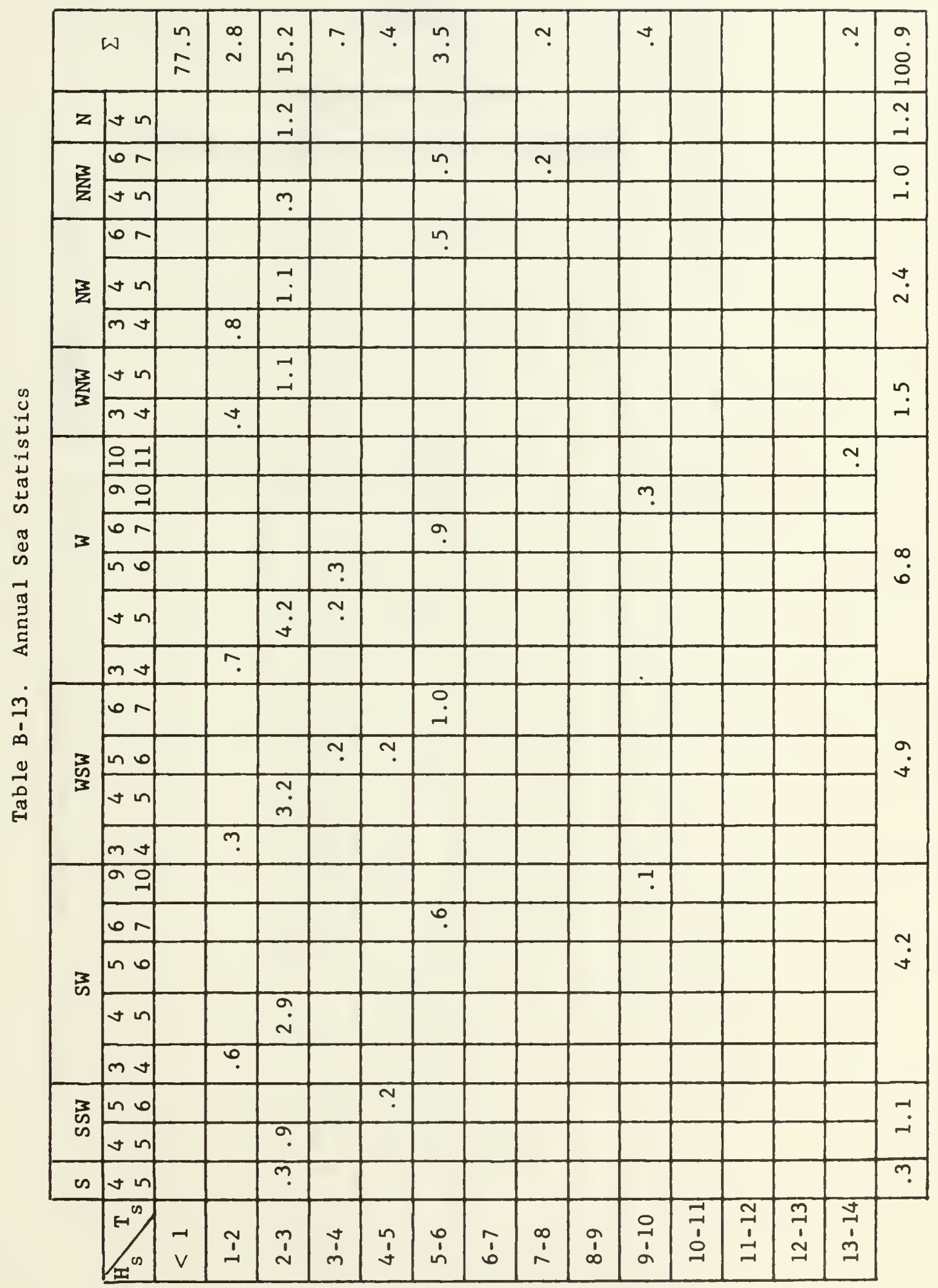


APPENDIX C

MONTHLY AND ANNUAL

FREQUENCY DISTRIBUTIONS OF ALL WAVES 

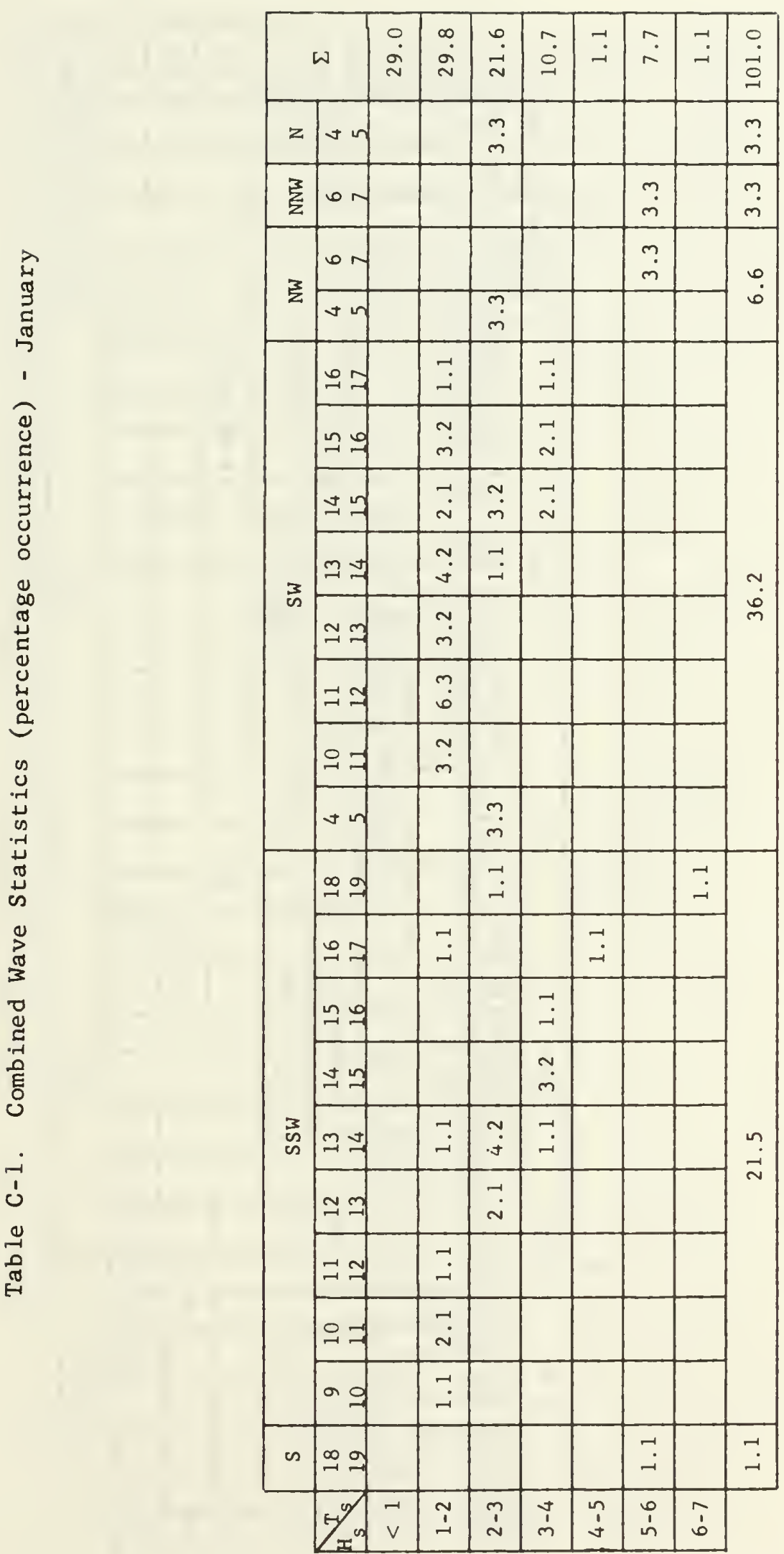


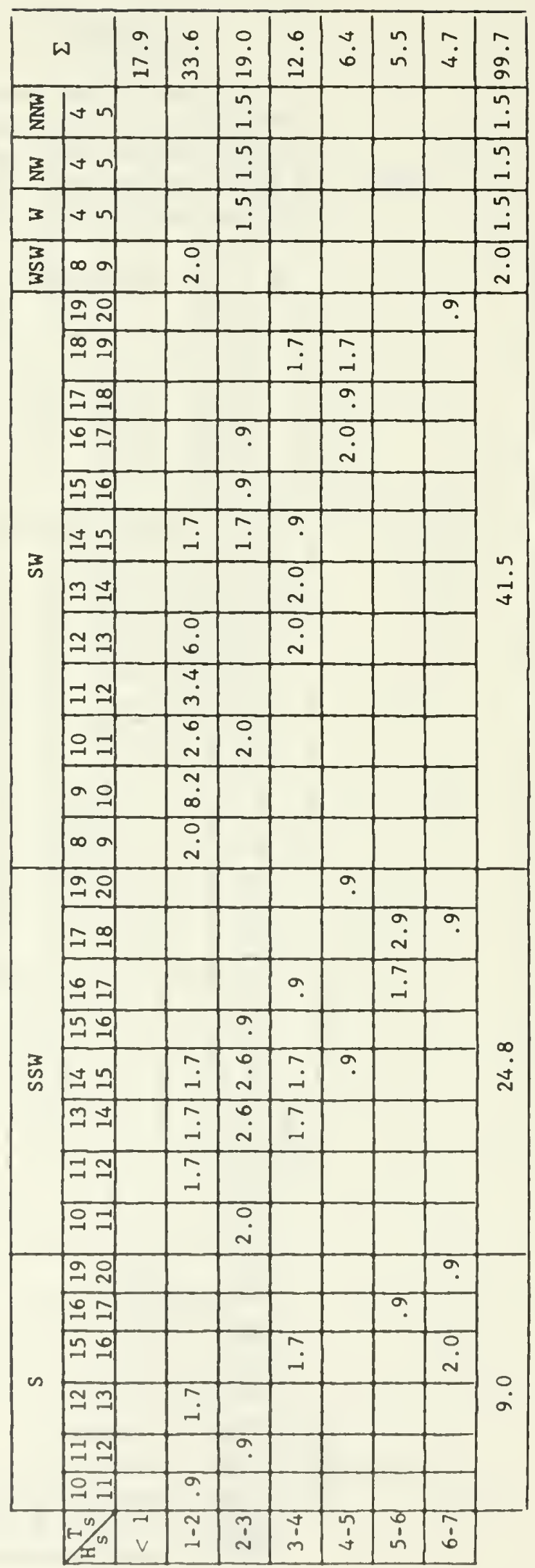


ป⿱

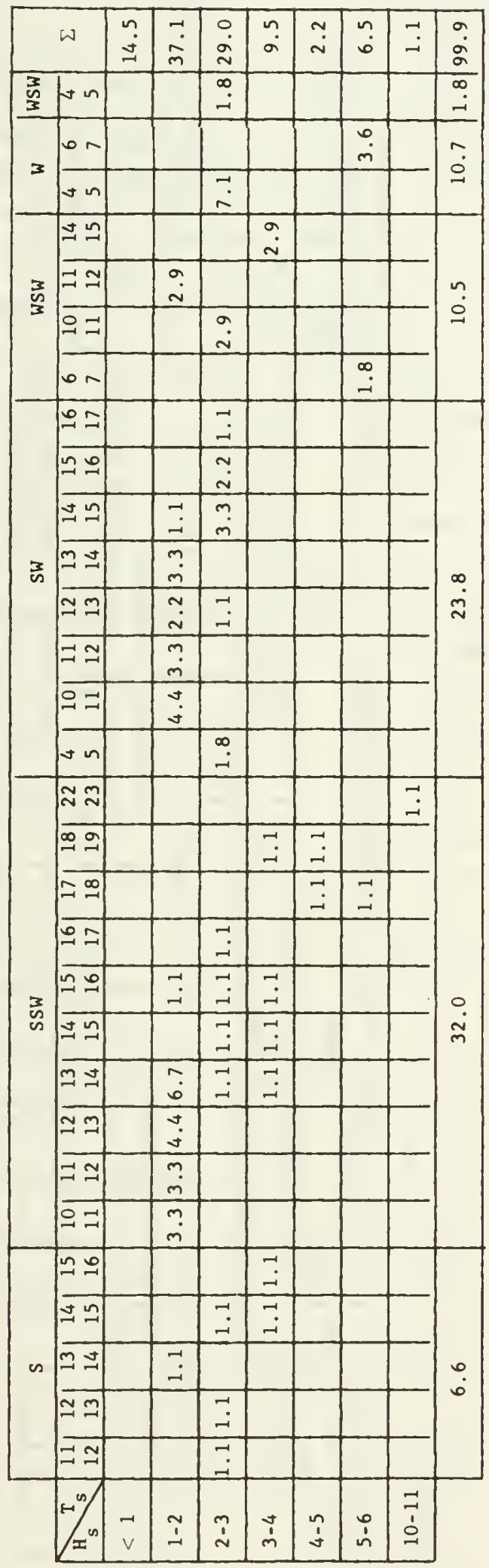


ป

\begin{tabular}{|c|c|c|c|c|c|c|c|c|c|c|}
\hline \multicolumn{2}{|r|}{$\omega$} & $\dot{m}$ & $\stackrel{\vec{m}}{\dot{m}}$ & $\stackrel{\vec{t}}{\vec{t}}$ & $\stackrel{\sim}{\infty}$ & 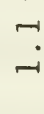 & $\dot{m}$ & $\stackrel{-1}{-1}$ & $\stackrel{-}{-}$ & 0 \\
\hline \multirow{2}{*}{3} & $\checkmark n$ & & & - & & & & & & \multirow{2}{*}{$\stackrel{r}{m}$} \\
\hline & $m+$ & & ? & & & & & & & \\
\hline$\frac{3}{3}$ & $\forall$ in & & & - & & & & & & ? \\
\hline \multirow{7}{*}{3} & ar 0 & & & & . & & & -1 & & \multirow{7}{*}{ a } \\
\hline & 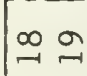 & & & & $\vec{\sim}$ & & $\overrightarrow{-}$ & & & \\
\hline & $\stackrel{\infty}{\sim} \stackrel{\infty}{-1}$ & & & & $\overrightarrow{-}$ & -1 & -1 & & & \\
\hline & $\simeq 0$ & & $\stackrel{m}{9}$ & & & & & & & \\
\hline & $\exists \simeq$ & & $\stackrel{v}{\circ}$ & -1 & $\dot{m}$ & & & & & \\
\hline & $m \pm$ & & ? & j & & & & & & \\
\hline & $\underset{1}{N}$ & & $\stackrel{0}{\infty}$ & $\stackrel{-1}{-1}$ & & & & & & \\
\hline \multirow{8}{*}{ w } & $\infty \begin{array}{cc}\infty & \sigma \\
-1 & 0\end{array}$ & & & -1 & & & & & & \multirow{10}{*}{$\frac{n}{2}$} \\
\hline & $=\infty$ & & & & & & $\ddot{-1}$ & & & \\
\hline & $\begin{array}{ll}0 & -1\end{array}$ & & & $\stackrel{-1}{-1}$ & & & & & & \\
\hline & $\simeq$ & & & $\stackrel{-1}{-1}$ & & & & & & \\
\hline & $\exists \sim$ & & $\dot{v}$ & $\stackrel{-1}{-1}$ & $\dot{v}$ & & & & & \\
\hline & $\underset{\sim}{\sim}$ & & $\stackrel{v}{m}$ & & & & & & & \\
\hline & $=\mathbb{I}$ & & $\dot{0}$ & & & & & & $\overrightarrow{-}$ & \\
\hline & $\begin{array}{lll}0 & -1 \\
-1 & -1\end{array}$ & & $\stackrel{-1}{-i}$ & & & & & & & \\
\hline \multirow[t]{2}{*}{$\sim s$} & $=\mathbb{Z}$ & & $\overrightarrow{-}$ & & & & & & & \\
\hline & $\sqrt{I^{n}}$ & $\begin{array}{l}r \\
V .\end{array}$ & $\stackrel{1}{1}$ & $\stackrel{m}{\sim}$ & $\begin{array}{r}+ \\
\dot{1}\end{array}$ & n & $\begin{array}{l}0 \\
\text { n' }\end{array}$ & $\begin{array}{l}\infty \\
1 \\
N\end{array}$ & $\begin{array}{l}\text { J } \\
\dot{1} \\
\text { mे }\end{array}$ & \\
\hline
\end{tabular}




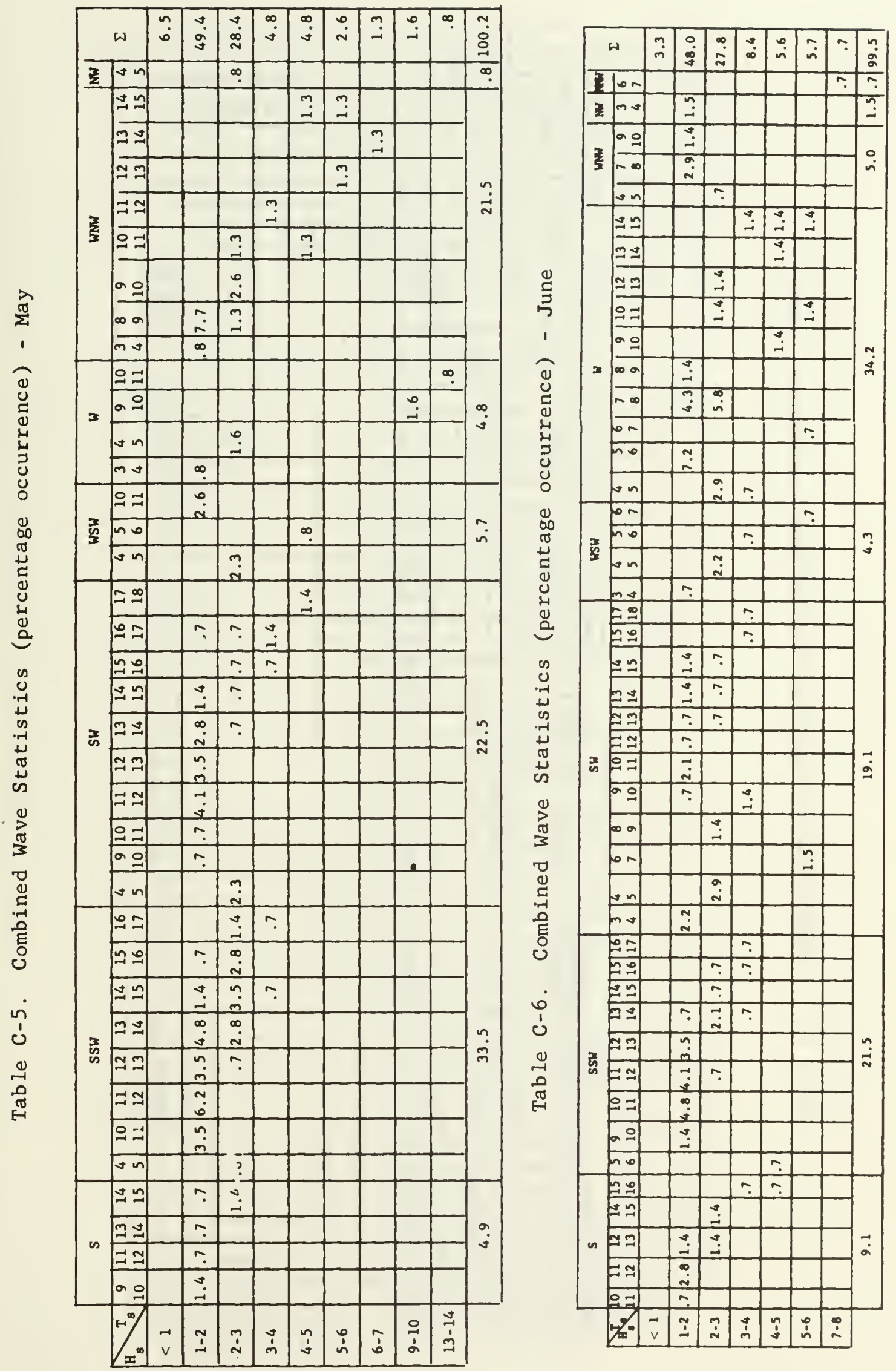


告

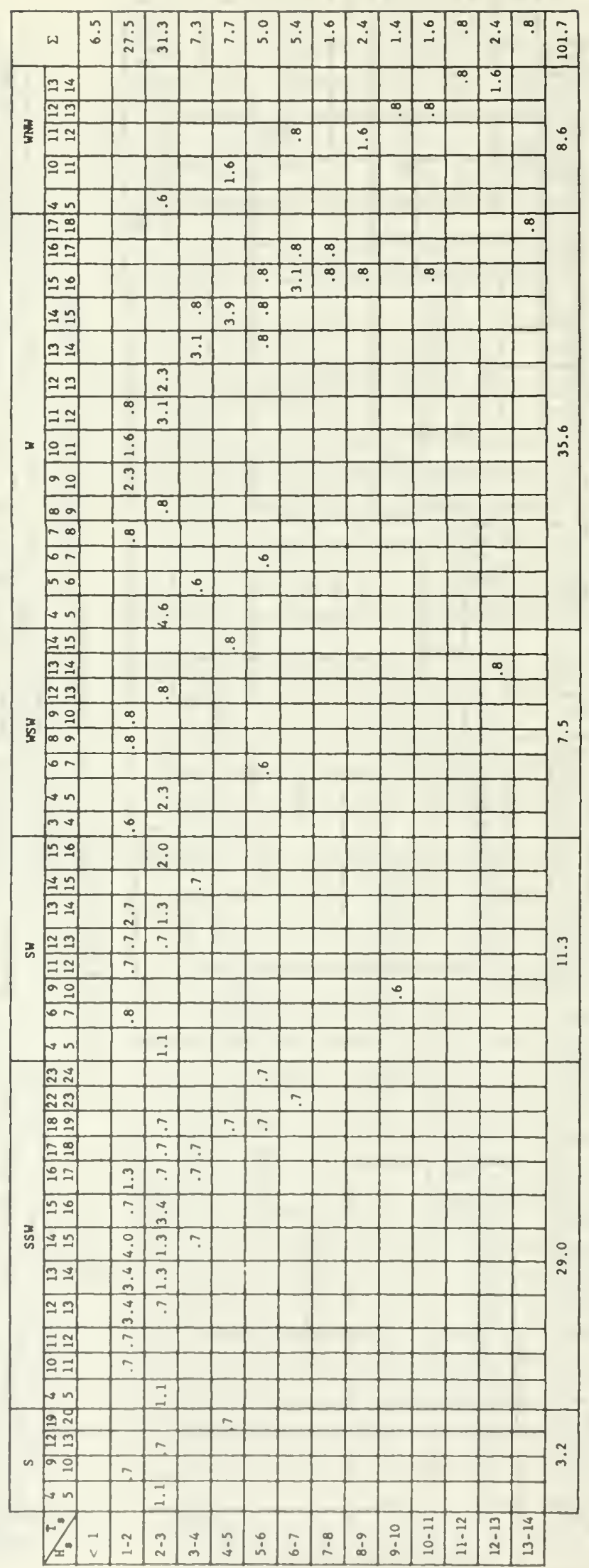


U

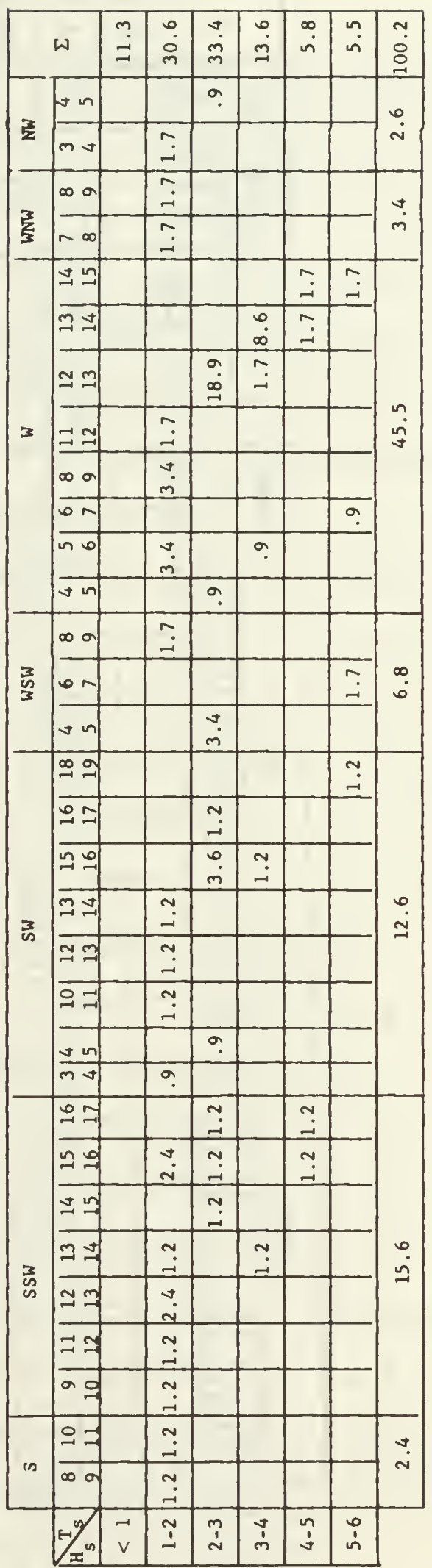




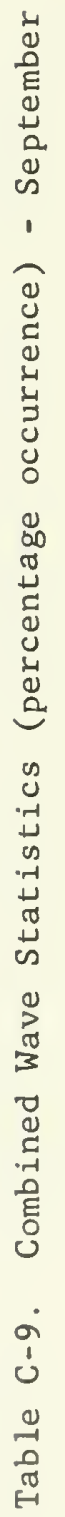

\begin{tabular}{|c|c|c|c|c|c|c|c|}
\hline \multicolumn{2}{|c|}{$\omega$} & $\stackrel{\sim}{\sim}$ & $\stackrel{r}{\dot{J}}$ & $\stackrel{\vec{n}}{\sim}$ & $\because$ & $\stackrel{v}{\dot{v}}$ & $\stackrel{+}{\dot{8}}$ \\
\hline 交 & $m v$ & & ? & & & & ? \\
\hline \multirow{2}{*}{ 胥 } & $\forall n$ & & & n? & & & \multirow{2}{*}{$\stackrel{0}{\dot{n}}$} \\
\hline & $m v \mid$ & & ? & 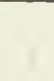 & & & \\
\hline \multirow{3}{*}{3} & $\begin{array}{lll}a & 0\end{array}$ & & $\begin{array}{l}\infty \\
\stackrel{\sim}{\sim}\end{array}$ & & & & \multirow{3}{*}{$\stackrel{\sim}{\sim}$} \\
\hline & $\forall \backsim$ & & & a & & & \\
\hline & $m v$ & & n? & & & & \\
\hline \multirow{2}{*}{$\begin{array}{l}3 \\
5 \\
3\end{array}$} & or & & & & & ? & \multirow{2}{*}{$\begin{array}{l}\infty \\
\infty\end{array}$} \\
\hline & $\forall \ln$ & & & ? & & & \\
\hline \multirow{6}{*}{3} & $\exists \simeq$ & & & $\stackrel{\sim}{\sim}$ & & & \multirow{6}{*}{$\begin{array}{l}\text { ? } \\
\text { ב }\end{array}$} \\
\hline & $2 \pm$ & & $\begin{array}{l}\infty \\
\sim\end{array}$ & & & & \\
\hline & $\approx 2$ & & $\stackrel{\square}{-}$ & & & & \\
\hline & $\Rightarrow \cong$ & & $\stackrel{-}{-}$ & & & & \\
\hline & 100 & & & & & $\sim$ & \\
\hline & $\begin{array}{lll}a & \text { in }\end{array} \mid$ & & & $\stackrel{\forall}{\dot{v}}$ & & & \\
\hline \multirow{9}{*}{$\begin{array}{l}3 \\
\infty\end{array}$} & $\vec{\sim} \approx$ & & & & & $\stackrel{\square}{ }$ & \multirow{9}{*}{ भु } \\
\hline & $=\infty$ & & & & $\begin{array}{l}\infty \\
\dot{\sim}\end{array}$ & & \\
\hline & 0. & & & $\stackrel{\sim}{\sim}$ & m & & \\
\hline & $\because 0$ & & 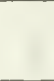 & $\begin{array}{l}\infty \\
\sim\end{array}$ & & & \\
\hline & $\therefore=$ & & $\stackrel{\square}{\lrcorner}$ & $\stackrel{+}{-}$ & & & \\
\hline & $\leadsto \Delta$ & & m. & & & & \\
\hline & $\simeq 9$ & & a & & & & \\
\hline & $\exists \cong$ & & $\begin{array}{l}\infty \\
\sim\end{array}$ & & & & \\
\hline & 윽 & & $\stackrel{\square}{\square}$ & & & & \\
\hline \multirow[t]{2}{*}{$\infty$} & $\simeq 9$ & & $\stackrel{\square}{-}$ & & & & $\stackrel{+}{-}$ \\
\hline & $-1 / 5 / 5$ & $\vec{v}$ & $\stackrel{1}{1}$ & $\dot{m}$ & İ & $\begin{array}{l}\dot{1} \\
\text { n' }\end{array}$ & \\
\hline
\end{tabular}




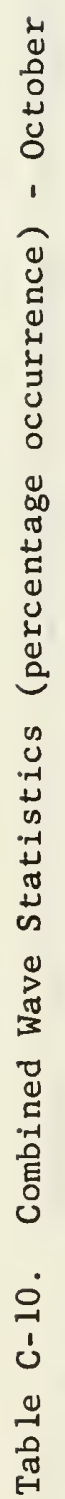

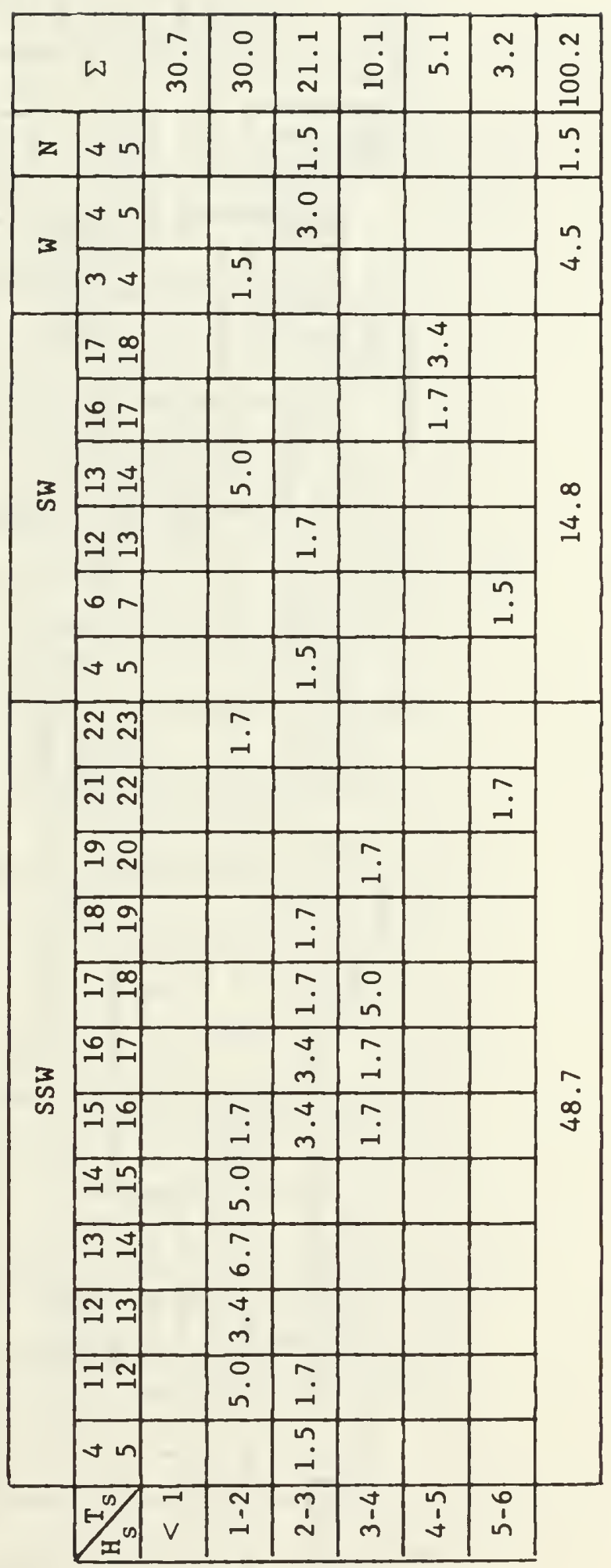




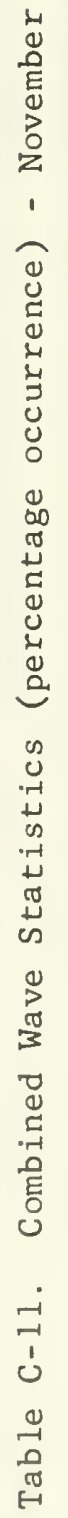

\begin{tabular}{|c|c|c|c|c|c|c|c|c|c|c|}
\hline & $\omega$ & $\stackrel{\sim}{\sim}$ & $\stackrel{\infty}{\dot{\sim}}$ & $\stackrel{r}{-}$ & $\stackrel{\infty}{\infty}$ & a & $\vec{r}$ & ? & ? & ن \\
\hline$z$ & $\forall \ln$ & & & $\vec{m}$ & & & & & & $\vec{m}$ \\
\hline$\frac{3}{3}$ & $a n$ & & & - & & & & & & - \\
\hline \multirow{7}{*}{3} & 01 & & & ? & & & & & & \multirow{7}{*}{ ने } \\
\hline & $\cong 0$ & & a & 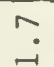 & ? & & & & & \\
\hline & 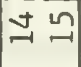 & & ? & a & 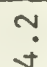 & & $\stackrel{v}{q}$ & & & \\
\hline & $\stackrel{\sim}{\sim} \pm$ & & $\stackrel{\sim}{-}$ & a & & & & & & \\
\hline & $\approx m$ & & 9 & & & & & & & \\
\hline & $\because \approx$ & & $\ddot{\dot{m}}$ & $\underset{j}{v}$ & & & & & & \\
\hline & $\therefore=$ & & $\stackrel{v}{~}$ & $\stackrel{v}{y}$ & & & & & & \\
\hline \multirow{13}{*}{ 艿 } & $\vec{\sim} \approx$ & & & & & & & & ? & \multirow{13}{*}{$\stackrel{+}{\sim}$} \\
\hline & 90 & & & & & & & a & & \\
\hline & $\left.\begin{array}{ll}\infty & 9 \\
-1 & -1\end{array}\right]$ & & & & & & ? & & & \\
\hline & $\sim^{\infty}$ & & & क & & & & & & \\
\hline & 07 & & & & ? & & & & & \\
\hline & $\simeq 0$ & & a & $\begin{array}{l}0 \\
\dot{v}\end{array}$ & & & & & & \\
\hline & $\pm \sim$ & & $\begin{array}{l}0 \\
\sim\end{array}$ & a & a & & & & & \\
\hline & $m \pm$ & & m. & ‡. & & & & & & \\
\hline & $\simeq 9$ & & & ? & & & & & & \\
\hline & $\exists \approx$ & & 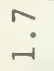 & & & & & & & \\
\hline & 음 & & ? & & & & & & & \\
\hline & क० & & क & & & & & & & \\
\hline & o in & & & - & & & & & & \\
\hline \multirow{7}{*}{$n$} & $\because 0$ & & & & ? & & & & & \multirow{6}{*}{$\stackrel{m}{\beth}$} \\
\hline & $\triangle \simeq$ & & & & a & & & & & \\
\hline & $\mathrm{m}=$ & & & & a & a & & & & \\
\hline & $\approx 9$ & I & ? & & $\underset{j}{Y}$ & & & & & \\
\hline & $\approx \cong$ & & ? & & & & & & & \\
\hline & क० & & - & & & & & & & \\
\hline & {$\left[-1 / I^{n}\right.$} & $\bar{v}$ & $\stackrel{N}{-1}$ & $\dot{\sim}$ & $\begin{array}{l}\text { I } \\
\dot{m}\end{array}$ & ? & $\begin{array}{l}0 \\
1 \\
\text { n' }\end{array}$ & $\begin{array}{l}\infty \\
1 \\
1\end{array}$ & à & \\
\hline
\end{tabular}




\begin{tabular}{|c|c|c|c|c|c|c|c|}
\hline & $\omega$ & $\begin{array}{l}0 \\
\dot{p}\end{array}$ & $\stackrel{\sim}{\tilde{m}}$ & $\begin{array}{l}a \\
\text { a }\end{array}$ & 0. & $\stackrel{0}{\dot{n}}$ & $\stackrel{\sim}{\circ}$ \\
\hline \multirow{8}{*}{3} & $\sim \underset{\sim}{\infty}$ & & & & & ? & \multirow{8}{*}{$\tilde{n}$} \\
\hline & $0=$ & & & & $\stackrel{0}{\dot{m}}$ & $\stackrel{n}{\sim}$ & \\
\hline & जी & & ? & ? & & & \\
\hline & $\exists \cong$ & & ? & $\begin{array}{l}0 \\
\dot{m}\end{array}$ & ? & & \\
\hline & $\underset{\sim}{m} \pm$ & & $\stackrel{\square}{r}$ & $\stackrel{+}{\dot{y}}$ & & & \\
\hline & $\approx m$ & & $\stackrel{+}{r}$ & & & & \\
\hline & $\exists \cong$ & & $\stackrel{n}{n}$ & & & & \\
\hline & 음 & & $\stackrel{0}{\dot{m}}$ & & & & \\
\hline \multirow{6}{*}{3} & $\because 0$ & & & $\stackrel{0}{\dot{m}}$ & & & \multirow{5}{*}{$\stackrel{9}{\cong}$} \\
\hline & $\pm \simeq$ & & & $\stackrel{n}{n}$ & ? & & \\
\hline & $\underset{\sim}{2}=$ & & $\stackrel{+}{\dot{g}}$ & $\stackrel{n}{n}$ & & & \\
\hline & $\underset{\sim}{\simeq}$ & & $\stackrel{0}{\dot{m}}$ & & & & \\
\hline & $\exists \simeq$ & & $\stackrel{0}{\dot{m}}$ & & & & \\
\hline & ${ }^{-10}$ & $\vec{y}$ & $\stackrel{\sim}{1}$ & $\stackrel{m}{\dot{1}}$ & $\stackrel{Y}{1}$ & $\begin{array}{l}n \\
1 \\
y\end{array}$ & \\
\hline
\end{tabular}




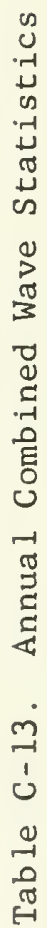

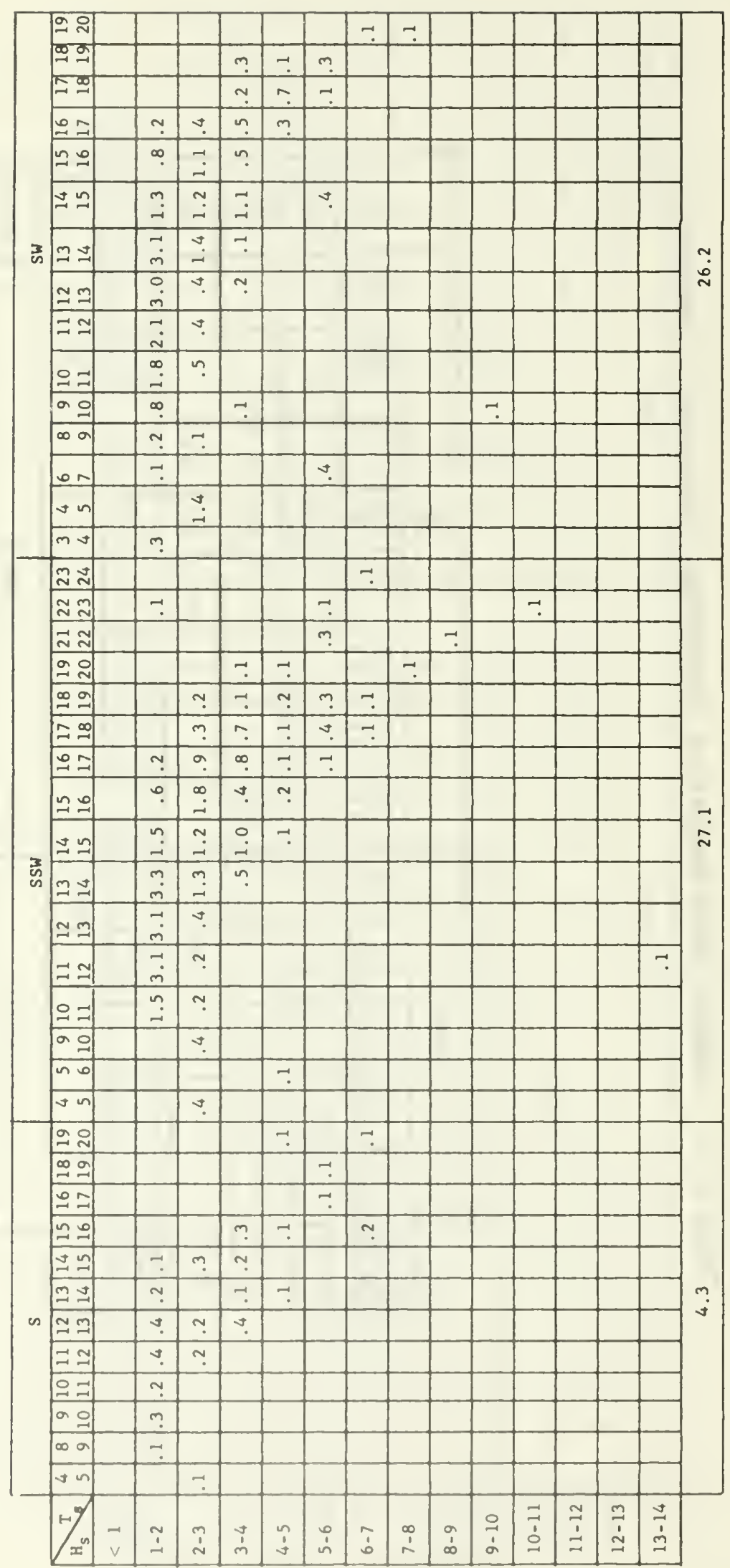




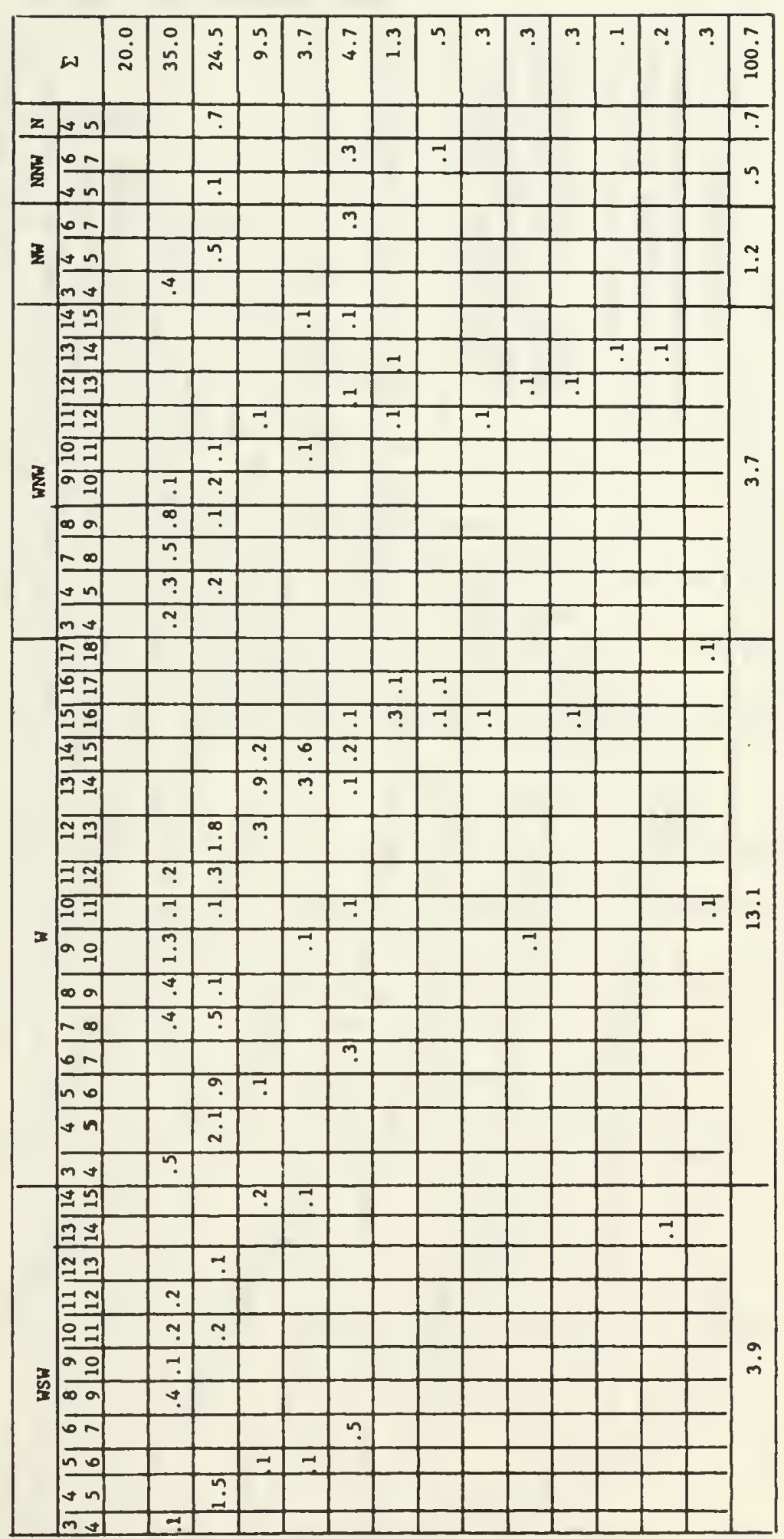


APPENDIX D

WAVE HINDCASTING CURVES 


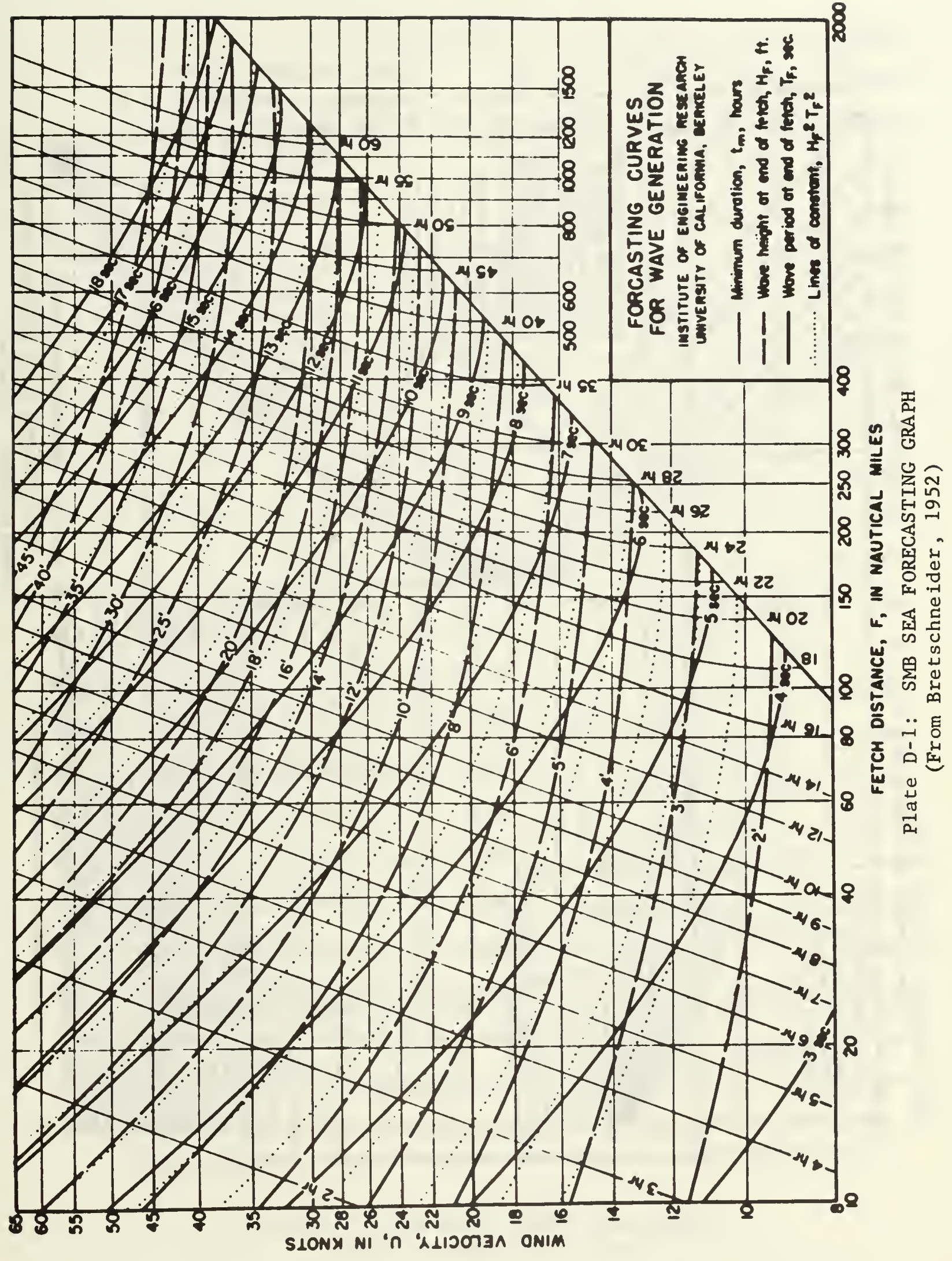




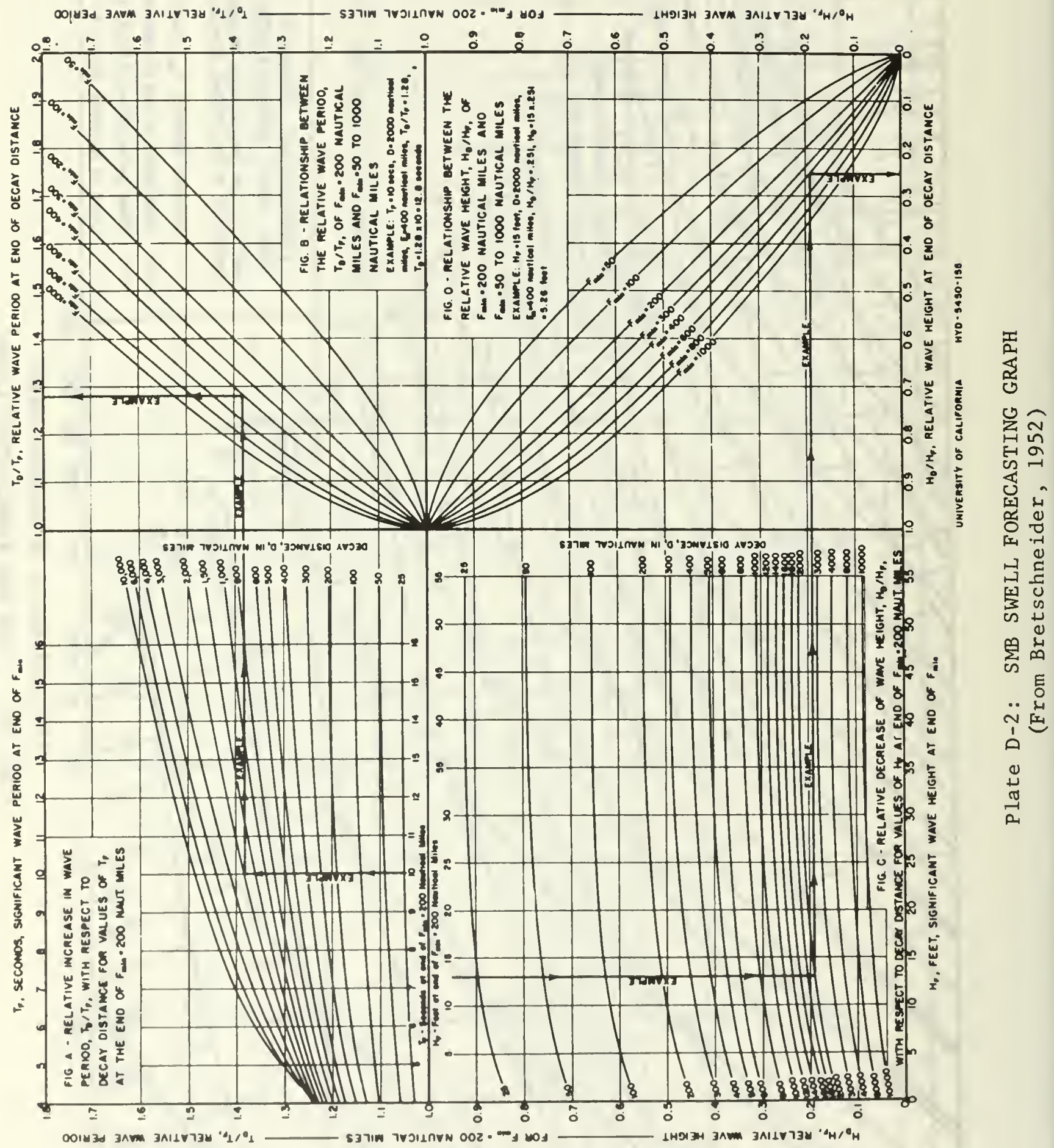


TRAVEL TIME OF SWELL BASED ON $T_{0}=0 / C_{0}$

FOR: $D=$ NAUTICAL MILES

$$
\begin{aligned}
T_{D} & =\text { SECONOS } \\
t_{D} & =\text { HOURS } \\
t_{0} & =6600 / T_{0}
\end{aligned}
$$

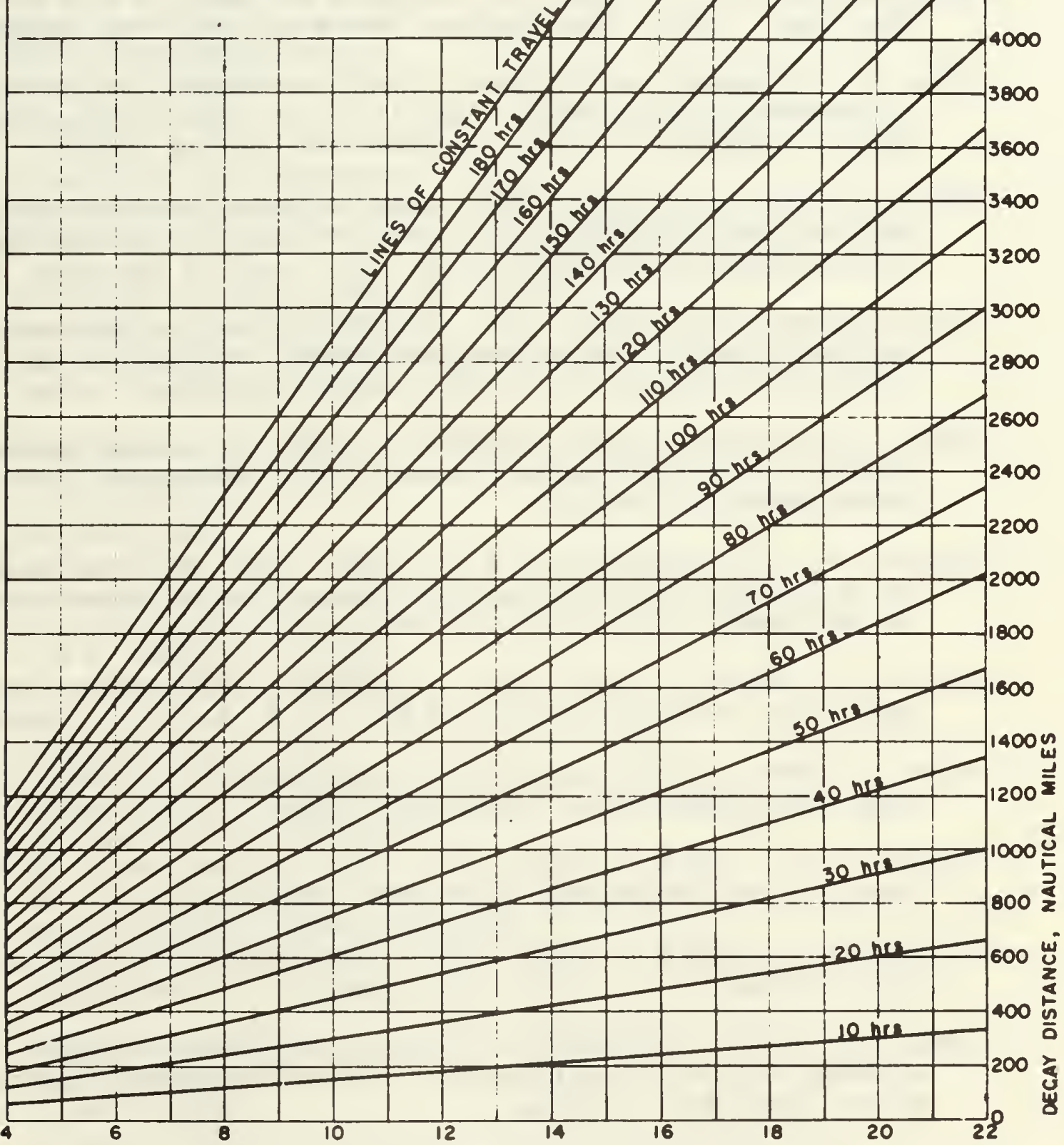

WAVE PERIOD AT END OF DECAY, TO, IN SECONOS

Plate D-3: SMB SWELL TRAVEL TIME GRAPH

(From Bretschneider, 1952) 


\section{REFERENCES}

Bretschneider, C. L., 1952. Revised Wave Forecasting Relationships.

Proc. Conf. on Coastal Engineering, Council on Wave Research, University of California, p. 1-5.

Bretschneider, C. L., 1952. The Generation and Decay of Wind Waves in Deep Water. Trans. Amer. Geophy. Un., V. 33, No. 3, p. 381-389.

Gelci, R., H. Cazale, and J. Vassal, 1958. The Spectro Angular Method of Forecasting Ocean Waves. Translation by Fleet Numerical Weather Central, Monterey, from Min. de Trav. Publ. et des Trans.

National Marine Consultants, 1960. Wave Statistics for Seven Deep Water Stations Along the California Coast. Prepared for the Los Angeles and San Francisco Districts, U. S. Army, Corps of Engineers, 20 pp.

National Marine Consultants, 1961. Wave Statistics for Three Deep Water Stations Along the Oregon-Washington Coast. Repared for the Portland and Seattle Districts, U. S. Army, Corps of Engineers, 17 pp.

Office of the Chief of Naval Operations, 1958. Meteorology for Naval Aviators. U. S. Government Printing Office, Washington, D. C., NAVAER $00-80 \mathrm{U}-24,300 \mathrm{pp}$.

Pierson, W. J., G. Neumann, and R. W. James, 1955. Practical Methods for Observing and Forecasting Ocean Waves by Means of Wave Spectra and Statistics. H. O. Pub. 603, 284 pp.

Rattray, M., and W. V. Burt, 1956. A Comparison of Methods for Forecasting Wave Generation, Deep Sea Res., V. 3, No. 2, pp. 140-144.

Roper, W., 1960. A Study of the Wave Climatology of the Gulf of Siam. Naval Postgraduate School, MS Thesis, 73 pp.

Sverdrup, H. U., and W. H. Munk, 1947. Wind, Sea and Swe11: Theory rof Relations for Forecasting. H. 0, Pub. 601, 44 pp.

Sverdrup, H. U., and W. H. Munk, 1951. Techniques for Forecasting Wind Waves and Swe11. H. O. Pub. 604, 38 pp.

Timmie, R., 1969. The Adequacy of Forecasting, Hindcasting, and the Use of Ocean Surfacc Wave Information. National Security Industrial Assoc., Tech. Rept., 152 pp.

U. S. Army, Corps of Engineers, 1966. Shore Protection, Planning and Design. Coastal Engineering Research Center, Tech. Rept. No. 4, U. S. Government Printing Office, Washington, D. C., 401 pp.

Wiegel, R. L., 1966, Occanographical Engineering. Prentice-Hall Inc., $532 \mathrm{Pp}$. 
No. Copies

1. Defense Documentation Center

Cameron Station

A lexandria, Virginia 22314

2. Department of Oceanography

Naval Postgraduate School

Monterey, California 93940

3. Professor Warren C. Thompson

Department of Oceanography

Naval Postgraduate School

Monterey, California 93940

4. Assistant Professor Edward B. Thornton

Department of Oceanography

Naval Postgraduate School

Monterey, California 93940

5. LCDR E. M. A. Perera

Naval Headquarters

P. 0. Box 593

Colombo, Ceylon

6. Oceanographer of the Navy

The Madison Building

$732 \mathrm{~N}$. Washington Street

Alexandria, Virginia 22314

7. Captain Paul M. Wolff

Commanding Officer

Fleet Numerical Weather Central

Monterey, California 93940

8. Mr. Joseph M. Caldwe11, Technical Director

Coastal Engineering Research Center

5201 Little Falls Road, N. W.

Washington, D. C. 20016

9. Captain of the Navy

Roya 1 Ceylon Navy

P. O. Box 593

Colombo, Ceylon 
10. The Secretary

Institute of Engineers of Ceylon

C/O Public Works Department

Colombo 1, Ceylon

11. The Director

Public Works Department

Colombo 1, Ceylon

12. The Chairman

Department of Civil Engineering

University of Ceylon

Colombo 1, Ceylon

13. The Librarian

University of Ceylon

Peradeniya, Ceylon

14. The Chief Hydrographer

C/O Indian Navy Headquarters

New Delhi, India

15. Library, Code 0212

2

Naval Postgraduate School

Monterey, California 93940 


\section{DOCUMENT CONTROL DATA - R \& D}

(Securtly classification of tille, body of abstract and indexing annotation must be ontered when the overall report ts clessilied) ORIGINATING ACTIVITY (COPporale author)

Naval Postgraduate School

Monterey, California 93940

Unclassified

2b. GROUP

REPORT TITLE

Climatological Wave Data for Colombo, Ceylon

\section{DESCRIPTIVE NOTES (Type of report and,inclusive dates) \\ Master's Thesis; April 1970}

- AU THOR(S) (First namo, middlo initial, Iast namo)

Edward M. A. Perera

\begin{tabular}{|c|c|c|}
\hline $\begin{array}{l}\text { AEPORT DATE } \\
\text { Apri1 } 1970\end{array}$ & $\begin{array}{c}\text { 79. TOTAL NO. OF PAGES } \\
88\end{array}$ & $\begin{array}{r}\text { 7b. NO. OF REFS } \\
13\end{array}$ \\
\hline $\begin{array}{l}\text { 1.. CONTRACT OR GRANT NO. } \\
\text { b. PROJECT NO. }\end{array}$ & 9A. ORIGINATOR'S REPOR & ER(S) \\
\hline $\begin{array}{l}\text { c. } \\
\text { d. }\end{array}$ & $\begin{array}{l}\text { 9b. OTHER REPORT NO(S) } \\
\text { (his soport) }\end{array}$ & her numbers that may be acalened \\
\hline
\end{tabular}

This document has been approved for public release and sale;

its distribution is unlimited.

12. SPONSORING MILITARY ACTIVITY

Naval Postgraduate School

Monterey, California 93940

Deep-water wave statistics for Colombo on the west coast of Ceylon have been compiled using the Sverdrup-Munk-Bretschneider wave-hindcast method applied to 12-hourly weather maps of the West Indian and South Atlantic Oceans for the one-year period from June 1968 through May 1969.

Results of the wave-hindcast analysis are presented in the form of monthly and annual height-period-direction frequency distributions. The predominant waves are in the one to three foot height range, have periods centered about 13-14 seconds, and arrive from westerly to south-southwesterly directions. Wave action is most frequent in May through September and least in December.

The wind waves and local swell on the west coast of Ceylon strongly reflect the seasonal Monsoons. The principal source of distant swell for this coast is the prevailing westerly wind belt of the Southern Hemisphere between Argentina and the longitude of Ceylon $\left(80^{\circ} \mathrm{E}\right)$. The subtropical anticyclone in the central Indian Ocean is a relatively quiet source region for swell compared to the Monsoon belt and the prevailing westerlies. 


\begin{tabular}{|l}
\hline Climatological wave data \\
Ocean wave statistics for \\
Wave statistics for Ceylon \\
Wave climatology of Ceylon
\end{tabular}







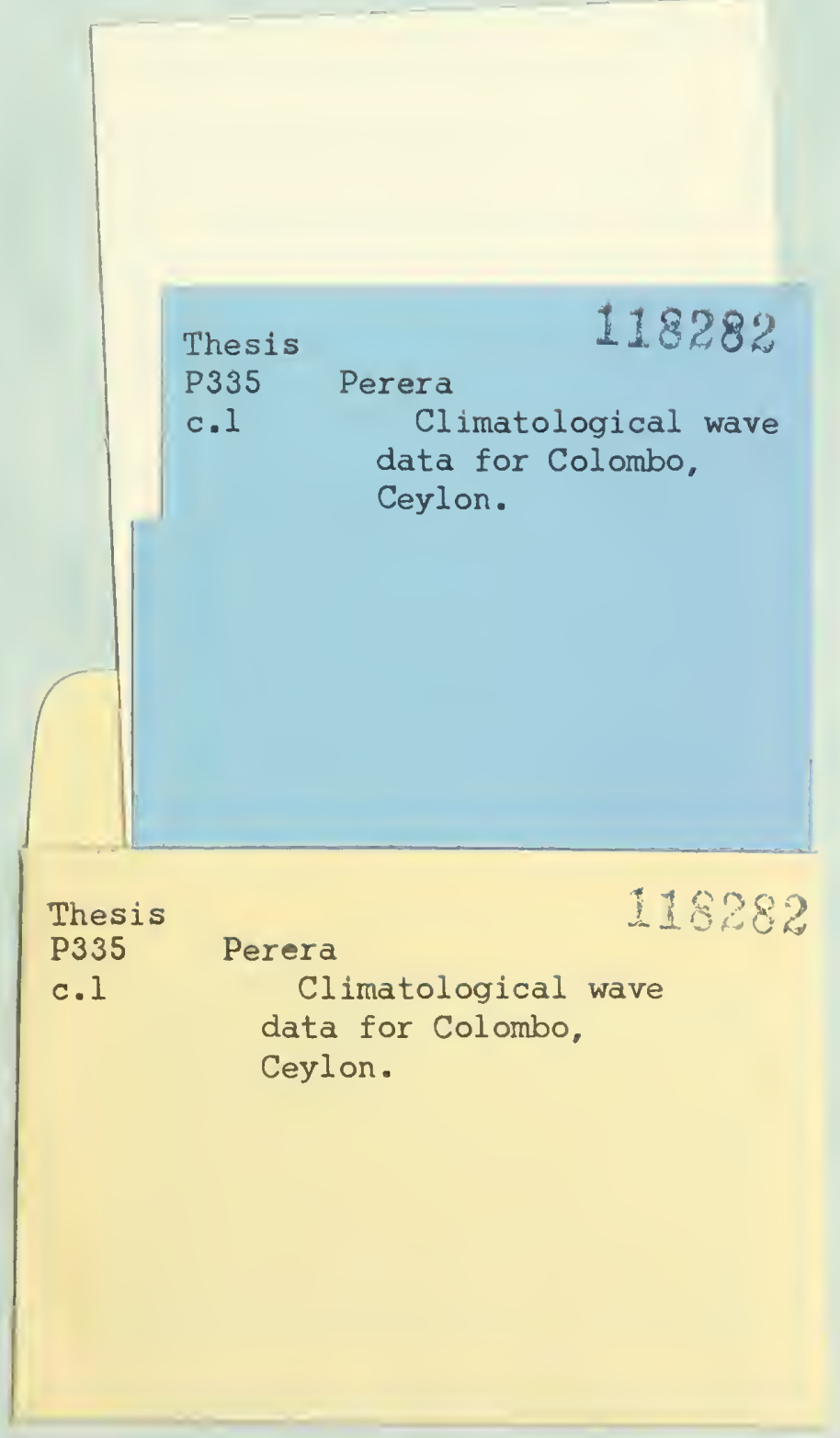


thesP335

Climatological wave data for Colombo, $\mathrm{Ce}$ |||||||||||||||||||||||||||||||||||||||||||||||||||||||||||| DUDLEY KNOX LIBRARY 